\title{
THE PROTEOMIC RESPONSE OF GILL TISSUE IN TIDALLY AND SUBTIDALLY-ACCLIMATED CALIFORNIA MUSSELS, MYTILUS CALIFORNIANUS, TO ACUTE EMERSION-INDUCED ANOXIA
}

\author{
A Thesis \\ presented to \\ the Faculty of California Polytechnic State University, \\ San Luis Obispo \\ In Partial Fulfillment \\ of the Requirements for the Degree \\ Master of Science in Biological Sciences
}

by

Aubrie Nicole Fowler

May 2017 
(C) 2017

Aubrie Nicole Fowler

ALL RIGHTS RESERVED 


\section{COMMITTEE MEMBERSHIP}

TITLE:

The Proteomic Response of Gill Tissue in

Tidally and Subtidally-acclimated California

Mussels, Mytilus californianus, to Acute

Emersion-induced Anoxia

AUTHOR: $\quad$ Aubrie Nicole Fowler

DATE SUBMITTED: $\quad$ May 2017

COMMITTEE CHAIR: Lars Tomanek, Ph.D.

Associate Professor of Biological Sciences

COMMITTEE MEMBER: Kristin Hardy, Ph.D.

Assistant Professor of Biological Sciences

COMMITTEE MEMBER: Elena Keeling, Ph.D.

Professor of Biological Sciences 


\section{ABSTRACT}

The Proteomic Response of Gill Tissue in Tidally and Subtidally-acclimated

California Mussels, Mytilus californianus, to Acute Emersion-induced Anoxia Aubrie Nicole Fowler

Intertidal mussels regularly experience emersion-induced anoxia, in contrast to normoxic conditions experienced during submersion. We therefore hypothesized that acclimation to a tidal rhythm, as opposed to a rhythm of constant submersion, preconditions the proteome of the California mussel, Mytilus californianus, to respond differently to emersion-induced anoxia. Following acclimation, mussels either continued to receive the acclimation conditions (control) or were exposed to 100\% nitrogen gas (anoxia) during aerial emersion. We collected gill tissue for subsequent analysis of protein abundance with 2D gel electrophoresis and protein identification with tandem mass spectrometry. Relative to subtidally-acclimated mussels, tidally-acclimated mussels showed a greater propensity to respond to distrupted protein homeostasis during emersion through higher levels of several small heat shock protein isoforms, while they showed lower levels of several chaperones involved in redox-sensitive protein maturation in the endoplasmic reticulum during acute anoxia. Several metabolic proteins showed elevated levels in tidally-acclimated mussels, suggesting a compensatory response to reduced feeding times. However, changes in the abundance of several tricarboxylic acid cycle enzymes (e.g. aconitase, succinate dehydrogenase) suggest that tidally-acclimated 
mussels are also primed to sense reactive oxygen species (ROS) and limit their production, respectively. These findings are further supported by higher abundances of several aldehyde dehydrogenases and thioredoxin peroxidase, which function as scavengers of aldehydes and ROS, common products of lipid peroxidation. Finally, tidally-acclimated mussels are also more responsive to changes in cytoskeletal and vesicular trafficking dynamics in response to acute anoxia. Together, our analysis showed that proteostasis, energy metabolism, oxidative stress and cytoskeletal and trafficking processes are all involved in priming tidally-acclimated mussels to respond more dynamically to acute emersion-induced anoxia in Mytilus gill.

Keywords: Mytilus californianus, proteomics, anoxia, acclimation 


\section{ACKNOWLEDGMENTS}

This work was made possible through the support of the National Science Foundation grant (IOS-1145840) to L.T. We would like to thank OMRON, Coastal Aquariums, Tinned Marine Wire, Irrigation Direct, Drain Master, and Glass-holes for donating supplies for the tidal simulator tanks that will be used for many future projects at the Cal Poly Pier with the Center for Coastal Marine Sciences. I would like to show my appreciation for the hard work and technical expertise of Rob

Brewster, Biological Sciences Department Technician, in the construction of tidal simulator tanks.

I would like to personally thank my thesis committee, Lars Tomanek, Kristin Hardy, and Elena Keeling as well as many professors from the Statistics department for their insightful advice on the analysis. Additionally, Christina Vasquez provided invaluable feedback during the writing process. Last, I would also like to thank all of my friends and family members who supported and encouraged me over the journey of acquiring my master's thesis. 


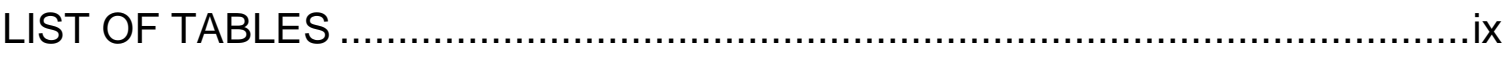

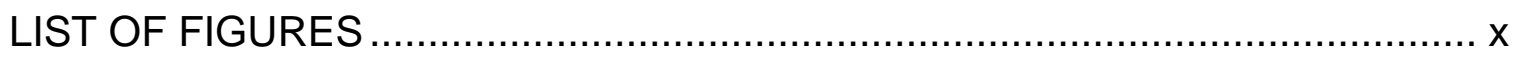

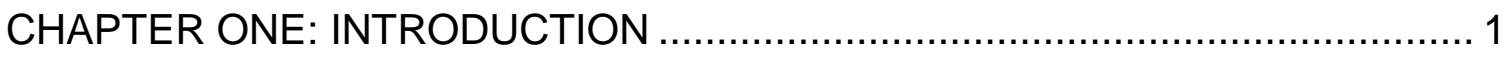

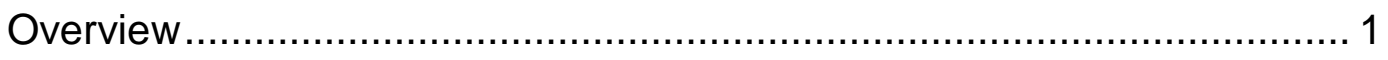

Mytilus as a study organism............................................................ 3

M. californianus: A natural history ......................................................... 4

Mytilus' response to environmental stress and acclimation ..................... 8

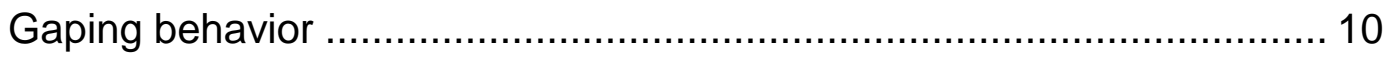

Metabolic response to oxygen limitation in bivalves ............................. 12

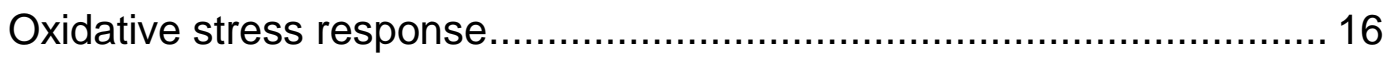

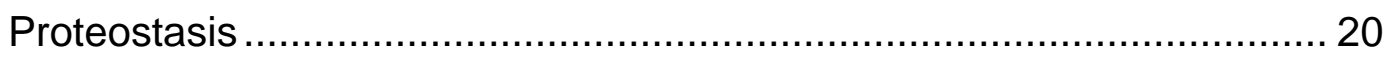

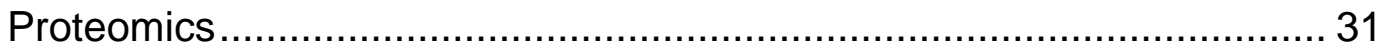

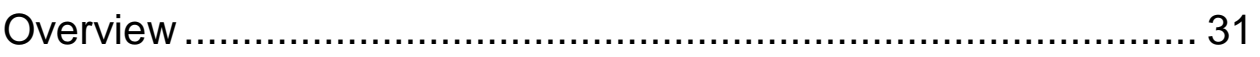

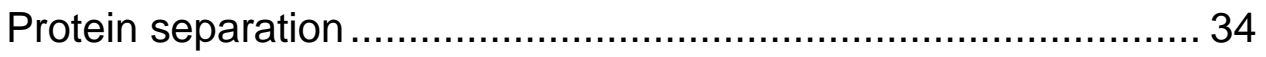

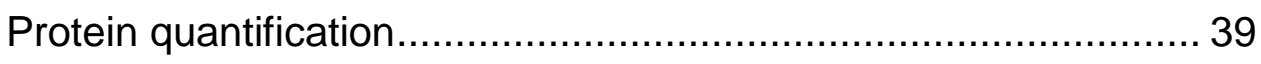

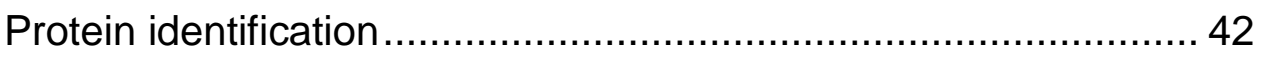

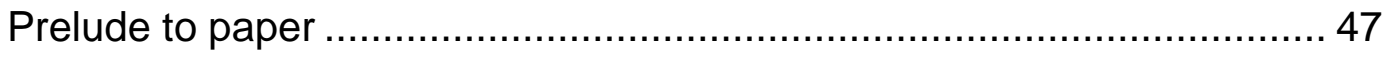

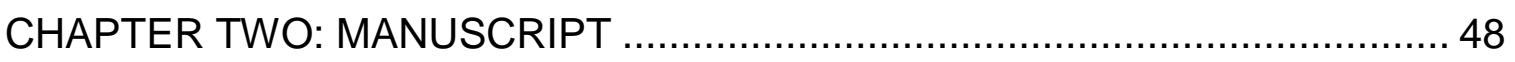

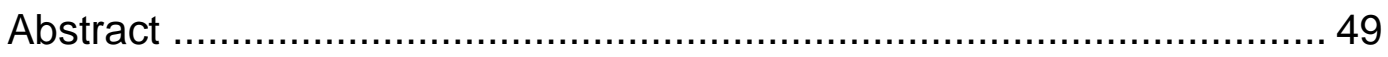

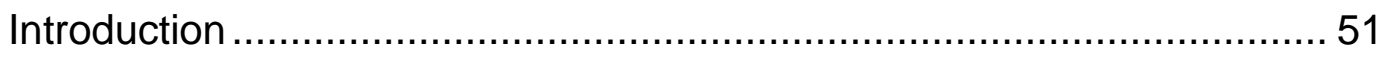

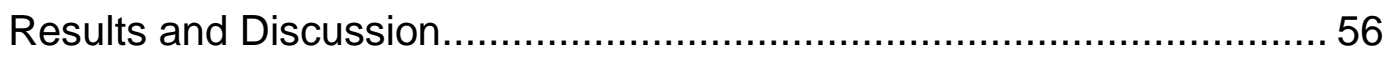

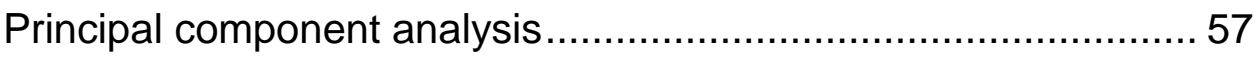




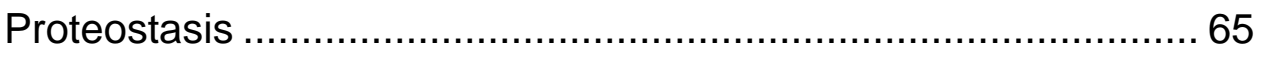

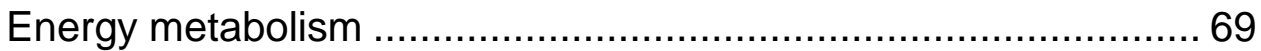

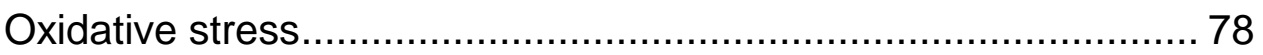

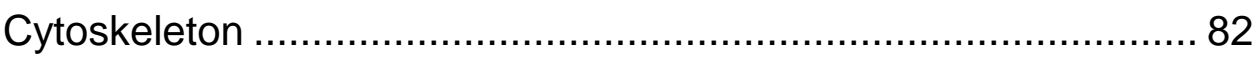

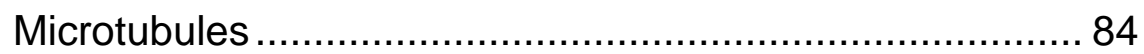

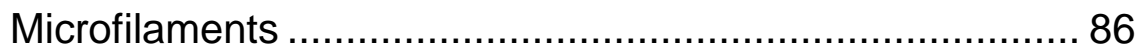

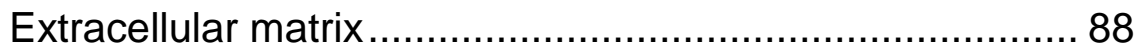

Intracellular signaling and vesicular transport ............................ 89

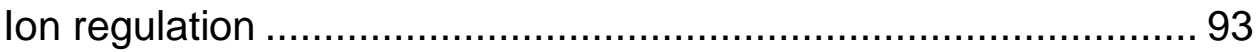

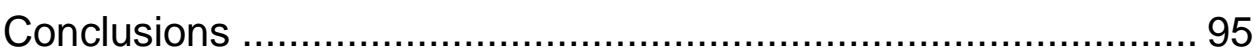

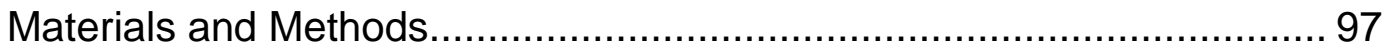

Animal collection and acclimation .............................................. 97

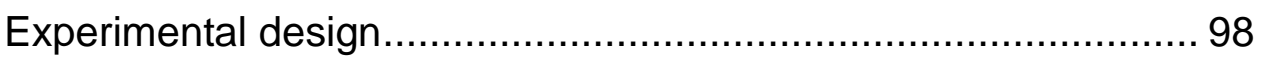

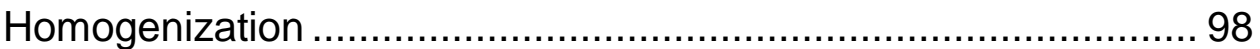

Two-dimensional gel electrophoresis ........................................ 99

Gel image analysis ........................................................... 100

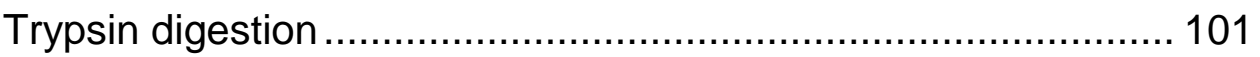

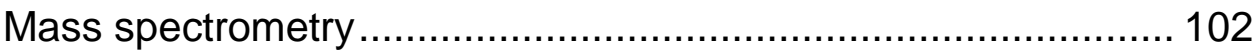

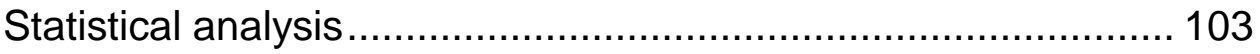

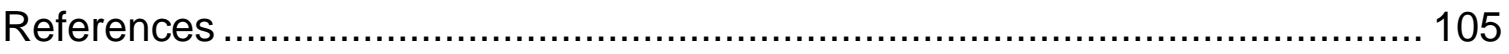

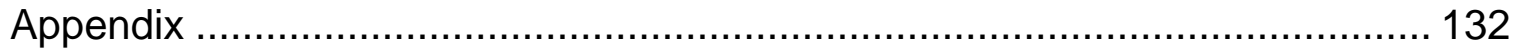




\section{LIST OF TABLES}

Table

Page

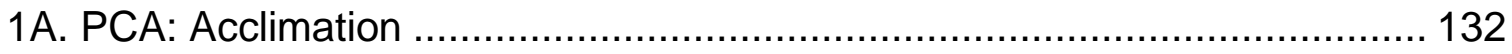

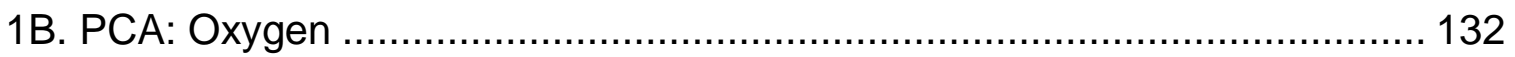

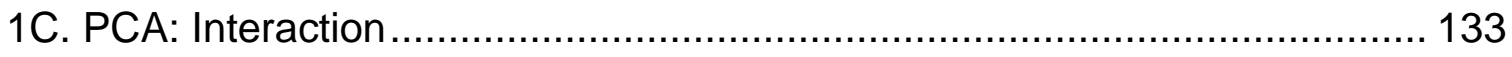

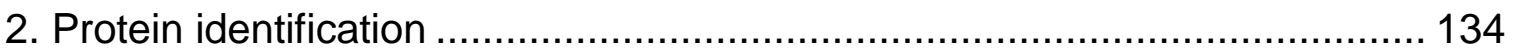

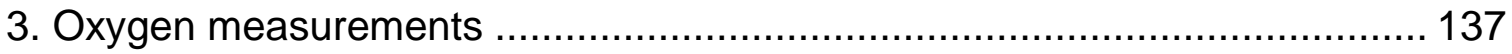




\section{LIST OF FIGURES}

Figure

Page

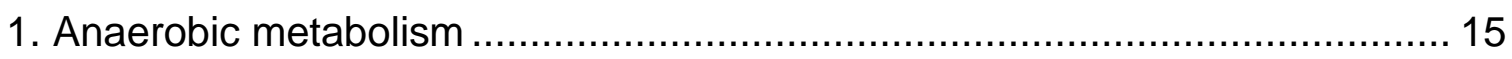

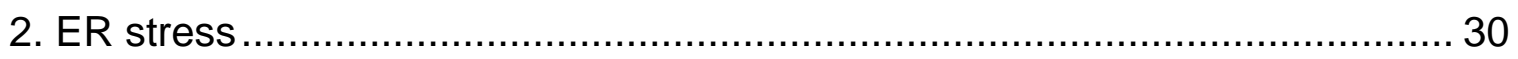

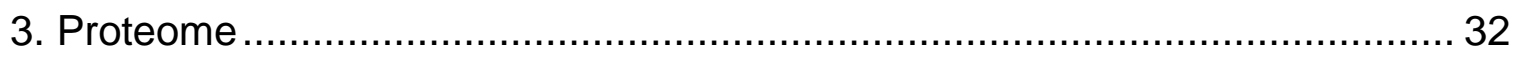

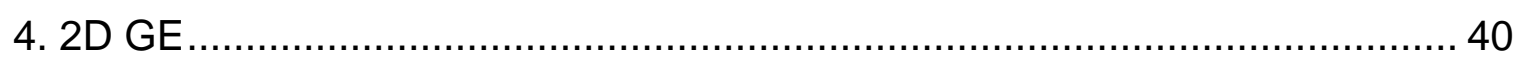

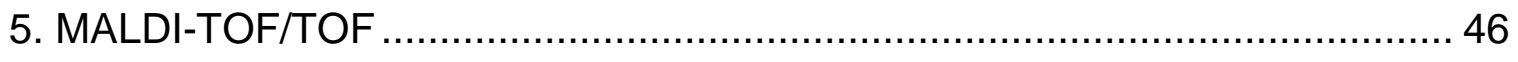

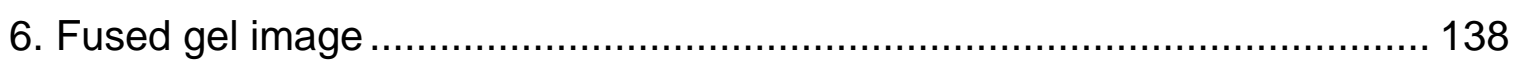

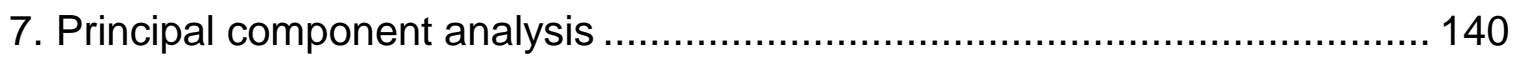

8. Hierarchical clustering: Protein homeostasis ............................................ 141

9. Expression profiles: Protein homeostasis ............................................... 142

10. Hierarchical clustering: Energy metabolism......................................... 143

11. Expression profiles: Energy metabolism ............................................... 144

12. Hierarchical clustering: Cytoskeleton ..................................................... 145

13. Expression profiles: Cytoskeleton...................................................... 146 


\section{CHAPTER ONE: INTRODUCTION}

\section{Overview}

Organisms have been known to exhibit phenotypic plasticity in response to either field acclimatization or lab acclimation over the course of days to weeks. This acclimatory plasticity affects the biological response to a subsequent stress (Prosser, 1991; Edmunds, 2014). One example of 'mussel memory' was evident in a study by Roberts and colleagues (1997) on the intertidal mussel, Mytilus californianus, which had greater heat shock protein expression due to elevated temperatures based on season and field acclimatization to either high or low intertidal sites, ultimately reducing the energy costs of protein turnover. These results led us to hypothesize that subjecting mussels ( $M$. californianus) to either constant immersion (subtidal conditions) or intermittent emersion (tidal conditions) would affect their proteome. Moreover, we predicted a tidal acclimation would allow for biochemical alterations conferring improved responsiveness to a subsequent stress, namely aerial emersion-induced anoxia that occurs during low tide.

Due to aerial exposure during low tide, intertidal organisms cope with many environmental stressors including, but not limited to, changes in oxygen and food availability, salinity, ultraviolet radiation, and temperature (Newell, 1979; Roberts et al., 1997). Stress can alter energy demands for survival and decrease aerobic scope due to increased cost of basal maintenance (e.g. survival), limited oxygen uptake and delivery systems, reduced capacity for energy acquisition and aerobic ATP synthesis, or a combination of these factors (Sokolova et al., 2013). 
A unifying theme for these environmental stressors is the occurrence of oxidative stress at the molecular level. Oxidative damage can occur when the oxygen radicals outweigh the antioxidant capacity, which can result in cellular damage (Kültz, 2005). Animals can withstand the highly variable intertidal environment due to biochemical adaptations that confer the physiological capacity to cope with these challenges. Specifically, anoxia alters protein functionality and thus affects protein homeostasis. The cell copes with oxygen deprivation by changing the abundance of or modifying proteins, regulating metabolism (e.g. reducing metabolic rate) (Hochochaka and Somero, 2002), and restoring redox balance.

Mussels of the genus Mytilus are ideal for studying environmental stress in marine systems because they are sessile invertebrates in the rocky intertidal (Campos et al., 2012). In the field, Mytilus spp. have a nearly worldwide distribution yet vary in their vertical distribution. One species of Mytilus, $M$. californianus, is an ecosystem engineer and prey of the keystone species of sea star Pisaster ochraceus (Menge et al., 2008; Menge et al., 1994) as well as a dominant inhabitant of the low to mid rocky intertidal of the Pacific coast (Seed, 1992; Morris, 1980; Lockwood et al., 2015). Moreover, the Mytilus genus has been the subject of numerous proteomic studies on environmental stress (Tomanek, 2010; Tomanek and Zuzow, 2010; Tomanek, 2012). Proteomics is an effective tool for investigating the physiological responses of marine invertebrates to environmental stress. Proteomic analyses include numerous studies of invertebrate responses to aerial-induced hypoxia (Fields et al., 2014), oxidative stress (McDonagh and Sheehan, 2006; McDonagh and Sheehan, 2007; 
Tomanek, 2015), and elevated temperature (Fields et al., 2012a; Fields et al., 2012b; Tomanek and Zuzow, 2010). Mytilus oxygen limitation studies thus far have focused primarily on anoxia while emersed (Shick et al., 1986; Wang and Widdows, 1993; Anestis et al., 2010; Diaz and Rosenberg, 1995). However, we still have a limited understanding of the protein changes experienced by intertidal mussels during emersion-induced anoxia.

The purpose of our study is to explore how organisms respond to aerial anoxia at the protein level. We aim to increase our understanding of physiological tolerance limits to stress and to characterize acclimatory plasticity, or mussel memory, in the stress response following a subtidal or tidal regime. In this account, I will address four parts to provide relevant and detailed background for this project: (1) the Mytilus study system, (2) the organismal and molecular impact of environmental stress (anoxia) on Mytilus, (3) the role of proteins in the stress response, and (4) the proteomic approach.

\section{Mytilus as a study organism}

The marine bivalve family of blue mussels (genus Mytilus) origins trace back to the North Pacific Ocean (Vermeij, 1991; Seed, 1992; Lockwood et al., 2015). The four congeners, Mytilus californianus, M. trossulus, $M$. edulis and $M$. galloprovincialis, shared a common ancestor approximately 7.6 mya (Ort and Pogson, 2007). Approximately 3.5 mya, M. edulis diverged from M. trossulus in the North Atlantic (Heath et al., 1995; Vermeij, 1991). About 2 mya, $M$. galloprovincialis emerged in the Mediterranean Sea (Barsotti and Meluzzi, 1968). 
A fifth congener, M. coruscus, is native to the western Pacific (Seed, 1992). To our knowledge, it is not known when or how M. californianus diverged.

Sessile intertidal Mytilus are ideal for the study of environmental stress due to their immobility as compared to other organisms that can move to escape stress (Halpin et al., 2002). This stationary position allows for the isolation of other abiotic factors (i.e. anoxia) during circatidal rhythms. Thus, intertidal organisms such as Mytilus have the potential to elucidate how stress influences molecular physiology (Hochacka and Somero, 2002; Lockwood et al., 2015). For example, Mytilus have been used in several proteomic studies involving environmental stress such as heat stress (Tomanek, 2008; Tomanek and Zuzow, 2010; Tomanek, 2014).

\section{M. californianus: A natural history}

M. californianus is of a distinct lineage from the other three species in the blue mussel complex (Ort and Pogson, 2007; Seed, 1992). The California ribbed mussel, $M$. californianus, is of particular interest because it is the dominant species in the low to mid rocky intertidal of the California coast. M. californianus can also experience subtidal conditions depending on their vertical position in the intertidal; they can also be found constantly immersed (e.g. on pier pilings). This is in comparison to the bay mussel neighbors of $M$. californianus: $M$. galloprovincialis (subtidal) and M. trossulus (intertidal). M. californianus is morphologically distinguished by its blue-black ( 130 mm long) shell with distinctive radial ribbing and growth lines which differs from the smooth blue- 
black and oblong morphology observed in the other mussel species (Morris et al., 1980).

M. californianus ranges from the Aleutian Islands in Alaska to southern Baja California, Mexico (Morris et al., 1980). Their range overlaps with congeners M. galloprovincialis, an invasive warm-adapted euryhaline species, and $M$. trossulus, a native cold-adapted stenohaline species (Braby and Somero, 2006). However, unlike M. galloprovincialis and $M$. trossulus, M. californianus is unable to hybridize with other Mytilus species due to its sex-specific mtDNA inheritance known as doubly uniparental inheritance (Ort and Pogson, 2007). This has implications for the biogeographic range as well as the ability of $M$. californianus to adapt to a changing environment in the face of interspecific competition. $M$. californianus can co-occur with its congener bay mussels, M. galloprovincialis and $M$. trossulus, although they are more common in sheltered habitats due to weaker byssal threads (Morris et al., 1980).

The California mussel forms extensive beds, which may be multi-layered (usually in the northern part of its range), where byssal threads secreted from the base of the foot attach to the rocky substrate and to other mussels forming aggregates when wave action is weaker (flow rate $<50 \mathrm{~cm} / \mathrm{s}$ ), which can be facilitated by the protective quality of mussel beds (Morris et al., 1980; Carrington et al., 2008). Thick mussel beds trap sediment, detritus, and water to provide food and shelter for diverse organisms to find protection between or attached to mussel shells (Paine, 1966) thereby earning the mussel the title as an 
"ecosystem engineer" and highlighting its importance in community dynamics and structure (Menge et al., 2008).

Mytilus frequently dominate the low to mid rocky intertidal region in temperate seas of the northern and southern hemispheres (Seed, 1992; Lockwood et al., 2015). California mussels typically occupy the mid intertidal region as the lower limits are set by biotic factors (predation, competition) and upper limits by abiotic factors (temperature stress, desiccation, food shortage) (Paine, 1974; Bayne et al., 1976a). Understanding how Mytilus copes with stress (oxygen deprivation) during aerial anoxia will help elucidate the differential abundances along the California coast (Braby and Somero, 2006; Tomanek, 2011).

California mussels are integral to intertidal marine food webs as they are preyed upon by the keystone species of sea stars, Pisaster ochraceous. Juvenile mussels may become food for oyster drill snails (Nucella emarginata, Ceratostoma nuttali, Roperia poulsoni) and seabirds (Wootton, 2002). In addition to their valuable ecosystem role, $M$. californianus are also an important source of food and bait. As the fishing pressure increases with human population size, the California mussel population structure changes with a decrease in average size (Erlandson et al., 2008).

Mussels are suspension-feeding bivalves that filter water for plankton and free-floating organic matter using gills with a network of cilia (Riisgård et al., 2011). Water is first drawn into the branchial chamber through the incurrent siphon. Bands of cilia facilitate water transport and subsequent separation of 
particles (Riisgård et al., 2011). The water is filtered of food particles using a mesh of finger-like extensions, cirri, covered in cilia forming a feather-like network to increase particle retention ("stickiness") in conjunction with mucus (Moore, 1971). The cirri then transfer particles to frontal surfaces of the gill before being funneled to the mouth by the labial palps (Moore, 1971). Gill tissue was the focus for our study due to it being the interface between the organism and its environment. Moreover, mussel gills filter seawater to obtain food and perform gas exchange and are the most active organ and most sensitive to oxygen deprivation (Rivera-Ingraham et al., 2013). Gill can act as an informative tissue for determining the effects of anoxia on energy metabolism proteins (Tomanek, 2008) and has already been used in numerous studies investigating proteomic changes in Mytilus to environmental stress (Tomanek and Zuzow, 2010; Tomanek, 2014). Overall, the ability of gills to filter nutrients, mediate gas exchange, and facilitate other metabolic processes makes them ideal tissues to use as the focus of my thesis work.

California mussels, $M$. californianus, are our model for tidal regime and oxygen limitation. Due to changes in tidal height, $M$. californianus are in constant flux between ample food availability, submergence in water, and optimal temperatures during high tide, and food deprivation, desiccation stress, increased temperatures, and aerially-induced anoxia during low tide. Additionally, M. californianus are known to regulate oxygen consumption rate during oxygen tension during low tide (Bayne et al., 1976b) and survive without oxygen known as anaerobiosis, as in M. edulis (Müller et al., 2012). 


\section{Mytilus' response to environmental stress and acclimation}

The underlying mechanisms of the physiological tolerance in Mytilus to environmental stress are of great interest. By determining biochemical adaptations to stressors, we can improve our understanding of what confers tolerance to specific levels of stress to predict how organisms may respond to subsequent stressors including climate change (Anestis et al., 2010). Ultimately, this will allow us to predict whether organisms will adapt, move, or die when it comes to stressful environments as well as understand what traits allow for an organism to occupy its fundamental niche.

Many studies have focused on the response of Mytilus to environmental stress including heat stress, osmotic stress, and desiccation (Tomanek, 2008; Tomanek and Zuzow, 2010; Tomanek, 2014; Dowd and Somero, 2013). Although there have been numerous studies on Mytilus' response to environmental stress, there is a gap in knowledge regarding Mytilus and their physiological response to aerial-induced anoxia. Thus, we are interested in elucidating the physiology of the anoxia stress response during emersion. One important level of change to deal with cellular stress is at the protein level.

Protein synthesis and degradation will fluctuate in order to balance the ebb and flow between stressful and non-stressful conditions to maintain homeostasis (Petes et al., 2008). During stressful conditions, organisms ultimately face a tradeoff between growth and reproduction with maintenance of cellular integrity and thus must allocate energy accordingly (Ivanina and Sokolova, 2013) which 
can be accomplished by changing protein abundances and/or shifting to different pathways.

Acclimatory plasticity involves the capacity to shift the position or width of the stress-tolerance window, although these adjustments are constrained by the species' environmental (e.g. food availability) and physiological conditions. To adapt, acclimatize in the field, or acclimate in the lab, organisms can adjust mechanisms for energy assimilation, mitochondrial capacity and abundance, enzyme activities, ion/gas transport, and membrane composition (Hochachka and Somero, 2002). These changes ultimately alter the global suppression of cellular protein synthesis. The stress response within the proteome can be triggered by exposure to several stressors including extreme hypoxia, anoxia, acute exposure to pollutants, freezing, and desiccation stress and involves a concerted suppression of mRNA transcription, maturation, and translational processes (Kwast and Hand, 1996; Larade and Storey, 2007; Tomanek, 2010; Tomanek and Zuzow, 2010; Tomanek, 2014; Tomanek, 2015).

The response to environmental stress is not solely controlled by heritable adaptations, but can also be regulated by acclimatory plasticity. Roberts et al. (1997) note the effects of field acclimatization and suggest the stress response for sessile organisms is partially modulated by environmental factors including tidal height. In turn, abiotic conditions such as tidal fluctuations alter protein turnover. Similarly, acclimation to a particular stress (e.g. tides, temperature) may influence the response to another stress (Feder and Hofmann, 1999). For instance, depending on the season, $M$. californianus produce a different 
abundance of heat shock proteins (HSPs), which help maintain protein function during elevated temperatures or other conditions that induce oxidative stress. In addition, inducible forms of HSPs have shown threshold-like responses that occur during extreme events and also occur during lower frequency changes via acclimatization (Halpin et al., 2004). Similarly, when acclimated to cyclic temperatures, $M$. edulis decreased its amplitude of response of oxygen consumption and filtration rate to fluctuating temperatures (Widdows, 1976).

Tidal rhythm is a stressor that acts continually and cyclically. Based on the transcriptome, acclimation to tidal rhythm may have primed $M$. californianus to elicit a more robust response. Specifically, lower intertidal $M$. californianus show smaller and less consistent rhythmic changes in gene expression than higher intertidal mussels that regularly experience periods of aerial emersion (Gracey et

al., 2008). Overall, by analyzing the impact of acclimation to a chronic stress (i.e. tides) on the response to an acute stress (anoxia), we can better predict how animals might cyclically alter molecular machinery such as their proteome to prepare for future stressors.

\section{Gaping behavior}

Some mussel species use gaping as an important behavioral adaptation to deal with low tide. Gaping is the opening of the valves to provide access to food, facilitate aerobic metabolism, and to lessen the deleterious metabolic effects (e.g. oxidative damage) following hypoxia-reoxygenation cycles and exposure to thermal extremes (Dowd and Somero, 2013). Gaping during 
episodes of elevated body temperature in air can ameliorate effects of high temperature via evaporative cooling in some bivalves (Lent, 1968). The emergence of mussels and associated closing of their valves has been linked to the onset of hypoxia (Gracey et al., 2008). In response to oxygen limitation, some mussels are known to control the degree of openness of shell valves (shell gaping) (Dowd and Somero, 2013).

Gaping in Mytilus seems to function primarily to maintain mantle cavity fluid oxygenation to support aerobic metabolism (Bayne et al., 1976b; Coleman, 1973; Dowd and Somero, 2013). When conditions are suboptimal, mussels may close their shell and valves to avoid desiccation. By preventing water loss, the shell water $\mathrm{pO}_{2}$ rapidly falls to zero (Rivera-Ingraham et al., 2013). As a consequence, those mussels (i.e. M. edulis) that chose the strategy of shell closure undergo metabolic depression, and thus decreased heat dissipation and ATP turnover (Wang and Widdows, 1993; Rivera-Ingraham et al., 2013).

Although previous studies investigating gaping in mussels have primarily focused on $M$. edulis, it is not completely clear whether gaping behavior is used by $M$. californianus. Based on metabolic rate and byproducts, evidence suggests M. californianus regulates its rate of oxygen consumption during a decline in oxygen tension and appears to resort to anaerobic metabolism (Bayne et al., 1976b; Widdows and Shick, 1985). Despite the capacity to consume oxygen while exposed to air (via gaping), M. californianus acquired an "oxygen debt" during aerial exposure in which the oxygen tension in the mantle cavity decreased to $\sim 40 \mathrm{mmHg}$ in both lab and field animals (Bayne et al., 1976b). 
Bayne et al. (1976b) observed a low proportion of animals gaping in field yet a higher proportion in lab where humidity was higher; $M$. californianus can extract oxygen from air during high humidity. However, aerobic metabolic rate was depressed below the standard rate and individuals acquire a large oxygen debt (Bayne et al., 1976b).

M. californianus may store oxygen in a trapped water reservoir in the mantle cavity during exposure for minimal respiration; they may periodically gape when this reservoir is insufficient (Moon and Pritchard, 1970). After acclimating mussels to constant immersion at $12-15^{\circ} \mathrm{C}, M$. californianus spent less time sealed during $13^{\circ} \mathrm{C}$ air exposures than $M$. galloprovincialis and $M$. trossulus, yet gaped continually only during elevated temperatures (i.e. $33^{\circ} \mathrm{C}$ air exposures) (Dowd and Somero, 2013). The corresponding total time sealed in an average 20 h control period was significantly lower in $M$. californianus than two blue mussel congeners (Dowd and Somero, 2013). Additionally, the behavioral responses to emersion and elevated body temperature differed between the first and subsequent episodes (increase in time sealed in $13^{\circ} \mathrm{C}$ air) (Dowd and Somero, 2013) indicating mussels were primed for the following aerial exposures.

\section{Metabolic response to oxygen limitation in bivalves}

There has been extensive study of behavioral, biochemical, and physiological responses of bivalves to limited oxygen availability (Brooks and Storey, 1997; de Zwaan et al., 1991, 1992; Grieshaber et al., 1994). Due to changes in tidal height, intertidal species are accustomed to experiencing 
hypoxia or anoxia induced by low tide. When a system becomes severely oxygen limited and physiological lines of defense are unable to compensate for the oxygen deficit, strategies to deal with oxygen deprivation must be employed. Hypoxia-tolerant species have developed back-up biochemical defenses including metabolic organization allowing for suitable substrates and for their regulated use (Hochachka and Somero, 2002).

Marine and freshwater bivalves are among the most hypoxia tolerant macrofauna; some benthic infauna species survive days and even weeks in complete anoxia (Abele et al., 2009; River-Ingraham et al., 2013). Organisms aim to prevent the depletion of internal stores and maintain the proper forms of fermentable fuel such as glycogen, which bivalves store in the mantle and hepatopancreas, and amino acids, which aid in the generation of ATP (Hochachka and Somero, 2002). Overall, the two main solutions to oxygen limitation in bivalves are (i) metabolic depression (as much as 10- to 20-fold reduction in ATP use during anoxia) and (ii) improved anaerobic efficiency in the form of ATP yield (Hochachka and Somero, 2002).

In terms of the second solution to anoxia, marine bivalves improve energetic efficiency by four methods: (1) converting glucose to octopine, lysopine, alanopine, or strombine (+2 moles ATP/mole glucose), (2) converting glucose to succinate (+4 ATP), (3) converting glucose to propionate (+6 ATP), and (4) converting aspartate to succinate (+1 ATP) (Hochachka and Somero, 2002). In molluscs, phosphoenylpyruvate carboxykinase (PEPCK), catalyzes the carboxylation of PEP to form oxaloacetate to ultimately form succinate and 
propionate. PEP is later converted to pyruvate which is able to be converted into many other end products. Notably, the fermentation of glycogen to propionate in bivalves appears to be more important for long-term anoxia (Hochachka and Somero, 2002). Utilizing succinate or propionate formation has the advantage of allowing for turnover of up to three times more ATP produced for every $\mathrm{H}^{+}$ formed and accumulated than in mammalian tissues which rely solely upon glycolysis (Hochachka and Somero, 2002).

Even with the energetic advantage of succinate/propionate metabolism, anoxia still results in gradual acidification. The need to deal with acidification has led to the development of other mechanisms such as: (1) decreasing ATP turnover rate, (2) maintaining high buffering capacities in fluids and tissues, (3) metabolizing anaerobic end products to detoxify the cell, and (4) utilizing $\mathrm{H}^{+}$consuming reaction pathways (Hochachka and Somero, 2002). Additionally, an oxygen-limited cell is distinguished by enhanced protein stability, decreased proteolysis, and induction of chaperones during the reprogramming of the normoxic cell to become hypoxia tolerant (Hochachka and Somero, 2002).

To complement the other biochemical adaptations to anoxia, Mytilus spp. also respond to oxygen limitation by accumulating iminoacid derivatives called opines (e.g. octopine, alanopine, strombine). Pyruvate is condensed with an amino acid (e.g. arginine, alanine, glycine) by octopine dehydrogenase with glycolytic NADH to form opines (Müller et al., 2012; Figure 1). These dehydration reactions are comparable to those performed by lactate dehydrogenase in the amount of energy produced (+2 moles ATP/moles glucose). However, the 
advantages of opines are the formation of less acidic end products and the maintenance of osmotic neutrality (Müller et al., 2012).

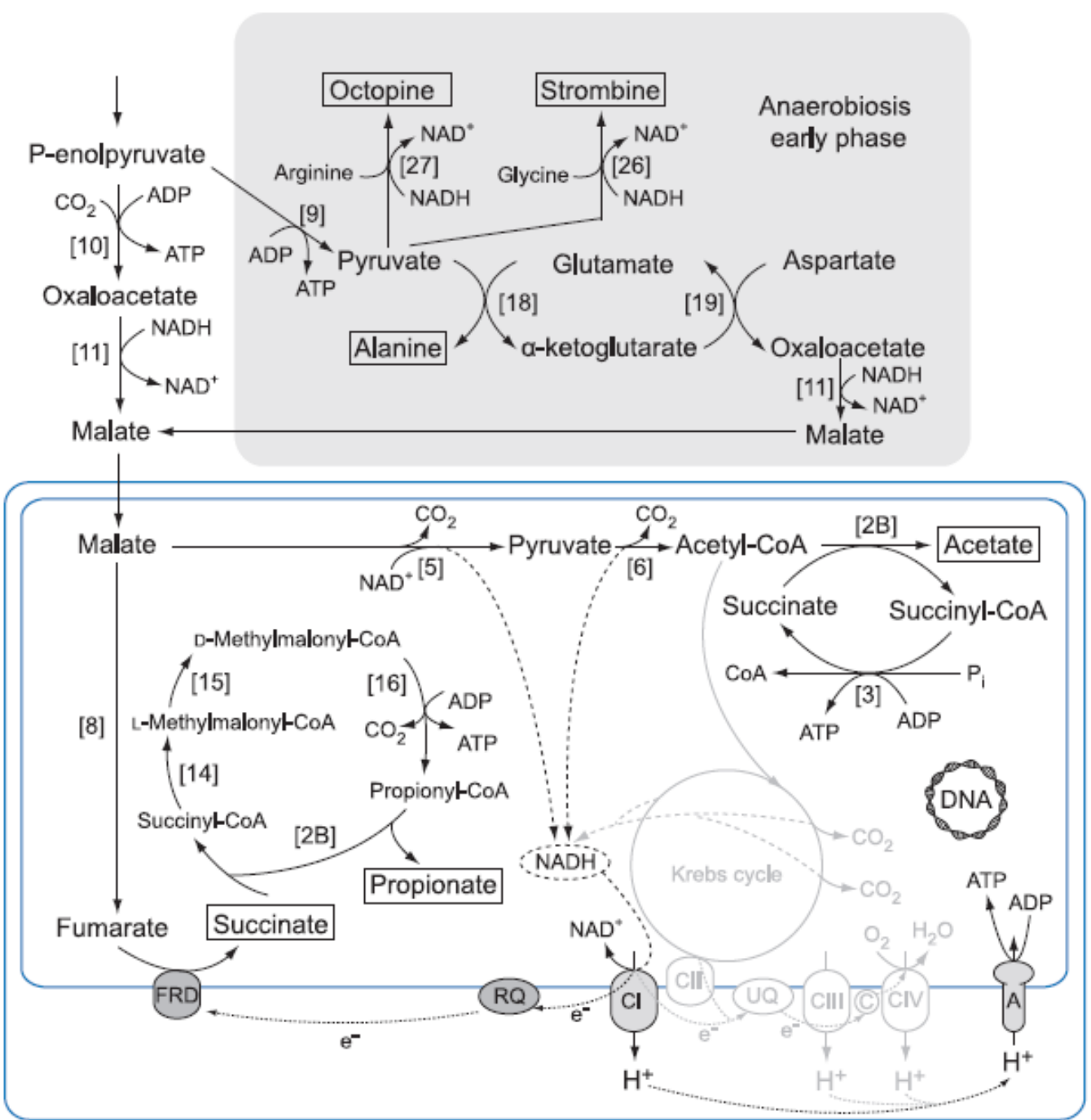

Figure 1. Anaerobic metabolism. Major pathways of facultative anaerobic energy metabolism in mitochondria of $M$. edulis (blue mussel) during periodic anaerobiosis (modified after Müller et al., 2012).

To finely-tune their response to oxygen deprivation, mussels also undergo different pathways as the length of hypoxia changes. During early phase hypoxia, 
mussels maintain redox balance using opines produced from pyruvate. Opines are stored in main tissues (i.e. body wall) under anaerobic conditions until they are reoxidized during normoxia (Müller et al., 2012). In addition to opines, succinate and alanine are also produced from the TCA cycle between oxaloacetate and succinate in reverse (Müller et al., 2012). Many hypoxiatolerant marine invertebrates share this characteristic of aspartate degradation and alanine production in addition to maintaining a large pool of free amino acids and glycogen reserves (Müller et al., 2012). In contrast, during extended periods of anaerobiosis, there is a transition to complete malate dismutation and acetate, propionate, and succinate accumulate in Mytilus (Müller et al., 2012). Moreover, prolonged anaerobiosis results in a preference for propionate over succinate in the mitochondria (Müller et al., 2012; Figure 1) because, as mentioned earlier, more ATP can be generated using propionate (Hochachka and Somero, 2002).

The numerous biochemical mechanisms used by marine bivalves confers a high tolerance to hypoxic and even anoxic conditions. We hypothesized that acclimation to a tidal regime (as opposed to a subtidal regime) would influence the energy status of $M$. californianus, partly due to the difference in oxygen availability. Moreover, we predicted that metabolic proteins would shift from aerobic to anaerobic pathways during anoxia treatment to a greater degree in mussels acclimated to a tidal cycle.

\section{Oxidative stress response}

Free radicals such as reactive oxygen species (ROS) are chemically reactive oxygen molecules with diverse roles in the cell. During non-stressful 
conditions, ROS are continually produced as a byproduct of energy metabolism. Moreover, ROS are essential for maintaining biological functions such as acting as messengers during redox signaling in preparation for response to stressors, activating various transcription factors to facilitate cross-talk between the nucleus and the mitochondria, promoting cellular proliferation and growth, and as a form of immune defense against invasive pathogens (Halliwell, 1992; Thannickal, 2000; Finkel and Holbrook, 2000; Jo et al., 2001).

In contrast, during stressful conditions, oxidative stress occurs when the scales tip in favor of free radicals rather than antioxidants. Stress-induced metabolic disturbance can result in oxidative stress due to the increased generation of ROS or RNS (reactive nitrogen species) and/or the suppression of the antioxidant defenses (Sokolova et al., 2013). Several transcriptomic and proteomic studies reveal a range of environmental stressors (e.g. temperature, salinity, $\mathrm{pH}$, and hypoxia) activate an anti-oxidative stress response, indicating the production of ROS is a nearly universal co-stressor (Logan and Buckley, 2015; Tomanek, 2014). Hypoxia and oxidative stress are inextricably linked partly because electrons leak from the slowed electron transport system (ETS) and because of re-oxygenation which causes ROS formation after hypoxia due to simultaneously enhanced flux of oxygen and reducing equivalents (Hermes-Lima and Zenteno-Savín, 2002; Welker et al., 2013).

Antioxidant imbalances and ROS can be found in the peroxisome, endoplasmic reticulum, and mitochondria. Within the mitochondria, the electron transport chain complexes I and III produce a large amount of ROS (Tomanek, 
2015). During increased ATP demand due to cellular stress, there is an increase in ROS and an increase in electron flux (Kültz, 2005; Tomanek and Zuzow, 2010; Sokolova et al., 2012). Regardless of where or how ROS production occurs, increases in intracellular ROS levels impact cellular processes in two different ways: either by damaging various intracellular biomolecules or activating certain signaling pathways as part of an antioxidant defense (Finkel and Holdbrook, 2000). For instance, ROS signal the cell to reprioritize energy allocation from cellular maintenance toward dealing with cellular stress.

Although ROS can be used as important signals, ROS also cause harm to cells by damaging DNA, protein, and lipids. A cause of cellular damage by ROS is leak of electrons from the ETS and TCA cycle, which leads to the formation of superoxide anions, hydroxyl radicals, and hydrogen peroxide (Finkel and Holbrook, 2000). Hydrogen peroxide is formed when superoxide diffusion across the mitochondrial membrane is catalyzed by mitochondrial and cytosolic superoxide dismutase (Mn-SOD and Cu/Zn-SOD, respectively). Although hydrogen peroxide is not a free radical, it is capable of diffusing through cellular membranes triggering extensive oxidative damage (Gunter et al., 2012). Hydrogen peroxide can accept electrons from transition metals (e.g. iron) and other donors to become a hydroxyl radical, which is the most reactive of the oxygen radicals (Finkel and Holbrook, 2000; Hermes-Lima et al., 1998).

To prevent or deal with ROS-induced macromolecular damage, the cell utilizes a variety of antioxidant systems. Common antioxidants that reduce the risk of hydroxyl radical formation include glutathione peroxidase (GPx), 
thioredoxin peroxidase (TPx), water soluble vitamins, and catalase. Glutathione peroxidase (GPx) helps to catalyze the conversion of hydrogen peroxide to water and oxidized glutathione in the cytosol and mitochondria (Gunter et al., 2012; Finkel and Holbrook, 2000). Similarly, thioredoxin enzymes, thioredoxin peroxidase and thioredoxin reductase, are involved in repairing oxidative cysteine damage (Kültz, 2005). The thioredoxin system works through the recycling of oxidized thioredoxin back to its reduced state by using electrons from NADPH (Kültz, 2005). In contrast, catalase (CAT) catalyzes the conversion of hydrogen peroxide to water and molecular oxygen primarily in peroxisomes (BenYoseph et al., 1996). Additionally, small water-soluble antioxidants such as ascorbate (vitamin C), $\beta$-carotene, and $\alpha$-tocopherol (vitamin E) detoxify ROS (McCall and Frei, 1999).

As a result of oxidative stress, the cell may increase the abundance of proteins involved in ROS scavenging (e.g. superoxide dismutase) or decrease ROS production through redox regulation (Sokolova et al., 2012; Tomanek, 2011). To facilitate antioxidant pathways to combat oxidative stress, antioxidants utilize NADPH as a reducing agent (Singh et al., 2007). The pathways for NADH and NADPH are highly regulated. NADH is involved in oxidative phosphorylation during glycolysis and the TCA cycle. In contrast, NADPH is involved in the oxidative phase of the pentose phosphate pathway (PPP). One way of producing $\mathrm{NADPH}$ in the mitochondria is with NADP-dependent isocitrate dehydrogenase in the TCA cycle (Jo et al., 2001) to ultimately reduce free radicals to make them non-reactive and thus non-damaging. 
Marine bivalves such as $M$. californianus routinely experience oxidative stress due to daily and seasonal fluctuations in oxygen. The increase of both endogenous and exogenous ROS may be triggered by $\mathrm{pH}$ changes and low oxygen (Sokolova et al., 2012; Tomanek, 2011). Since mussels have a limited capacity to regulate dynamic $\mathrm{pH}$ changes, an increase in $\mathrm{pCO}_{2}$ can cause oxidative stress (Tomanek et al., 2011). Although the sources and pathways of ROS production by mitochondria are highly conserved, some unique pathways seem to only exist in marine bivalves (Donaghy et al., 2014). Specifically, Donaghy and colleagues (2014) characterized the distinctive sites of ROS production in bivalves. After long-term anaerobiosis, propionate is preferentially formed instead of succinate; this shift may be detected through changes in metabolic proteins including succinate dehydrogenase. We aimed to detect changes in proteins involved in energy metabolism and oxidative stress proteins to better elucidate how $M$. californianus responds to shorter and longer-term anoxia. In order to understand why proteomics is so useful for studying the molecular response to environmental stress, it is first necessary to explain how cells maintain protein homeostasis.

\section{Proteostasis}

The role of protein homeostasis, or proteostasis, is to maintain the function of proteins by keeping proteins in their native, properly folded conformation (Kim et al., 2013). Especially during cellular stress, molecular chaperones function to assist in folding de novo proteins, maintaining preexisting 
proteins in their native states, and preventing protein aggregation to maintain proteostasis in response to its perturbation. When the activity of chaperones is insufficient, proteins that are irreversibly misfolded either aggregate or are degraded. Proteins are susceptible to misfolding and aggregation due to their need to balance both conformational stability and catalytic flexibility. This susceptibility influences the probability of proper folding for a population of proteins which changes depending upon physiological conditions (Kim et al., 2013).

Molecular chaperones are a highly evolutionarily conserved yet diverse group of proteins classified by sequence homology. Chaperone functions include general proteome maintenance, macromolecule complex assembly, protein transport and degradation, aggregate dissociation, quality control, and refolding of stress-denatured proteins (Kim et al., 2013). Nascent and preexisting proteins are both at risk of misfolding and aggregation due to the exposure of hydrophobic regions, non-native post-translational modifications, and disulfide bridges which all affect protein folding and stability. The risk of misfolding and aggregation is made worse by an imbalance between protein synthesis, metabolic stress, heat stress, oxidative stress, and other stressors (Buchberger et al., 2010).

The cellular stress response is an adaptive response aimed at reducing protein damage through a decrease in global protein translation and an increase in molecular chaperones and proteolytic proteins (Kültz, 2005). Two major stress responses occur in the cell: the heat shock response and the unfolded protein response. First, the heat shock response occurs in the cytosol and nucleus. 
During heat stress, increased levels of nonnative protein conformations shift chaperones away from heat shock factor 1 (HSF1). This causes the trimerization of HSF1, which binds to promoter regions called heat-shock elements to activate HSF1 based on the temperature-dependent promoter-binding ability (Buckley et al., 2001). Post-translational modifications of HSF1 also help modulate the stress response. Importantly, mussels and other intertidal organisms regularly induce the heat shock response due to tidal fluctuations (Tomanek, 2010; Buckley et al., 2001; Hofmann and Somero, 1996). Conversely, during non-stressful conditions, HSP90 (and possibly HSP70 and HSP40), by forming a multi-chaperone complex retains HSF1 as an inactive monomer in the cytosol. Second is the unfolded protein response, which restores endoplasmic reticulum proteostasis (Buchberger et al., 2010).

Before going into depth about endoplasmic reticulum (ER) chaperones, a more thorough description of the ER will help set the stage for the regulation of protein folding. The ER is a membranous tubular network specific to eukaryotic cells in which secreted and membrane proteins fold and mature. It plays major role in lipid and protein biosynthesis, the protein secretory pathway, and $\mathrm{Ca}^{2+}$ homeostasis (Pluquet et al., 2015). The three domains of the ER include the rough ER (ribosomes attached), the smooth $\mathrm{ER}$, and the nuclear envelope. The ER is the compartmentalized modulator of cotranslational translocation of nascent polypeptides, retrotranslocation of misfolded polypeptides into the cytosol, and the oxidation and reduction of cysteine residues of secretory and membrane proteins (Araki and Nagata, 2012). Perturbations of ER functions 
cause ER stress which activates transcriptional and translational controls which cope with protein toxicity or the accumulation of misfolded proteins (Pluquet et al., 2015). A crucial feature of the ER is it has a highly oxidizing environment to facilitate protein folding and quality control via the maintenance of disulfide bonds. Nascent proteins entering the ER lumen undergo folding, posttranslational modifications, and later acquisition of disulfide bonds and assembly into oligomers; this process is facilitated by peptidyl prolyl cis-trans isomerases (PPI), protein disulfide isomerases (PDI), and other chaperones including the HSP70 known as immunoglobulin-binding protein (BiP) or glucose-regulated protein 78 (GRP78) (Pluquet et al., 2015). These processes will be covered in more detail in the following sections.

Endoplasmic reticulum stress is caused by conditions such as hypoxia, oxidative stress, accumulated misfolded proteins, and inadequate numbers of chaperones (Pluquet et al., 2015). Aberrant folding in the ER is partly attributed to very high $(100 \mathrm{mg} / \mathrm{mL})$ protein density in the $\mathrm{ER}$ and also concomitant protein maturation (Araki and Nagata, 2012). To cope with ER stress, cells use ERassociated protein degradation, which exports unfolded proteins from the ER to the cytosol where they are degraded by the ubiquitin-proteasome system (Pluquet et al., 2015). There are many possible deleterious or even apoptotic effects of ER stress such as overwhelming protein processing and elevated levels of ROS (Lortz et al., 2015).

Stress or over-expression of proteins may cause protein aggregation in the ER. As a result, potentially toxic aggregated proteins may be sequestered in 
a subcompartment to later be cleared by autophagy. The cell may also try to eliminate aggregates either by resolubilization and refolding (e.g. with sHSPs or HSP100) or by degradation. Along with HSP100, HSP70 is able to filter aggregated proteins to either undergo refolding into the native state or to be destined for proteasomal or lysosomal degradation. Notably, only a mobile, presumably nonaggregated subpopulation of substrate is eliminated by ERassociated degradation (Buchberger et al., 2010). The decision between aggregation and recovery as opposed to degradation is partially based on energy status, the need to reduce ROS, and time (Kim et al., 2013).

One category of molecular chaperone found in the cytosol, the ubiquitous and highly conserved small heat shock proteins (sHSPs), named for their low molecular weight (15-30 kDa) function to buffer the aggregation of misfolded proteins. SHSPs are ATP-independent chaperones that bind misfolded proteins, although the mechanism for binding is poorly understood. Rather than being constitutively active, sHSPs are activated by stress (Haselbeck et al., 2005). The primary function is to prevent the aggregation of misfolded proteins and loosen aggregates by coaggregation to ultimately reduce molecular entropy (Buchberger et al., 2010). In addition to preventing aggregation, sHSPs also function in de novo folding, protein transport and degradation, refolding of stress-denatured proteins, and overall proteome maintenance (Kim et al., 2013). Furthermore, sHSPs facilitate refolding as part of the HSP70/100 systems (Buchberger et al., 2010). 
Another important chaperone that functions in protein quality control is HSP70, which is localized to the cytoplasm, mitochondria, and ER. HSP70 proteins function in the regulation of the HSR, protein folding, and protein translocation across membranes. Like sHSPs, HSP70 is the stress inducible form whereas HSC70 (heat shock cognate) is constitutively expressed (Kourtidis et al., 2006). ATP-controlled HSP70 activity may induce conformational changes in the substrates to prevent aggregation and assist in folding (Buchberger et al., 2010). The mechanism by which HSP70 peptide binding and release is regulated is very ATP expensive (Kim et al., 2013).) For ATP-dependent chaperones, ATP binding and hydrolysis drives the shift between the states of differing affinities for misfolded proteins. However, ATP does not seem to regulate HSP70 activity directly (Haselbeck et al., 2005).

Within the ER, there are four main processes involved in maintaining proteostasis. First, translocation of a nascent protein with an ER signal sequence occurs post-translationally through a protein channel in the ER. Second, ER chaperones assist in protein folding. With respect to the improperly folded proteins, in conjunction with the ER stress response (e.g. to glucose starvation, acidosis, and hypoxia), there are a few key chaperones, including glucoseregulated proteins (GRPs). GRPs protect more against stress incurred by depletion of $\mathrm{ER} \mathrm{Ca}^{2+}$ (Lee, 2001). Importantly, GRP genes can be induced by other perturbations of $\mathrm{ER}$ function such as agents affecting $\mathrm{Ca}^{2+}$ stores or inhibiting glycosylation (Lee, 2001). GRP94 and GRP78 are two key players in the ER lumen. GRP78 is a chaperone that binds $\mathrm{Ca}^{2+}$ and acts to protect de 
novo translocated and misfolded proteins with exposed hydrophobic regions and assists with folding to the native state (Lee, 2001). Moreover, GRP78 is required for the translocation process and degradation of misfolded proteins of the ER lumen (Buchberger et al., 2010). GRP78 requires DNAJ/HSP40 cochaperones and nucleotide exchange factors for stimulation and regulation of ATP hydrolysis necessary for GRP78 activity (Araki and Nagata, 2012). In addition to helping assemble misfolded or unfolded proteins and preventing aggregation, GRP78 also has roles in ERAD (Araki and Nagata, 2012).

The third ER proteostasis process is disulfide bond formation, which allows for the proper tertiary structure crucial for protein function and stability. Folding of most nascent proteins in the ER involves the use of disulfide bonds

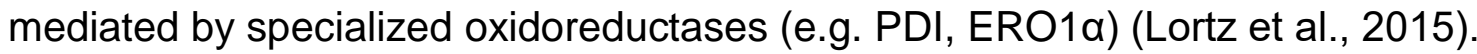
To fold a protein, cysteine amino acids are brought within close enough proximity for oxidoreductases such as PDI to form disulfide bonds (Bulleid and Ellgaard, 2011). PDIs make, shuffle, and break disulfide (S-S) bonds within polypeptides (Buchberger et al., 2010). The highly oxidative environment of the ER is suitable for the oxidation of free sulfhydryl $(\mathrm{SH})$ groups on cysteines to form disulfide bonds. Due to the requirement of an oxidative environment, disulfide bond formation is intrinsically linked to the production of redox balance and ROS. Consequently, PDIs are an alternative path that serves to alleviate excess ROS production in the ER (Araki and Nagata, 2012). Similarly, ERO1 $\alpha$ activity is regulated by the isomerization and reduction of intramolecular disulfide bonds facilitated by PDI. ERO1 $\alpha$ has been referred to as the oxidative engine and 
primary oxidase of PDI (Araki and Nagata, 2012). Some studies have found hydrogen peroxide $\left(\mathrm{H}_{2} \mathrm{O}_{2}\right)$, an important radical and signaling molecule, may directly oxidize PDIs (Araki and Nagata, 2012). In turn, PDI oxidizes cysteine residues in newly synthesized proteins, which generates $\mathrm{H}_{2} \mathrm{O}_{2}$ for each disulfide bond produced. Thus, $\mathrm{H}_{2} \mathrm{O}_{2}$ is released by this enzymatic folding pathway into the ER lumen and reutilized through ER-specific peroxidases (e.g. glutathione peroxidases and peroxiredoxin) to maintain and enhance oxidative protein folding (Lortz et al., 2015).

Fourth, quality control in the ER involves chaperones such as calnexin and calreticulin which bind carbohydrates to misfolded proteins. In a feedback loop manner, these lectins ensure glycosylated proteins are correctly folded. Most proteins have a sugar added ( $\mathrm{N}$-glycosylated for stability) once they enter the $E R$, then subsequent trimming by a glucosidase until all sugars are removed allows for checks and quality control by the calnexin/calreticulin (CNX/CRT) system. Proteins remain bound to CNX/CRT until all sugar groups are trimmed once properly folded to prevent aggregation and premature export from the ER (Araki and Nagata, 2012). Overall, the N-glycan composition acts as a recognition code for lectins. Some argue there is a bipartite substrate recognition system in which, on the one hand, chaperones and folding catalysts directly bind unfolded or misfolded protein regions while lectins and sugar-modifying enzymes "read" and modify the N-glycan status (Buchberger et al., 2010). This quality control falls under the ER quality control system which helps with folding and 
modification of secretory and membrane proteins in addition to removing terminally misfolded proteins by ER-associated or autophagic degradation. In addition to ER chaperone systems, another important molecular chaperone is T-complex protein which is in the HSP60/chaperonin family. Tcomplex protein contains the TRIC/CCT-TCP1 ring complex. Unfolded polypeptides enter the center of the ring and are folded in an ATP-dependent manner. The TCP-1 folding cage of T-complex protein primarily helps fold cytoskeletal proteins such as actin and tubulin (Fields et al., 2012; Sternlicht et al., 1993). T-complex protein is a key chaperone that also helps regulate the formation of mitotic spindles and thus cell proliferation (Brackley and Grantham, 2009).

When chaperone systems are insufficient, proteins are degraded. Protein degradation occurs in two major ways: the (i) ubiquitin-proteasome system (UPS) and (ii) the machinery of autophagy (Kim et al., 2013). As a part of the UPS, when proteins are misfolded beyond repair, proteins are ubiquitinated as a tag for degradation in the $26 \mathrm{~S}$ proteasome usually with chaperones (e.g. HSP70, HSP90) that maintain target proteins in a nonaggregated state. Chaperones cooperate with various E3 ubiquitin ligases in recognizing and targeting misfolded proteins for proteasomal degradation (Kim et al., 2013; Buchberger et al., 2010). Since the $26 \mathrm{~S}$ proteasome can become inhibited by aggregate formation, the UPS is not the major pathway for the removal of aggregates. Instead, the cell uses autophagy to engulf and break down aggregates (Buchberger et al., 2010). A second mechanism of degradation occurs when 
aggregated proteins cannot be unfolded for proteasomal degradation, thus requiring the action of the lysosome or vacuole.

In contrast to cytosolic proteins, which are sent to the proteasome, ER proteins have significant topological problems because of the lack of enzymatic activities of the unfolded protein system in the ER lumen. Consequently, luminal and membrane proteins are translocated back (or retrotranslocated) to the cytosolic face of the ER membrane where the polypeptide chain is ubiquitinated because there is no ubiquitylation system in the ER lumen (Buchberger et al., 2010). Chaperone-mediated refolding and targeted degradation by the unfolded protein system is ATP-dependent, meaning the overall energy balance of refolding should be favorable compared to degradation followed by de novo synthesis, which is slower and more error-prone than refolding under stress (Buchberger et al., 2010). The unfolded protein response occurs in response to the disruption of ER homeostasis (Figure 2). It involves transient attenuation of novel protein synthesis, degradation of misfolded proteins, and the onset of apoptosis (Lee, 2001). The unfolded protein response operates by attenuating protein synthesis and by activating a cascade of transcription factors that regulate genes encoding chaperones for components of autophagy machinery, and the ER-associated degradation system. The unfolded protein response also controls other pathways of lipid and energy metabolism (Pluquet et al., 2015). As opposed to the unfolded protein response, post-translational and posttranslocational reshuffling is energetically unfavorable and inefficient, making nonnative conformations of membrane proteins degradation targets (Buchberger 
et al., 2010). Terminally misfolded or unassembled proteins that are unable to acquire their native structure must be degraded as to not waste efforts to fold the accumulation of misfolded proteins in the ER.

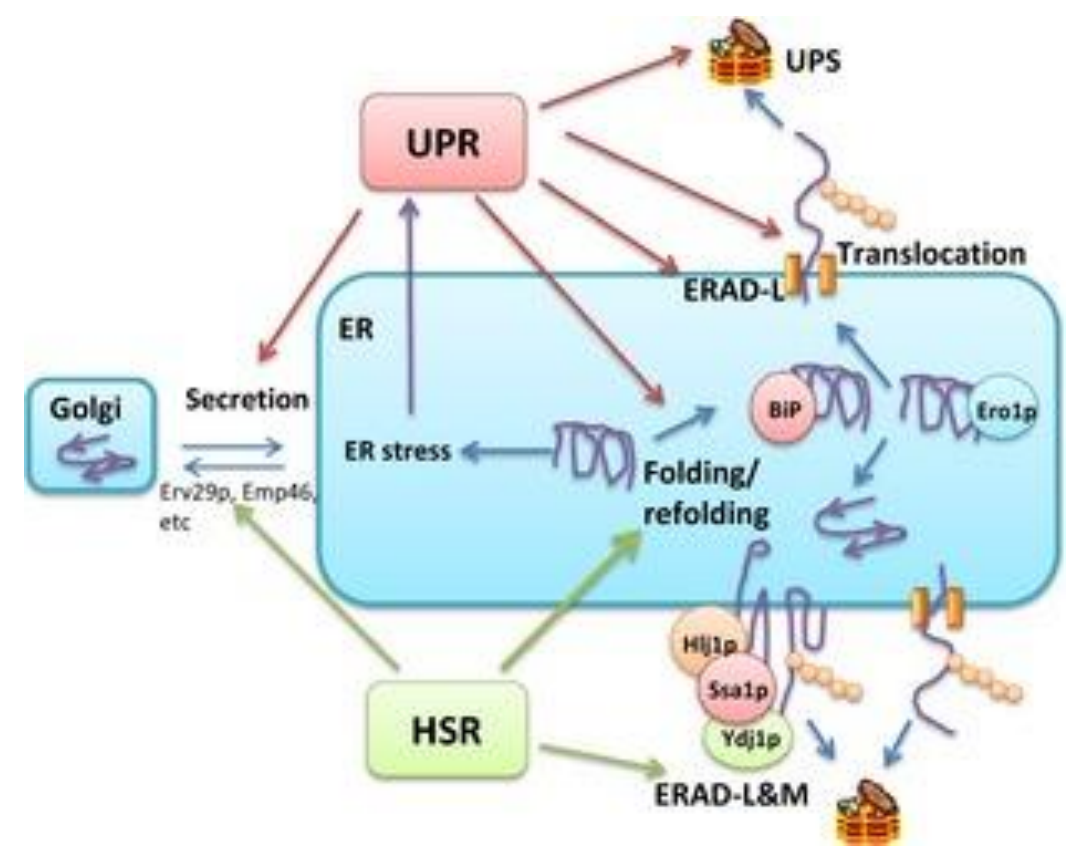

Figure 2. ER stress. Proposed model for HSR and UPR control of the secretory pathway under ER stress (Hou et al., 2013).

ER degradation and homeostasis also involves both the regulation of $\mathrm{Ca}^{2+}$ concentration and redox status. An increase in $\mathrm{Ca}^{2+}$ in the lumen may help stabilize proteins for secretion and enhance ER chaperone capacities (Araki and Nagata, 2012). In the event that protein refolding or aggregation prevention is no longer favorable, proteins are degraded. However, the molecular mechanism to determine which proteins are reparable or irreparable remains unclear. Some proteins are degraded even under normal conditions, while others fold with near 
perfect efficiency. Damaged proteins are retrotranslocated into cytosol for proteolysis by $26 \mathrm{~S}$ proteasomes. The ubiquitin tag (added in the cytosol) ensures efficient delivery of damaged proteins to the proteasome. The ubiquitin tag on STY residues (polar amino acids) on ERAD substrates recruits E3 ligases, chain elongation factors, and other key players. ERAD factor turnover is done to avoid time-intensive translational UPR responses (Araki and Nagata, 2012). All in all, proteostasis involves several chaperoning systems that work in concert to maintain the proper folding and functionality of proteins. We used a proteomics approach in order to generate hypotheses about these proteostasis-related processes by analyzing abundance changes in the entire proteome.

\section{Proteomics}

\section{Overview}

"Omics" is a relatively new approach to conducting scientific research. Omics are the collective technologies applied to investigate the relationships and different types of molecules that make up the cells of an organism. There are several types of omics studies including genomics, transcriptomics, proteomics, metabolomics, glycomics, and lipomics. Omics global molecular and biochemical approaches can provide important insights into molecular mechanisms of the action of multiple stressors in order to better understand the biological system under observation or experimentation (Tomanek, 2011; Connor and Gracey, 2012; Sokolova et al., 2013). 


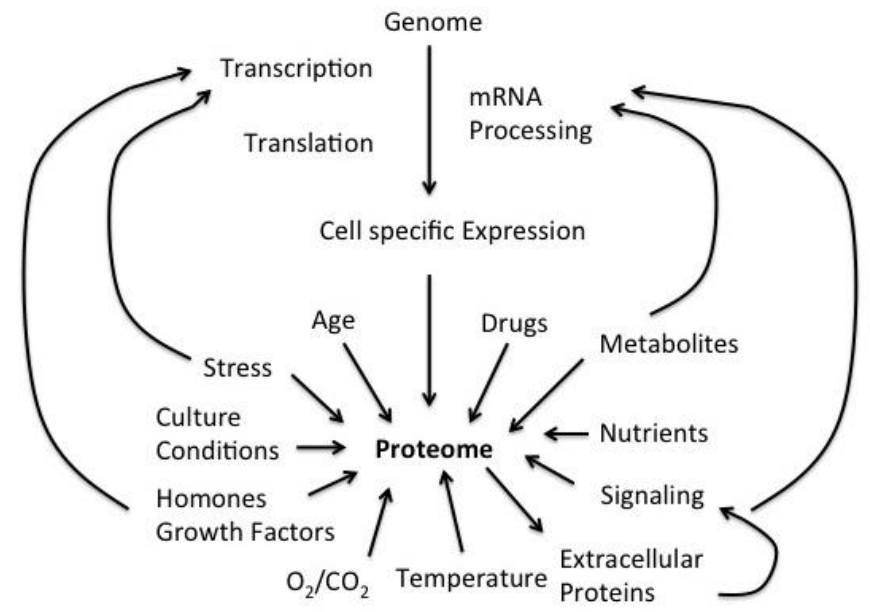

Figure 3. Proteome. Internal and external influences on the proteome, which is in constant flux (modified after Lovrić, 2011).

We chose to use proteomics, or the study of the changes in global protein abundance, for our study because proteins are sensitive to intrinsic regulation, have a fast response time, and change with external perturbations (Tomanek and Zuzow, 2010). The over-arching goal of proteomics is to create a snapshot of the protein abundance changes occurring within a given tissue (Campos et al., 2012). As proteins are involved in every biological process in the cell and act as the functional unit of living organisms, proteomics is an ideal tool to understand how the organisms respond to stress (Blackstock and Weir, 1999). Proteomics is a way of describing the protein abundance changes and therefore the phenotype of a particular organism (Rabilloud, 2002; Walsh et al., 2005; Abbott, 1999). Moreover, proteome-based profiling can provide insight into the mechanistic nature of the environmental stress response (Veldhoen et al., 2012) as the 
proteome is influenced by countless stressors such as oxygen and nutrient availability, extracellular proteins, growth factors, and temperature (Figure 3).

The proteome is influenced by protein compartmentalization, protein turnover (synthesis and degradation), and post-translational modifications (PTMs) (Tomanek and Zuzow, 2010). PTMs (e.g. phosphorylation, gluathinolyation) are covalent modifications on the side chains or backbones of nascent proteins (Seo et al., 2008; Walsh et al., 2005). Since increasing the abundance of proteins is energetically expensive, altering protein abundance may not be optimal for regulating activity during periods of acute stress (Lodish et al., 2007). PTMs are a quicker response mechanism that allow for an increase in the number of functions a given protein can perform (Lodish et al., 2007; Seo et al., 2004). To detect these effectors of the proteome, there are nuances to the way proteomics can be conducted that optimize the output.

There are two main approaches for proteomics: bottom-up and top-down (Lovrić, 2011). Top-down approaches are based on decomposition of the whole system into its parts to understand the sub-systems (Lovrić, 2011). In this context, whole proteins are analyzed by mass spectrometry, which generates the data necessary for characterization of those proteins (Lovrić, 2011). Meanwhile, bottom-up approaches are based on synthesis of whole systems from the pieces (e.g. peptides identified using mass spectrometry are compiled to characterize proteins that were separated using 2D gel electrophoresis (GE)) (Lovrić, 2011).

The next level that differentiates proteomic approaches involves the separation technique. First, gel-based proteomics has the advantage of easy 
handling and reproducibility. Gels can separate more than 10,000 proteins in a single gel and the available software can handle the analysis of a large sample size (Berth et al., 2007). Additionally, 2D GE allows for the separation of various protein isoforms with different post-translational modifications, such as phosphorylation which adds a negative charge to one or several amino acids, glycosylation which neutralizes negative charges, and acetylation which suppresses positive charges on amino groups (Michel et al., 2003).

Other separation techniques include semi-gel-free and gel-free systems (e.g. shotgun gel-free liquid chromatography) (Berth et al., 2007). Additional separation methods are often employed to supplement or enhance the intrinsic limitations of gel-based methods, which include poor detection of low abundance proteins, extremely basic or acidic proteins, hydrophobic proteins (e.g.

membrane), or nuclear proteins (Rabilloud, 2002). Despite these limitations, the gel-based method is the most commonly used bottom-up approach and was the approach used for this experiment (Lovrić, 2011).

\section{Protein separation}

Protein separation can be broken down into three steps: (i) sample preparation, (ii) isoelectric focusing (IEF), and (iii) 2D GE (Lovrić, 2011). Sample preparation is a crucial step because each protocol must be optimized for different cell types (Görg, 2004). Successful sample preparation is defined by four criteria: (1) successful removal of any additional sample contaminants, e.g. lipids, nucleic acids, polysaccharides, salts, and buffers, (2) maximum retention 
of original proteins in the sample, (3) preservation of the PTMs, and (4) compatibility with later analytical steps in the proteomic workflow (Lovrić, 2011). Moreover, proteins should be completely denatured, disaggregated, reduced, and solubilized (Görg, 2004).

Following dissection, tissues are homogenized with homogenizing buffer to release proteins from their intracellular environment and to facilitate lysis of the cell membrane (Görg, 2004). In addition to the mechanical force, neutral buffer chaotropes can be used to disrupt the hydration shell around proteins. Chaotropes such as thiourea and urea are molecules in water solution that disrupt hydrogen bonds of secondary and tertiary protein structures and interfere with hydrophobic interactions (Görg, 2004; Shaw and Riederer, 2003). Chaotropes also function as protease inhibitors to prevent the degradation of proteins (Shaw and Rierderer, 2003).

In combination with thiourea and urea, zwitterionic detergents which are surfactants such as amidosulfobetaine (ASB-14), help to solubilize integral membrane proteins and break down protein-protein interactions (Görg, 2004; Lovrić, 2011). Furthermore, the reducing agent dithiothreitol (DTT) acts to cleave inter- and intra-molecular disulfide bridges and prevent their re-oxidation to maintain proteins in an unfolded state (Görg, 2004; Shaw and Rierderer, 2003). This homogenization buffer additionally contains a mixture of carrier amphoyltes (IPG buffer), which are ions that can act as an acid or base to prevent fluctuations in pH and enhance sample solubility (Görg, 2004). Generally, the 
optimal $\mathrm{pH}$ range is between 4 and 7 , which corresponds to the normal physiological range (Lodish et al., 2007; Lovrić, 2011).

The first step in protein separation is to remove all other macromolecules except for proteins (Shaw and Rierderer, 2003). Contaminants are removed with TCA/acetone to precipitate proteins, which inevitably results in some protein loss (Görg, 2004). Nonidet P-40 is a non-ionic detergent that solubilizes membrane proteins and prevents protein-protein interactions. CHAPS is a non-denaturing zwitterionic detergent used to solubilize proteins. DTE is a reducing agent similar to DTT (Görg, 2004; Lovrić, 2011). These chemicals work together to isolate proteins and prevent their aggregation.

The next step after protein precipitation is quantification. We chose to use a spectrophotometric-based assay to detect protein concentration and ultimately normalize all samples for total protein. Some spectrophotometric-based assays are sub-optimal because they have limited sensitivity or because they complex with several buffer components including reducing agents (DTT), chaotropes (thiourea), carrier ampholytes, and detergents (CHAPS and SDS) (Mackintosh et al., 2005). To avoid this limitation, we used a 2D Quant Kit (GE Healthcare BioSciences, Pittsburgh, PA, USA) which quantifies proteins based on specific binding of $\mathrm{Cu}^{2+}$ ions to proteins suspended in a Cu-containing solution. For this type of assay, protein concentration is inversely related to absorbance (at 480 $\mathrm{nm}$ ) of unbound $\mathrm{Cu}^{2+}$-colorimetric agent complexes (Mackintosh et al., 2005). Once the total protein was quantified, we separated proteins by their charge. 
The first dimension separation, IEF, uses an electrical gradient to separate and takes advantage of the characteristic of proteins to become charged molecules. Proteins can be diluted in working rehydration buffer and subsequently loaded on an IPG gel strip. Separation in the first dimension allowed for a decrease in background smearing and improved resolution of proteins on the gel image for ease of analysis (Görg, 2004). Proteins are separated along a $\mathrm{pH}$ gradient based on the protein's isoelectric point ( $\mathrm{pl})$, or the $\mathrm{pH}$ at which the net charge is zero (Lovrić, 2011). Some proteins are amphoteric meaning the various side chains may be charged depending on environmental pH (Lovrić, 2011; Ahn and Simpson, 2007). Consequently, the charge of each protein is unique given the variation of amino acid sequences and PTMs. This inherent variability allows for the separation of different proteins and different charge isoforms (Lovrić, 2011).

The IPG strip size and pH for IEF is dependent upon the study system and goals for analysis. We used strips with a pH range of 4-7. Since there is an inverse relationship between protein retention and resolving power, this was considered when selecting $\mathrm{pH}$ range. This range decreased our resolution (relative to wider $\mathrm{pH}$ range strips), but improved our protein retention and separation (Righetti et al., 1983). Additionally, most proteins fall within the $\mathrm{pH} 4-7$ range since it is close to physiological $\mathrm{pH}$.

Before separation by molecular weight, proteins were equilibrated for two periods of 15 minutes in an anionic detergent with a hydrophilic sulfate group that imparts a negative charge on peptides along a denatured backbone (Lovrić, 
2011). Equilibration buffer contains Tris- $\mathrm{HCl}(\mathrm{pH} 8.8)$, urea, glycerol, and SDS. For the first equilibration period, we added dithiothreitol (DTT, a reducing agent that cleaves disulfide bonds). For the second equilibration period, we added iodoacetamide (IAA, to bind covalently with free DTT and resultant cysteine residues so they are unable to reform disulfide bonds). Overall, equilibration maintains protein denaturation.

Next, charged and equilibrated proteins are separated by molecular weight with SDS-PAGE which is an acrylamide matrix with cross-linking bisacrylamide monomers (Lovrić, 2011; Görg, 2004). We used 11\% gels to allow for 10 to $100 \mathrm{kD}$ proteins to move through the acrylamide-bisacrylamide mesh as a protein size filtration system in which smaller proteins migrate farther down the gel. IPG strips with proteins separated by pl sit on top of a pre-cast polyacrylamide gel. The electric current moves negatively charged proteins through the gel matrix toward the positive cathode (Lovrić, 2011).

After the proteins have been separated in two dimensions, the gels are stained for visualization and analysis (Berth et al., 2007). Various staining methods confer differential detection and resolution. Notably, the staining method must be compatible with the identification process. Proteomic stains have a few options. Stains may be fluorescent (SYPRO Ruby, LavaPurple) or colorimetric (Colloidal Coomassie Brilliant Blue (CBB), silver stain) (Ball and Karuso, 2007). We chose to use CBB, the more commonly used stain, because it is easy to use, has a wide dynamic range, is inexpensive, and is compatible with most protein detection methods (including mass spectrometry (MS)) (Görg, 2004). CBB has a 
lesser ability to detect lower abundance proteins (10 ng protein/spot) whereas silver stain is more sensitive ( $0.1 \mathrm{ng}$ protein/spot). However, silver stain results are not as reproducible and interfere with ionization during mass spectrometry. Fluorescent stains have high sensitivities (1-2 ng protein/spot), highly dynamic ranges, and are MS compatible (Ball and Karuso, 2007; Görg, 2004). The main deterrents to using a fluorescent staining procedure are the need for expensive equipment that requires precise calibration and analysis of digitized gel images that are sensitive to background noise and artifacts.

\section{Protein quantification}

In order to analyze protein spot abundances in the 2D gels, we used Delta2D image analysis software (Decodon, Greifswald, GER). Delta2D has the advantage over other software such as PDQuest and Melanie III (Berth et al., 2007 ) in that it removes gel image distinctions to get rid of noise. Delta2D allows for the comparison of gels before protein spot boundaries are detected. To compare protein spot volumes across groups, first gel images must be loaded and grouped by treatment. Second, gels are warped to reconcile variations in gels due to differences in gel polymerization, current leakage during electrophoresis, and variations in $\mathrm{pH} /$ temp running buffer to match protein spots across gels (Berth et al., 2007). Match vectors, both automatically and manually generated, create a pixel-pixel comparison between gels of two colors (i.e. orange and blue in Delta2D) between a chosen representative or master gel image and all other gel images individually (Figure 4; Görg, 2004; Lovrić, 2011). 
Ultimately, all gels are warped to generate a fusion image or proteome map, which is a snapshot of global protein abundance at the time of tissue extraction.

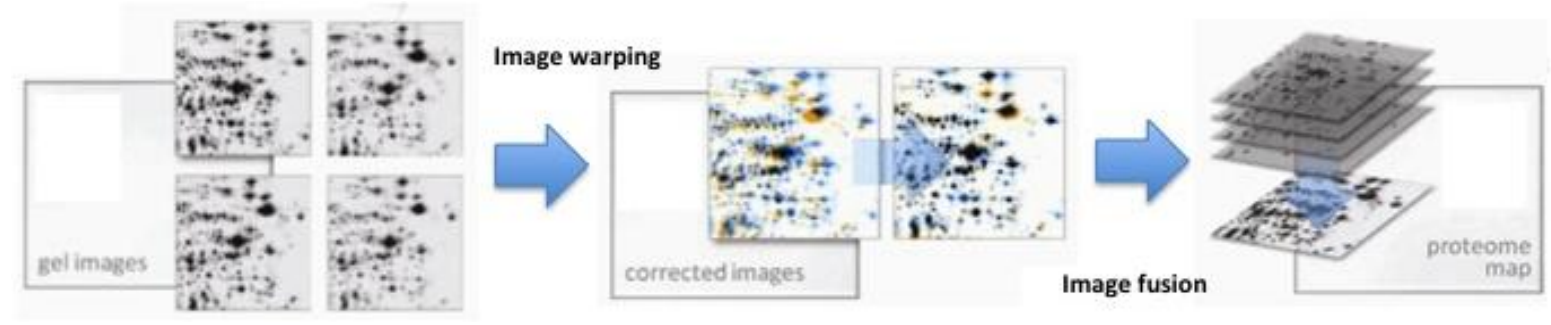

Figure 4. 2D GE. 2D GE-based proteomics analysis in Delta2D (modified after Berth et al., 2007).

After the fusion image is made, spot boundaries are generated with spot detection. Delta2D uses Gaussian models to create an algorithm to determine spot intensities and boundaries, followed by manual revision (Berth et al., 2007; Lovrić, 2011). The spot boundaries are then transferred to all original gel images (Figure 4; Berth et al., 2007). To remove noise, background subtraction is used. This involves taking raw spot volume (spot area and pixel density) normalized against total spot volume of all proteins in same gel and on other gel images and ultimately quantifies relative protein abundance as spot volume (measured in pixel density) (Berth et al., 2007). Background subtraction allows for the removal of differences due to differences in staining, image exposure times, protein loading, and any other gel inconsistencies (Berth et al., 2007).

For our study, we first used multivariate analyses (two-way permutation ANOVA) in Delta2D. We used a two-way 1000-permutation ANOVA to protect against departures from normally distributed errors and equal variances (Ludbrook and Dudley, 1998; Anderson and Braak, 2003) and because we had 
several independent treatment groups (>t- or F-tests) (Ludbrook and Dudley, 1998). Since there was a missing group (72NS) and thus an unbalanced design, we conducted two separate two-way ANOVAs (acclimation x oxygen and acclimation $x$ time, although only acclimation $x$ oxygen is discussed in this thesis). Instead of using a multiple-comparison correction (e.g. Bonferroni) to limit the number of false positives, we used a lower threshold $(\alpha=0.02)$ to limit the type I error rate and avoided overstating our conclusions. Our aim was to not limit potential hypotheses that could be generated from the proteome changes in order to tell a more complete story at the biochemical level.

To analyze which proteins in each group were statistically different from one another, we used Tukey's post-hoc pairwise comparison tests based on a one-way ANOVA for a single protein $(P<0.05)$ using Minitab (version 16; Minitab Inc., State College, PA, USA).With the expression profiles generated and Tukey's test results, we could compare each group independently to a single other group.

One other set of analyses employed were principal component analyses (PCAs). The PCA was used to determine the proteins contributing most to the variability between groups. A PCA can assess the relative importance of specific proteins whose abundances changed significantly following treatment (Berth et al., 2007). PCA is a multivariate analysis that reduces the dimensionality of a large, complex dataset by creating linear combinations of the variables that maintain the fundamental sources of variability within the data (Rencher and Christensen, 2012). 
In this experiment, each gel image is considered a data vector. First, the loading values are determined by the spot intensities based on pixel volume at each location on each gel (Berth et al., 2007). Next, the PCA takes these loading values or spot intensities and generates eigenvalues (magnitude) and eigenvectors (directionality). Eigenvalues and eigenvectors from the PCA quantify the contribution of each protein to separate samples, providing information about the location of most of the variability in the dataset (Rencher and Christensen, 2012; Berth et al., 2007).

\section{Protein identification}

The last part of the proteomic workflow is protein identification. We attempted to identify all proteins as opposed to only those significantly changing in abundance. The most common approach for identification is mass spectrometry (MS). Equipment often used for MS is matrix-assisted laser desorption ionization (MALDI) or electrospray ionization (ESI) with high pressure liquid chromatography (HPLC) (Aebersold and Mann, 2003). We will focus on our identification method, MALDI, which is the preferred tool for 2D gels (Lovrić, 2011).

MALDI protein identification involves three main steps: (1) excising spots manually with spot cutter and digesting with (commonly) trypsin (a protease that cuts at unique sites to generate predictable peptide fragments (Aebersold and Mann, 2003); trypsin cleaves on the C-terminus of lysine or arginine residues (Lovrić, 2011); (2) determining the abundance and experimental mass of each 
protein and matching them to a database of calculated peptide masses to generate peptide mass fingerprints (PMFs) (Aebersold and Mann, 2003); and (3) further fragmenting with tandem MS (MS/MS) to confirm this match and to obtain amino acid composition and a peptide fragment fingerprint (PFF) (Tomanek, 2011). EST libraries are genomic databases often used to search uninterrupted, combined PMFs and PFFs against known nucleic acid sequences (Choudhary et al., 2001). We compared experimental data to theoretical enzymatic digestions (Tomanek, 2011; Lovrić, 2011). Positive peptide matches depend on factors including PTMs/variable peptide modifications, the purity of the peptide sample, the type of database search conducted (e.g. search parameters, error rate), and the presence of theoretically possible sequences in the database (Lovrić, 2011). Mass spectrometers can be separated into three common parts: ion source, mass analyzer, and detector (Aebersold and Mann, 2003; Suckau et al., 2003). Of the multiple types of mass spectrometers available, there are two soft ionization methods for molecules with large molecular mass. Soft ionization methods, which generate gas phase ions from nonvolatile analytes with minimal ionization, include electrospray ionization (ESI) and matrix-assisted laser desorption ionization (MALDI) (Aebersold and Goodlett, 2001). ESI and MALDI differ in whether the approach involves top-down or bottom-up proteomics. ESI is usually paired with top-down proteomics approaches which involve the analysis of complex protein samples and yield multiple isotopic peaks and charge states (Lovrić, 2011). The resulting ions get further fragmented so resulting fragment masses can be compared to expected masses from known sequences to find 
PTMs and mutations (Lovrić, 2011). ESI ionizes peptides in solution and is coupled with liquid based chromatography (HPLC) (Aebersold and Mann, 2003).

In contrast, MALDI ionizes peptides out of solid media following a bottomup approach (Lovrić, 2011). Commonly, the dried droplet technique is applied by using dry, crystalline matrix (e.g. $\alpha$-hydroxycyano cinnamic acid) to suspend digested proteins which are then plated on a target plate (Lovrić, 2011). In the MS, laser pulses ionize samples out of the matrix to form positively charged peptides which are accelerated by voltage plates toward the mass analyzers (Aebersold and Mann, 2003). The mass analyzer subsequently measures the mass-to-charge ratio $(\mathrm{m} / \mathrm{z})$ of each ionized peptide in the sample (Aebersold and Mann, 2003).

MALDI is usually coupled with time-of-flight (TOF) analyzers. TOF analyzers are based on differential acceleration of ions of the same charge but different mass in an electric field (Lovrić, 2011). Thus the lighter ion travels faster and reaches the target sooner so the mass of ions is determined based on the time spent in the 'flight tube' (Lovrić, 2011). MALDI-TOF/TOF tandem MS has two co-linearly arranged TOF analyzers separated by a collision cell (Suckau et al., 2003; Figure 5). In two-phase separation, high abundance precursor ions of one $\mathrm{m} / \mathrm{z}$ ratio are separated and fragmented by high-energy collisions in the collision cell (Leung and Pitts, 2008). Second, fragmented ions enter the second TOF analyzer, which are separated to determine amino acid sequence of the precursor ions (Leung and Pitts, 2008). The advantage of tandem MS (TOF/TOF) is better sensitivity and increased accuracy of mass instruments for PMFs 
because trypsin fragment matches are more reliable for identification than molecular weight alone (Aebersold and Mann, 2003).

Following two-phase separation with tandem TOF, ionized peptides move to the detector from the mass analyzer (Figure 5). The detector determines the abundance of ions for each $\mathrm{m} / \mathrm{z}$ ratio (Aebersold and Mann, 2003).

Consequently, a PMF or unique pattern of peaks with different molecular weights is produced on a coordinate plane ( $\mathrm{m} / \mathrm{z}$ range plotted against intensity) based on the $\mathrm{m} / \mathrm{z}$ ratios detected (Lovrić, 2011). For each $\mathrm{m} / \mathrm{z}$ ratio, peak amplitude is directly proportional to protein expression (Lovrić, 2011). Next, the molecular weights of experimental peaks are compared with a database (MASCOT) composed of theoretical proteins from sequenced organisms based on proteins cleaved with trypsin in silico (Görg, 2004; Tomanek, 2011). The MASCOT search engine uses a molecular weight search engine (MOWSE) algorithm to score protein hits against different databases (two databases for this experiment): (1) an EST library with thousands of different gene sequences for $M$. californianus and M. galloprovincialis and (2) Swiss-Prot (last update: June 2009) with 17,360 molluscan protein sequences (Tomanek and Zuzow, 2010). PMFs allow for proteins in a sample to be identified, especially for model (genome sequenced) organisms (Görg, 2004). 


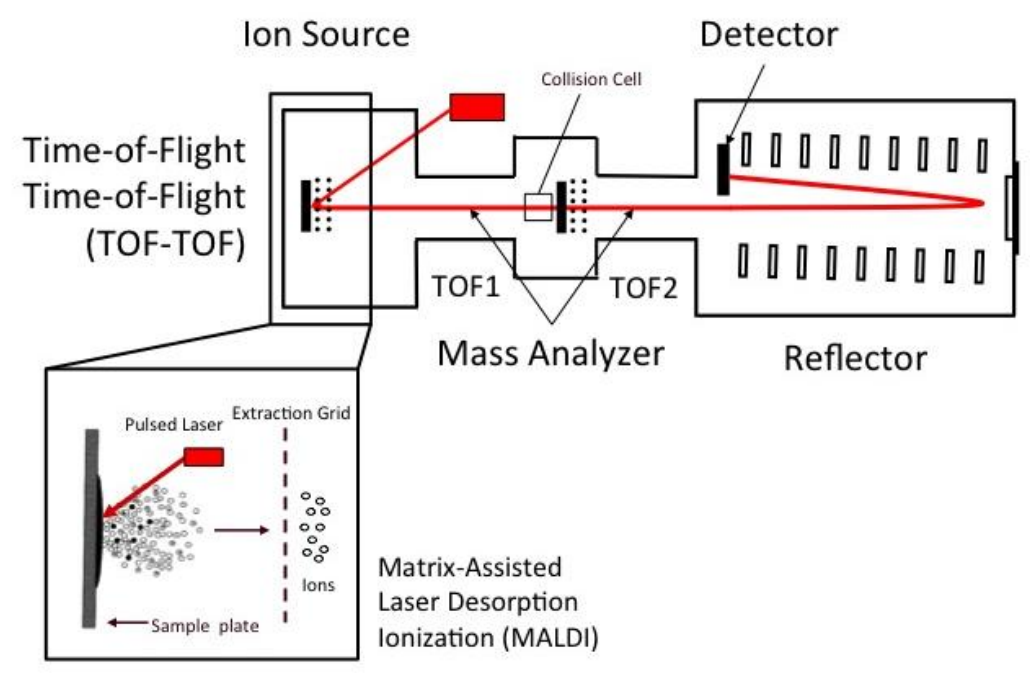

Figure 5. MALDI-TOF/TOF. MALDI-TOF/TOF mass spectrometer schematic (modified after Aebersold and Mann, 2003; Suckau et al., 2003).

The MASCOT search results in scores assigned based on the probability that the match to the protein sequence in the database is a chance event (Perkins et al., 1999). If the MOWSE score is above the significance threshold $(P<0.05)$ or two or more peptide fragments are matched, a protein is considered to be a significant match (Perkins et al., 1999). High scores therefore indicate a greater probability that the hit is a correctly identified protein (Perkins et al., 1999). To identify proteins during the MASCOT search, PMFs can be additionally searched against NCBI BLAST (basic local alignment search tool) databases.

After protein identification, heat maps can be generated with hierarchical clustering in Delta2D. Hierarchical clustering groups proteins into clusters based on similarities in their abundance, thereby linking proteins with similar degrees of variation in response to the same treatment (Berth et al., 2007). This information provides insight into which proteins interact in a variety of pathways (Berth et al., 
2007). Protein identifications can additionally be combined with their loading values within the components of a PCA to further elucidate functional relationships between proteins.

\section{Prelude to paper}

The purpose of our study is to explore how organisms respond to aerial anoxia at the protein level. We aim to increase our understanding of physiological tolerance limits to stress and to characterize acclimatory plasticity, or mussel memory, in the stress response following a subtidal or tidal regime. As previously mentioned, oxygen limitation induces a shift from aerobic to anaerobic pathways. We hypothesize acclimation conditions will influence the proteomic response of gill tissue to emersion-induced anoxia.

Therefore, we predict proteostasis, as mediated by chaperones, will be maintained in a greater capacity in tidally-acclimated mussels than subtidallyacclimated mussels. Moreover, a tidal regime may prime mussels with an overall greater ability to scavenge ROS or a metabolism rate or shift that produces fewer ROS during stress, which could provide a physiological advantage that enables an organism to perform better under more stressful conditions. Finally, we predict cytoskeletal proteins and their associated signaling molecules will impart structural integrity to the gill tissue, even during aerial anoxia, more so in mussels that received a tidal than subtidal acclimation. Overall, we anticipate that acclimation will greatly influence protein abundance changes to influence the response to a subsequent stress in $M$. californianus. 


\title{
CHAPTER TWO: MANUSCRIPT
}

The proteomic response of gill tissue in tidally and subtidally-acclimated California mussels, Mytilus californianus, to acute emersion-induced anoxia

\author{
Aubrie Fowler ${ }^{1}$ and Lars Tomanek ${ }^{*}, 1$
}

Version: May 23, 2017

${ }^{1}$ California Polytechnic State University

Department of Biological Sciences

Center for Coastal Marine Sciences

Environmental Proteomics Laboratory

1 Grand Ave.

San Luis Obispo, CA 93407-0401

U.S.A.

${ }^{*}$ Author for correspondence

ABSTRACT: 268 words

MAIN TEXT: 12,852 words

SUPPLEMENTAL MATERIAL: 0 words

RUNNING TITLE: Mytilus mussel anoxia acclimation proteomics 


\begin{abstract}
Intertidal mussels regularly experience emersion-induced anoxia, in contrast to normoxic conditions experienced during submersion. We therefore hypothesized that acclimation to a tidal rhythm, as opposed to a rhythm of constant submersion, preconditions the proteome of the California mussel, Mytilus californianus, to respond differently to emersion-induced anoxia. Following acclimation, mussels either continued to receive the acclimation conditions (control) or were exposed to 100\% nitrogen gas (anoxia) during aerial emersion. We collected gill tissue for subsequent analysis of protein abundance with 2D gel electrophoresis and protein identification with tandem mass spectrometry. Relative to subtidally-acclimated mussels, tidally-acclimated mussels showed a greater propensity to respond to distrupted protein homeostasis during emersion through higher levels of several small heat shock protein isoforms, while they showed lower levels of several chaperones involved in redox-sensitive protein maturation in the endoplasmic reticulum during acute anoxia. Several metabolic proteins showed elevated levels in tidally-acclimated mussels, suggesting a compensatory response to reduced feeding times. However, changes in the abundance of several tricarboxylic acid cycle enzymes (e.g. aconitase, succinate dehydrogenase) suggest that tidally-acclimated mussels are also primed to sense reactive oxygen species (ROS) and limit their production, respectively. These findings are further supported by higher abundances of several aldehyde dehydrogenases and thioredoxin peroxidase, which function as scavengers of aldehydes and ROS, common products of lipid
\end{abstract}


peroxidation. Finally, tidally-acclimated mussels are also more responsive to changes in cytoskeletal and vesicular trafficking dynamics in response to acute anoxia. Together, our analysis showed that proteostasis, energy metabolism, oxidative stress and cytoskeletal and trafficking processes are all involved in priming tidally-acclimated mussels to respond more dynamically to acute emersion-induced anoxia in Mytilus gill.

Keywords: Mytilus californianus, proteomics, anoxia, acclimation 


\section{Introduction}

The rocky intertidal zone is a highly variable environment exposing inhabitants to a wide range of temperatures, oxygen and nutrient availability, desiccating conditions, wave action, and salinity stress, all of which vary with the timing and duration of the tidal cycle and thus the vertical position within the intertidal zone (Helmuth, 2002; Newell, 1979; Roberts et al., 1997). Abiotic stressors associated with tidal fluctuations can cause macromolecular damage and challenge the redox balance of the cell, triggering the acute activation of the cellular stress response (CSR) in intertidal organisms (Somero, 2002). In particular, sessile organisms must cope with extreme fluctuations between high and low tide conditions. High tide, or immersion, allows for continuous filter feeding, gas exchange and excretion of wastes, while temperature conditions are within thermal optima (Denny and Gaines, 2007). In contrast, during low tide, animals close their shells to limit any evaporative water loss preventing desiccation, filter-feeding ceases, temperature may increase above thermal optima, and emersion-induced oxygen deprivation will set in (Denny and Gaines, 2007). Sessile organisms are unable to escape the abiotic stressors found in the intertidal, but they have developed physiological adaptations to cope with the associated stressors (Halpin et al., 2002). Over longer time periods, intertidal organisms acclimatize to changing environmental conditions (e.g. seawater temperature) through the cellular homeostasis response in which new thresholds for the activation of the cellular stress response are set (Tomanek, 2010). 
Mussels of the genus Mytilus respond to acute environmental stress by down-regulating aerobic metabolism during aerial emersion (Bayne et al., 1976; Shick et al., 1988), increasing the rate of ATP production through alternative anaerobic pathways during emersion-induced hypoxia (de Zwaan and Mathieu, 1992; Grieshaber et al., 1994), and synthesizing heat shock proteins in response to stress (e.g. heat, anoxia) (Roberts et al., 1997; Tomanek and Zuzow, 2010; Anestis et al., 2010). Reduced oxygen availability plays an important role in setting tolerance limits to environmental stress because Mytilus undergoes metabolic shifts to cope with anaerobiosis (Anestis et al., 2010). For instance, $M$. edulis begins counteracting oxygen shortage during mild hypoxia by increasing energetic expenditures for oxygen uptake via enhanced respiratory activity in gill tissue, thus creating an oxygen debt that leads to the onset of metabolic rate depression and the switch to anaerobiosis at $6.5 \mathrm{kPa}$ of oxygen (RiveraIngraham et al., 2013). In M. galloprovincialis, anaerobic conditions results in a biphasic response with early activation of glycolysis followed by a later phase of metabolic depression, which helps to stabilize ATP concentrations (Anestis et al., 2010). Ultimately, the reduced metabolic rate decreases the capacity for growth, reproduction, and general maintenance (Sokolova et al., 2012). In addition to metabolic depression, the response of Mytilus to acute emersion-induced hypoxia includes an increase in the activity of alternative anaerobic pathways, generating opines such as strombine and alanopine, instead of lactate, during short-term hypoxia, and succinate, propionate, acetate, and alanine during prolonged hypoxia (Müller et al., 2012). 
Furthermore, while some bivalves, e.g. the cockle Cardium edule and the mussel Geukensia demissa, respond to emersion by opening their shells (i.e. gaping) to increase gas exchange and thereby stay largely aerobic, mussels of the genus Mytilus generally seal their shells during emersion, although they start to gape when air temperatures and mussel body temperatures become hot, most likely to augment evaporative cooling (Dowd and Somero, 2013; Shick et al., 1988). In addition, gaping may also facilitate the escape of $\mathrm{CO}_{2}$ during prolonged air exposure during low tide or during environmental hypoxia/anoxia due to oxygen minimum zones (de Zwaan and Wjisman, 1976; de Zwaan, 1977; Widdows and Shick, 1985; Müller et al., 2012; Diaz and Rosenberg, 1995; Somero et al., 2016). When gaping is too costly, oxygen tension in the fluids of the shell cavity drops to below $20 \%$ (normoxia) and the animals become hypoxic (Widdows et al., 1979). The tolerance to survive hypoxic or anoxic conditions during emersion improves when Mytilus are acclimated to intertidal in comparison to subtidal conditions (Altieri, 2006; Guderly et al., 1994).

Mytilids are foundation species, prey sources, and competitors in the intertidal community (Seed and Sachanek, 1992). In particular, the ribbed or California mussel $M$. californianus dominates the low to mid rocky intertidal from Baja California, Mexico to Alaska (Seed, 1992; Morris, 1980; Lockwood et al., 2015). Thus, other species are secondarily dependent on their response to stress (Altieri, 2006). The distribution of M. californianus extends across a steep gradient of environmental stress between intertidal and subtidal habitats (Altieri, 2006). Variation in physical conditions occurs seasonally and as a function of 
height along the vertical gradient of the intertidal zone (Roberts et al., 1997), which can affect the length of time at which mussels are aerially-emersed to influence the cellular stress response. Roberts et al. (1997) showed laboratory acclimation or field acclimatization (seasonal) to temperature stress induces HSPs at a threshold temperature that is $6^{\circ} \mathrm{C}$ higher than the threshold in winteracclimatized $M$. californianus, likely because higher levels of constitutively expressed heat-shock proteins are already present. Moreover, physiological processes may be compartmentalized temporally based on the position of Mytilus spp. in the intertidal zone in which growth and cell proliferation increases during low tide and decreases during high tide to restore cellular energy levels (Lockwood et al., 2015; Zaldibar et al., 2004). This indicates higher and lowersite mussels differ in their response to environmental stress at the biochemical level, indirectly due to tidally-entrained foraging activities modifying caloric intake (Palmer, 1973; Palmer, 1975) and directly due to stress levels associated with changing tidal height (Stillman and Barnwell, 2004). Thus, understanding the influence of acclimation regime on $M$. californianus which inhabits sites that expose them to two extremes of air exposure, either constant submersion (subtidal conditions) or once or twice-daily aerial emersion (tidal conditions), can ultimately provide insight into underlying processes of variation in physiological tolerances (Altieri, 2006).

Although many studies have focused on oxygen deprivation in mussels, little is known about the systemic cellular changes that accompany the greater anoxia tolerance of mussels acclimatized or acclimated to frequent aerial 
exposure. For example, it is not known how mussels acclimated to tidal conditions protect their macromolecules from damage during conditions of anoxia beyond the upregulation of molecular chaperones of the HSP70 family (Roberts et al., 1997), or how they cope with the challenge of frequently experiencing oxidative stress during reperfusion of their shell cavity with oxygenated seawater upon the return of the tide and the opening of the shell. Changing chaperone abundance is one cellular response that may protect a mussel acclimated to tidal conditions from frequent air exposure and thus prolonged emersion-induced anoxia. Increased knowledge about the response of mussels to oxygen depleted conditions will also help us predict how this species will respond to the increased occurrence and extent of more extensive oxygen minimum zones (Somero et al., 2016). The molecular and physiological responses of intertidal mussels to conditions such as anoxia can provide information important in the context of global climate change (Anestis et al., 2010).

A valuable tool for investigating the physiological responses of marine invertebrates to environmental stress, proteomics is the study of global changes in the abundance of proteins. Proteomics has been used to study the physiological response of molluscs to elevated temperature (Fields et al., 2012a; Fields et al., 2012b; Tomanek and Zuzow, 2010), hyposalinity (Tomanek et al., 2012), emersion-induced hypoxia (Fields et al., 2014), and oxidative stress (McDonagh and Sheehan, 2007; Tomanek, 2015). Although mussels of the genus Mytilus have been the focus of many of these studies, we still have a limited understanding of the proteomic changes experienced by intertidal 
mussels during emersion-induced anoxia. Studies on the response of Mytilus to anoxia have so far focused primarily on animals that were submerged (Shick et al., 1986; Wang and Widdows, 1993; Anestis et al., 2010; Diaz and Rosenberg, 1995).

The purpose of our study was to characterize the proteomic response of gill tissue in the California mussel, M. californianus, acclimated for seven weeks to either subtidal (constant submergence) or tidal ( $6 \mathrm{~h}$ high tide: $6 \mathrm{~h}$ low tide) conditions followed by either the same regime as during the acclimation period (normoxic control) or exposure to shorter- and longer-term (6 and $72 \mathrm{~h}$, respectively) emersion-induced anoxia ( $<1 \%$ oxygen). Proteins were quantified

and identified using 2D gel electrophoresis and tandem mass spectrometry. One limitation of our study is the missing treatment ( $72 \mathrm{~h}$ subtidal normoxia) which was compromised during the experiment. Our results suggest that acclimation to tidal conditions, as opposed to a subtidal conditions, prepares gill tissue to respond to emersion-induced anoxia by changing the abundance of proteins involved in proteostasis, energy metabolism, and oxidative stress.

\section{Results and Discussion}

We generated a fused image (proteome map) comprising gels from all treatments $(N=54)$ representing the average of the normalized pixel volume of all protein spots detected. In this fused gel image (Fig. 6), we detected 370 proteins total. Of those detected, we identified 163 (44\%) proteins by tandem mass spectrometry regardless of the significance of changes in spot volume or position 
(Table 2). Regardless of identification, 205 (55\%) proteins changed significantly in abundance (acclimation regime, oxygen availability, or their interaction; twoway permutation ANOVA; $P<0.02)$. Of those proteins we identified, $115(56 \%)$ significantly changed in abundance. Our analysis ignored the effect of time based on preliminary statistical analyses that showed time had a relatively small effect on the proteome.

Changes in protein abundance may be attributed to an increase or decrease in synthesis, degradation, or post-translational modifications (PTMs). Thus, our interpretation is based on a subset of protein isoforms, which might not represent the full complement of isoforms of a particular protein. Furthermore, it is possible that we did not detect all isoforms of a protein because they are outside the $\mathrm{pH}$ or mass range we analyzed and thus the overall sum of the detected protein isoforms does not represent the total abundance of the protein. With these limitations in mind, our interpretations are meant to be hypotheses that generally require further validation.

\section{Principal component analysis}

We conducted principal component analyses (PCAs), which convert a set of observations of possibly correlated variables into a set of linearly uncorrelated values called principal components. Our PCA includes proteins that changed significantly for either the acclimation regime (Fig. 7A; Table 1A), acute oxygen availability (Fig. 7B, Table 1B), or interaction effect (Fig. 7C; Table 1C) based on 
a two-way permutation ANOVA $(P<0.02)$. We identified proteins that contributed most to the separation between treatments based on their loading values.

The first PCA (Fig. 7A) includes 73 identified proteins that were significant for the tidal regime main effect only. The first component (PC1; 19.44\%) separated the emersion (tidally-acclimated) (negative values on the $x$-axis) from the constant immersion (subtidally-acclimated) group (positive values on the $x$ axis). The second component (PC2; 7.34\%) separated the tidally-acclimated mussels by oxygen treatment along the $y$-axis. Along PC2, 0 and $6 \mathrm{~h}$ normoxia (0NT, 6NT) were located along the positive end of PC2 and separated from the $72 \mathrm{~h}$ anoxia (72AT) treatment on the negative side of PC2. The $72 \mathrm{~h}$ normoxia (72NT) and $6 \mathrm{~h}$ anoxia (6AT) treatments overlapped along PC2, indicating similarity in protein changes while $6 \mathrm{~h}$ normoxia (6NT) was shifted in the positive direction along the $y$-axis (Fig. 7A). Relative to the effect of acclimation regime, acute oxygen availability had a limited effect on shifting samples along PC2, as expected for this group of proteins, suggesting that the response to acute anoxic conditions was not as large as the effect of acclimation to different tidal conditions, particularly in subtidally-entrained mussels, which remained relatively unchanged after short and long-term anoxia treatment.

Along PC1, acclimation regime influenced proteins involved in proteostasis, cytoskeletal structure, oxidative stress, and energy metabolism. For instance, major vault protein, tubulin, heavy metal-binding protein, calreticulin, sHSP, NADP-dependent isocitrate dehydrogenase (ICDH), and glucoseregulated protein 78 (GRP78) contributed positively to PC1 (Table 1A), indicating 
greater protein abundance for those mussels acclimated to constant immersion (subtidal) conditions (Fig. 7A). Proteins involved in proteostasis (sHSP, peptidylprolyl cis-trans isomerase), cytoskeleton (actin, F-actin capping protein), and signaling (CDC42, progesterone receptor) contributed negatively to PC1 (Table $1 \mathrm{~A})$, generally indicating decreased protein abundances for tidally-acclimated mussels (Fig. 7A). These results suggest that constant immersion correlates with greater abundance of ER chaperones, sHSPs and T-complex protein, a chaperone of actin and tubulin. In contrast, acclimation to a tidal regime generally increased the abundance of CDC42, a small G-protein that regulates cytoskeletal dynamics, and F-actin capping protein, possibly limiting actin treadmilling. Interestingly, indicators of other aspects of proteostasis including protein translation (eukaryotic initiation factor 3), degradation (proteasome $\alpha$ ), and transport across the mitochondrial membrane (mitochondrial processing peptidase) were higher in tidally-acclimated mussels.

PC2 separated groups within the cluster of tidally-acclimated mussels, while subtidally-acclimated groups overlapped, suggesting that all mussels from the subtidal regime changed little in response to acute anoxia. PC2 (positive) consisted primarily of molecular chaperones, specifically sHSPs (seven of the top ten proteins) (Table 1A). Small HSPs shifted the tidally-acclimated mussels from the 0 and $6 \mathrm{~h}$ normoxia (0NT and $6 \mathrm{NT}$ ) and $6 \mathrm{~h}$ anoxia (6AT) treatments in the positive direction along the $y$-axis to indicate an increase in SHSPs relative to the $72 \mathrm{~h}$ anoxia (tidal) group (Fig. 7A). In contrast, proteins involved in energy metabolism (ATP synthase, methylmalonate semialdehyde dehydrogenase), ion 
regulation (heavy metal binding proteins, $\mathrm{Na}^{+} / \mathrm{H}^{+}$exchange regulatory factor 3 ), and cytoskeletal elements (tubulin) contributed negatively to PC2 (Table 1). There was a general decrease in abundance, primarily for 72AT and to a lesser extent for 72NT and 6AT (Fig. 7A), which suggests that these proteins contribute to the separation of the early ( 0 and $6 \mathrm{~h}$ ) from the later $(72 \mathrm{~h})$ time points. Thus, tidally-acclimated mussels showed greater separation due to changes in the abundance of proteins involved in proteostasis and energy metabolism, possibly correlated to the tidal regime than oxygen treatment per se, than mussels acclimated to constant immersion (see interaction effect below). To summarize, proteins involved in proteostasis, cytoskeletal dynamics, ion regulation, and energy metabolism that contributed most to the separation between treatments due to acclimating mussels to different tidal regimes, separated treatments primarily along PC1. It is therefore possible that acclimation to aerial emersion, as opposed to constant immersion, causes mussels to reallocate resources to deal with the challenges associated with experiencing emersion to air and subsequent reperfusion with oxygenated water.

The PCA based on proteins that significantly changed with anoxia (oxygen availability main effect) included only 18 identified proteins (Fig. 7B). The anoxiatreated mussels (positive on PC1) are separated from normoxia treatments primarily along PC1 (19.30\%). In contrast, PC2 (13.96\%) separates the treatments by tidal regime with tidally-acclimated mussels on the positive end of the $y$-axis and subtidally-acclimated mussels on the negative end, with one exception (72AT). The functions of proteins that contributed to the separation of 
the groups included proteostasis, energy metabolism, and cytoskeleton. In contrast to the distinct separation between acclimation treatments in the first PCA (Fig. 7A), the oxygen treatments were overall a lot closer to each other and even partially overlapped, suggesting that these treatments did not have as large of an effect on the gill proteome as acclimation regimes. We partially attribute this to a fast downturn of cellular activities either due to the acute aerial exposure in the subtidally-acclimated mussel or the anoxic conditions, or the combination of both.

Treatments were separated along PC1 by proteins that are involved in energy metabolism, proteostasis, and cytoskeleton, however, the only discerning signal was that four metabolic proteins showed higher abundances in the normoxic treatments, including two isoforms of L-xylulose reductase (carbohydrate metabolism; \#293 and 302), arginine kinase (ATP buffering; \#193), and aconitase (tricarboxylic acid or TCA cycle; \#61) (Table 1B). Arginine kinase (AK) is a metabolic protein that replenishes ATP from phosphoarginine during anoxia, without generating $\mathrm{H}^{+}$(Ellington, 2001; Grieshaber et al., 1994). Proteomes of marine invertebrates can have multiple AK isoforms (Garland et al. 2015). However, this particular isoform of AK decreased at 6 and $72 \mathrm{~h}$ anoxia in the subtidally-acclimated mussels, but only decreased after prolonged (72 h) anoxia in tidally-acclimated mussels. One possibility is that anoxia treatment leads to a PTM that we are not able to detect, possibly a phosphorylation which is a PTM that can modify AK so mussels can prepare for extended periods of aerial exposure by regulating phosphoarginine levels (Fields et al., 2014; Garland et al., 2015). Furthermore, phosphorylation or other PTMs of AK may improve the 
ability of invertebrates to cope with variable environmental anoxia and other stressful conditions that lead to increased tissue acidosis, e.g. heat and hypercapnia (Ellington, 1989; Ellington, 2001; Garland et al. 2015). Alternatively, the decrease in AK in response to anoxia could be an indicator of metabolic depression known to occur during the emersion of intertidal mussels (Shick et al., 1988; Tomanek and Zuzow, 2010).

Proteins that changed significantly for the oxygen main effect and contributed most to PC2 include proteins involved in cytoskeletal structure, metabolism, and chaperoning. In the positive section along the $y$-axis, meaning proteins that increased abundance in response to tidal acclimation (with the exception of 72AT), such as actin-binding protein F-actin capping protein, as well as tubulin (vesicular transport or cilia structure) and dynein light chain roadblock (an accessory component for the intracellular retrograde motility of vesicles and organelles along microtubules) (Table 1B). These proteins may be associated with vesicular transport. Moreover, one isoform of aconitase, an oxygen-sensitive protein, also increased in abundance in tidally-acclimated mussels. In the negative section of PC2, several chaperones (sHSPs, HSP70, peptidyl prolyl cistrans isomerase) showed greater abundances in subtidally-acclimated mussels, possibly due to changes in protein maturation. Overall, acute anoxia had a lesser effect on the mussel proteome based on the number of significant proteins in contrast to the acclimation main effect, however, the percentage of variation explained by PC1 was similar (both about 19\%; Figs. 7B and 7C). Likewise, the 
PCA based on the interaction effect shows that the effect of oxygen availability was greater than effect of acclimation to different tidal regimes (Fig. 7C).

Twenty-four identified proteins contributed significantly to the interaction effect (Fig. 7C). The PCA generally separated different oxygen treatments along PC1 $(23.29 \%)$ and separated tidal regime treatments along PC2 (10.0\%). While PC1 separated early tidal $(0 \mathrm{~h})$ and late subtidal (6 and $72 \mathrm{~h}$ ) (negative on the $x$ axis) from late tidal (6 and $72 \mathrm{~h}$ ) and early subtidal ( $0 \mathrm{~h}$ ) (positive), PC2 separated tidally- (positive on the $y$-axis) from subtidally-acclimated (negative) mussels.

PC1 (Fig. 7C) separated groups based on proteins involved in energy metabolism and protein homeostasis. PC1 included cytochrome b-C1 (complex III of the electron transport system or ETS), aldehyde dehydrogenase (oxidative stress, aldehyde scavenger), triosphosphate isomerase (glycolysis), and malate dehydrogenase (mitochondrial, TCA cycle). Together these enzymes (Fig. 10; clustered together in cluster III) shift the normoxic and anoxic treatments 0NS, 72NT, 6AT and 72AT toward the positive end along PC1 (Fig. 7C), indicating these groups had increased abundance (particularly at $72 \mathrm{~h}$ after a tidal regime) relative to the other treatments. Furthermore, the greater abundances of proteins significant for the interaction effect could indicate greater activities of these specific enzymes as a conserved response to anoxia regardless of acclimation regime. The negative loading values for PC1 also result from several chaperones, such as T-complex protein, the two endoplasmic reticulum (ER) chaperones protein disulfide isomerase (PDI) and calreticulin, as well as sHSP 
that had lower abundances at 0 and $6 \mathrm{NT}, 6 \mathrm{NS}, 6 \mathrm{AS}$, and $72 \mathrm{AS}$ relative to the other treatments (Table 1C), possibly indicating low rates of protein maturation in the ER.

Along PC2, treatments were separated by proteins involved in proteostasis and energy metabolism (Table 1C). The PCA separated subtidally(negative section) from tidally-acclimated mussels (positive). In the positive section, chaperones including sHSPs and HSP70 as well as aconitase showed higher abundances under normoxia in the tidally- but not subtidally-acclimated mussels (\#61; Fig. 11). We identified two aconitase isoforms significant for the interaction effect, which differed from an isoform that was significant for an oxygen main effect, suggesting that either different paralogous homologs or isoforms of the same gene product showed different responses to the effect of tidal regime on the response to acute anoxia, probably as a result of PTM(s). One likely PTM is the glutathionylation of cysteine residues, which inactivates aconitase and is known to occur during oxidative and nitrosative stress (Mailloux et al., 2013; Han et al., 2015). Glutathionylation reduces the pl, or charge at which the protein net charge is zero, by $0.5 \mathrm{pH}$ units (Ubuka et al., 1987; Garland et al., 2015). We observed a pl difference of 1.0 between two aconitase isoforms (53 and 57; Fig. 10). Thus, we hypothesize aconitase is glutathionylated twice to regulate its function in response to the interaction of acclimation regime and anoxia treatment. Towards the negative section of PC2, there were a number of proteins involved in proteostasis that had lower abundances for tidally- than subtidally-acclimated mussels (calreticulin for protein folding of glycosylated 
proteins, PDI for disulfide bond formation, and T-complex protein for the folding of actin and tubulin) in addition to the reverse pattern in metabolic proteins (ATP synthase and cytochrome b-C1 involved in the ETS). We note that subtidallydiffered from tidally-acclimated mussels primarily along PC1, while PC2 only seemed to separate tidally-acclimated mussels from one another. This indicates that acclimation to regular aerial emersion affects the mussel's proteomic response to acute anoxia. To streamline our discussion, we grouped proteins into the following functional categories: proteostasis, energy metabolism, oxidative stress, cytoskeleton, signaling, vesicle transport, and ion regulation. We will now provide a more detailed analysis of the proteomic changes by functional category which we analyzed using hierarchical clustering (Figs. 8, 10, and 12) and expression profiles of proteins that were significant for the interaction (Figs. 9, 11, and 13).

\section{Proteostasis}

The goal of protein homeostasis, or proteostasis, is to maintain protein function by keeping proteins in their native, properly folded conformation (Kim et al., 2013). Molecular chaperones (heat shock proteins or HSPs), which regulate proteostasis (Feder and Hofmann, 1999), responded largely to either tidal regime

(Fig. 8; clusters I, II, and III), oxygen (I) or showed interaction effects (II) (two-way permutation ANOVA; $P<0.02$ ). Cluster I (Fig. 8) included the cytosolic HSP70, mitochondrial HSP60, signal sequence receptor (SSR) protein, and several ER chaperones, including glucose-regulated protein 78 (GRP78), protein disulfide 
isomerase (PDI), calreticulin (CRT), and a subunit of the proteasome $(\alpha)$, which is involved in protein degradation. The only significant protein in this cluster was an isoform of HSP70. HSP70, which stabilizes denaturing proteins, facilitates protein folding, and protein translocation across membranes (Kourtidis et al., 2006), significantly increased abundance in subtidally-acclimated mussels for the tidal regime and oxygen availability main effects (two-way permutation ANOVA; $P<0.02)$. HSP70 induction may indicate greater rates of protein folding during constant submersion, especially during anoxia (6AS and 72AS).

Cluster II, which exhibited a large effect of acclimation and less of an interaction effect, was marked by lower protein abundance for the tidal acclimation groups than for the subtidal acclimation groups. More specifically, tidally-acclimated treatments (6AT, 72NT, and 72AT) showed consistently lower abundances of several chaperones. Protein changes included isoforms of major vault protein (MVP), T-complex protein, protein disulfide isomerase (PDI), peptidyl prolyl cis-trans isomerase (PPI), CRT, HSP70, sHSPs, and GRP78. MVPs $(\# 5,6)$ increased in the subtidally-acclimated mussels based on a significant acclimation regime effect (Fig. 8). MVPs are part of the family of ubiquitous vault particles, which are barrel-shaped cellular structures bigger than ribosomes (Suprenant et al., 2007). Although their function is not well understood, MVPs have been implicated in the cellular response to acute heat stress in mussels (Tomanek and Zuzow, 2010), in the maintenance of sterility in human airway gland mucus (Joo et al., 2015), and in stress-induced signaling cascades, including the MAPK pathway (Berger et al., 2009). Thus MVPs in gill 
tissues of mussels may respond to acute heat stress, and are elevated following acclimation to constant immersion. Isoforms of two ER chaperones, CRT and PDI, as well as one of three different subunits of T-complex protein ( $\alpha$ ), involved in folding cytoskeletal proteins such as actin and tubulin (Fields et al., 2012; Sternlicht et al., 1993), showed an interaction effect, possibly indicating the sensitivity with which protein maturation in the ER responds to anoxia depends on the tidal regime. PDI, which aids in aids in protein folding by making, shuffling, and breaking disulfide bonds within polypeptides (Buchberger et al., 2010), increased significantly in all constant immersion treatments, except 0NS, relative to tidal groups (Fig. 9; Tukey's post hoc; $P<0.05$ ). This indicates oxygen and acclimation both affect disulfide bond formation and protein homeostasis in the ER. Peptidyl-prolyl isomerase (PPI or cyclophilin) is a molecular chaperone localized to the ER; the higher abundance (at 6NT) may indicate increased protein maturation through the ER. This has been hypothesized by Tomanek (2014) to affect the production of glycoproteins that might be excreted as mucus to aid in the filter feeding function of mussel gill tissue. GRP78, which showed a greater abundance in mussels acclimated to constant immersion (Fig. 8; cluster II), acts to protect de novo translocated and misfolded proteins with exposed hydrophobic regions and to assist with folding to the native state in the ER (Buchberger et al., 2010). To summarize, cluster II shows that acclimation to different tidal regimes has a strong effect on how gill can respond to a proteostasis challenge due to anoxic conditions. Thus this cluster identified protein maturation in the ER as a cellular process that is highly sensitive to 
anoxic conditions. The ER is a highly reducing environment which makes it more likely for proper protein structure via oxidative folding (Tu and Weissman, 2004). Therefore, our results support the postulate that stressors including oxygen and nutrient deprivation, perturbation of redox status, and atypical calcium regulation can all trigger the ER stress response (Mei et al., 2014).

Cluster III (Fig. 8) mainly included sHSPs that increased in abundance in mussels acclimated to a tidal regime. sHSPs function to buffer the aggregation of misfolded proteins and are activated by stress (Haselbeck et al., 2005). We hypothesize these 15 isoforms of sHSPs are active due to the repeated stress from the tidal cycle, i.e. short-term hypoxia and reperfusion with oxygen during re-immersion, which is absent in mussels acclimated to constant immersion. We know from previous studies (Roberts et al., 1997; Feder and Hofmann, 1999) that intertidal Mytilus mussels increase molecular chaperones (HSP70, HSP90) after exposure to low tide conditions both in field and laboratory settings. In addition, HSP40, a co-chaperone of HSP70, regulates adenosine triphosphate (ATP)dependent polypeptide binding by HSP70 (Fan et al., 2003). HSP40 showed a significant acclimation main effect (Fig. 8; cluster III). Again, this indicates that acclimation to different tidal regimes had a greater effect on the maintenance of the gill proteome than acute anoxia challenge. Cluster III also includes proteins involved in protein synthesis and processing (eukaryotic translation initiation factor 3, 40S ribosomal protein, and mitochondrial processing peptidase), and degradation (proteasome, four $\alpha$ subunits). Another protein in cluster III, mitochondrial-processing peptidase (MPP), is involved in the hydrolysis of 
mitochondrial proteins. Specifically, MPP cleaves the N-terminal extensions of most mitochondrial proteins destined for the mitochondrial matrix and many of those targeted to the intermembrane space and inner membrane once the precursor has reached its final destination in the mitochondrion (Gakh et al., 2002). We observed greater protein abundance of MPP following a tidal than subtidal regime to suggest different desinations for proteins based on acclimation regime. In addition, three isoforms of the a subunit of the proteasome increased protein abundance in tidally-entrained mussels indicating aerial emersion may result in greater protein turnover and degradation. Together, the increase in chaperones in tidally-acclimated mussels (e.g. SHSPs) implies that the hypoxic conditions and the reperfusion of the mantle cavity of the mussel with oxygenated seawater require a greater effort to coordinate protein aggregation and degradation.

\section{Energy metabolism}

We identified proteins involved in ATP buffering (AK), glycolysis (phosphoglycerate kinase (PGK), triosphosphate isomerase (TPI)), TCA cycle (pyruvate dehydrogenase (PDH), citrate synthase (CS), aconitase, succinate dehydrogenase $(\mathrm{SDH})$, mitochondrial malate dehydrogenase $(\mathrm{MDH}))$, the electron transport chain (NADH dehydrogenase, cytochrome b-C1/reductase, cytochrome $c$ oxidase), oxidative phosphorylation (ATP synthase $\alpha / \beta / \Delta$ ), and alternative metabolic pathways (cytosolic MDH, L-xylulose reductase) as changing abundance in response to the different tidal regimes, changes in 
oxygen tension, or their interaction (Fig. 10). The two-way permutation ANOVA $(P<0.02)$ revealed that metabolic proteins significantly changed abundance predominantly in response to tidal regime (Fig. 10; clusters I, II, and IV), in response to the interaction (III), and less so in response to oxygen availability (some in each cluster). Cluster I included several proteins representing glycolysis, TCA cycle, and oxidative phosphorylation that were significant for a tidal regime main effect, with a generally greater abundance in subtidally- than in tidally-acclimated mussels. Cluster II included proteins involved in oxidative phosphorylation (ATP synthase $(\alpha)$ ), oxidative stress (Cu/Zn-superoxide dismutase), and ion balance (NHE-RF3), several of which showed a tidal regime main effect. ATP synthase ( $\alpha$ ) also showed an effect in response to oxygen availability. Cluster III was distinct from other clusters because the majority of its proteins were significant for an interaction effect. Those included mitochondrial aldehyde dehydrogenase (ALDH), $\alpha$-aminoadipic semialdehyde dehydrogenase, and proteins representing glycolysis (TPI), TCA (mitochondrial MDH), ETS (cytochrome b-C1/reductase), and oxidative phosphorylation (ATP synthase $(\alpha)$ ). Proteins in cluster III had lower abundances at 0 and $6 \mathrm{~h}$ normoxia (tidal acclimation) and after anoxia (6 and $72 \mathrm{~h}$; subtidal acclimation) based on the interaction effect. Cluster IV mainly included proteins responding to the different tidal regimes including isovaleryl-CoA dehydrogenase, $\mathrm{PDH}$, and aconitase. Proteins of this cluster showed greater abundances in tidally- than subtidallyacclimated mussels. The remainder of the energy metabolism section is broken down by pathway for clarity. 
Glycolysis produces ATP via substrate level phosphorylation during aerobic and anaerobic conditions. We identified two glycolytic enzymes operating near equilibrium under in vivo conditions: phosphoglycerate kinase 1 and triosephosphate isomerase (TPI). The former showed elevated but not significant abundances during constant immersion, and the latter showed a significantly elevated abundance at 6 and $72 \mathrm{~h}$ of anoxia in tidally-acclimated mussels. A greater abundance of an isoform of TPI may increase its activity and shift dihydroxyacetone phosphate towards the production of glyeraldehyde 3phosphate and away from forming glycerol 3-phosphate and triglycerides. This potential shift would allow tidally-acclimated mussels to increase the flux through glycolysis and produce more ATP during anaerobiosis.

We identified changes in the abundance of two $\operatorname{PDH}(\alpha, \beta)$ and the four TCA cycle enzymes citrate synthase, aconitase, dihydrolipoyl dehydrogenase (a subunit of $\alpha$-ketoglutarate dehydrogenase, discussed in the section on oxidative stress), succinate dehydrogenase (part of complex II of the ETS), and two mitochondrial isoforms of malate dehydrogenase. PDH levels were overall elevated in tidally-acclimated mussels (especially 72NT) based on a significant acclimation effect. Although citrate synthase levels were also higher in tidallyacclimated mussels (at 6AT and 72NT), the differences were not significant. Three of the five isoforms of aconitase either showed a tidal regime (acclimation) main (\#55) or an interaction effect (\#57 and 61). The significant isoforms showed greater abundances in tidally-acclimated mussels. The two isoforms that were significant for an interaction, showed lower abundances during anoxic in 
comparison to normoxic conditions at $6 \mathrm{~h}$ and $72 \mathrm{~h}$ in the tidally- but not the subtidally-acclimated mussels (Tukey's post hoc; $P<0.05$ ). Overall subtidallyacclimated mussels showed overall lower levels and fewer changes in the abundance of aconitase with time and anoxic conditions, suggesting that aconitase is a key indicator of the anoxic response in tidally- but not subtidallyacclimated mussels. Additionally, aconitase is involved in the conversion of citrate to isocitrate and plays an important role in sensing changing environmental oxygen and ROS concentrations (Walden, 2002). Greater levels of superoxide produced by the ETS decrease the activity of aconitase and thus the flux through the TCA cycle and the production of reducing equivalents like NADH that feed into the ETS (Walden, 2002). Moreover, aconitase is tightly regulated by several PTMs, including glutathionylation, which is directly linked to the redox status of the cell (Walden, 2002). Glutathionylation of cysteine residues on aconitase inhibits its activity (Mailloux et al., 2013). Of the five aconitase isoforms we identified two (\#55 and 61) that showed a complementary abundance pattern at $72 \mathrm{~h}$, but not at $6 \mathrm{~h}$, in tidally-acclimated mussels only, suggesting a switch in PTMs. However, only \#55 and 57 appear to have been affected by glutathionylation (see PCA section). Two mitochondrial MDHs (mMDH; \#232, 234) had complementary abundances for ONS, possibly indicating a PTM. Specifically, mMDH (\#232) abundance decreased at 6 and $72 \mathrm{~h}$ of anoxia in subtidally- but not tidally-acclimated mussels. A cytosolic and one of two mitochondrial isoforms of MDH (\#232) were significant for an interaction effect, with the cytosolic isoform increasing from 0 to $6 \mathrm{~h}$ normoxia in the subtidally- 
acclimated mussels. It is possible that both isoforms show an interaction effect because of changes in the activity of the malate-aspartate shuttle, which might suggest a difference in redox balance between the acclimation treatments (Chandel, 2015).

With the exception of succinate dehydrogenase $(\mathrm{SDH})$, all other TCA cycle enzymes showed greater abundance in tidally- than in subtidallyacclimated mussels. This suggests that a tidal but not a subtidal regime may increase metabolism during normoxia and emersion-induced anoxia. SDH may be an exception due to one of its two functions: (i) it converts succinate to fumarate in the TCA cycle while (ii) simultaneously transferring electrons from FADH to cytochrome $c$ reductase (or b-C1) via ubiquinol as part of the ETS. SDH is also known to be involved in the production of ROS through reverse electron transfer, a process that leads to the backflow of electrons towards complex I (Tomanek, 2015). Inactivating SDH, which leads to the accumulation of succinate, has also been shown to be important source for the production of ROS during ischaemia and even more so during subsequent reperfusion in mammalian heart when the succinate is quickly oxidized (Chouchani et al., 2014). Furthermore, populations of butterflies with SDH mutations leading to the accumulation of succinate activate the hypoxia-inducible factor 1 (HIF-1), which leads to greater tolerance to anaerobic conditions (Marden, 2013). Thus, the decrease in SDH may help tidally-acclimated mussels to cope with increased ROS production under ischemic conditions during low tide and subsequent reperfusion with incoming high tides. 
In general, as with most TCA cycle proteins, we observed an increase in ETS proteins in tidally-acclimated mussels. The ETS is not only the most efficient source of ATP, but also a major site of ROS production, especially at complexes I and III (Tomanek, 2015; Murphy, 2009). We identified all four complexes of the ETS, including NADH dehydrogenase, SDH, cytochrome b-C1/reductase, and cytochrome $c$ oxidase, and ATP synthase as a representative of oxidative phosphorylation. Both NADH dehydrogenase and cytochrome $c$ oxidase showed no significant changes with tidal regime, oxygen availability, or their interaction. SDH showed an overall lower abundance in tidally-acclimated mussels. Specifically, SDH showed lower abundances for 6NT and 72AT, especially in comparison to 72AS (Tukey's post hoc; $P<0.05$ ), possibly reducing the production of ROS during the transition from low to high tides. Cytochrome bC1/reductase, a major site of ROS production (Andreyev et al., 2005), was significant for an interaction effect (Fig. 11) and increased in tidally- but not subtidally-acclimated mussels at $6 \mathrm{~h}$ of anoxia and at $72 \mathrm{~h}$ of anoxia and normoxia. The relatively greater abundance of cytochrome b-C1reductase in tidally-acclimated mussels may be another indicator that the production of ROS is a major concern in mussels experiencing a tidal regime. Studies on $M$. californianus from high and low intertidal sites (Moon and Pritchard, 1970) and tidally-acclimated M. edulis (Shick et al., 1986) support our findings. While the majority of the TCA cycle and ETS enzymes clustered together, mainly because of higher abundance in tidally-acclimated mussels (Fig. 11, cluster IV), SDH 
(cluster I) was a notable exception to this pattern, showing lower levels in tidallyacclimated mussels.

Finally, we also identified five isoforms of different subunits of ATP synthase, three of which, including two $\alpha$ subunits, which showed a tidal regime and oxygen main (\#136) as well as an interaction effect (\#143), respectively, one $\beta$ subunit (\#152), which showed an oxygen main effect, while one $\alpha(\# 135)$ and one $\delta$ (\#359) subunit did not change significantly with any of the treatments. The $\alpha$ and $\beta$ subunits $(\# 136,152)$ that showed a main effect for oxygen availability were two out of only six metabolic enzymes showing an oxygen main effect. Thus, these isoforms are highly responsive to ambient oxygen levels, most likely to dissipate the proton gradient across the inner mitochondrial membrane and thus lower levels of ROS production during anoxia (Ivanina et al., 2012). Similarly, previous work using the eastern oyster (Crassostrea virginica) demonstrated prolonged long-term hypoxia (six days of $0.2-0.5 \% \mathrm{O}_{2}$ ) and posthypoxic recovery resulted in elevated proton conductance of isolated mitochondria, with a $60-70 \%$ and $100-250 \%$ increase (at 20 and $30^{\circ} \mathrm{C}$, respectively) in mitochondria from oysters recovering from hypoxia compared with their normoxic counterparts (Ivanina et al., 2012). ).

We identified several enzymes involved in alternative metabolic pathways such as L-xylulose reductase and cytosolic MDH (cMDH). L-xylulose reductase is an enzyme in the glucuronic acid cycle (carbohydrate metabolism) that catalyzes the NADPH-linked reduction of I-xylulose to xylitol in addition to other carbohydrate molecules (Zhao et al., 2009) which ultimately enter the pentose 
phosphate pathway (PPP). Moreover, I-xylulose reductase has been postulated to play a role in water reabsorption and cellular osmoregulation by producing xylitol (Zhao et al., 2009). L-xylulose reductase (\#293), significant for the oxygen main effect, decreased in subtidally-acclimated mussels and showed a significantly higher abundance at $0 \mathrm{~h}$ in tidally-acclimated mussels (ONT) (Fig. 10; cluster II; Fig. 11). This indicates a shift toward the PPP (rather than glycolysis) to generate NADPH, 5-carbon sugars, and ribose-5-phosphate (nucleotide precursor) (Kruger and Schaewen, 2003), either to provide higher levels of NADPH for biosynthetic processes, scavenge ROS, or provide nucleotides for cell growth for more so in 0NT than for subtidally-acclimated mussels. In addition, glutamate dehydrogenase (Fig. 10; cluster II), key for the extraction of ammonia $\left(\mathrm{NH}_{3}\right)$ from amino acids to provide carbon skeletons for catabolic processes (Fields et al., 2014), was generally in greater abundance in subtidally-acclimated mussels, possibly as a means of increasing protein synthesis. In conjunction with these catabolic processes, isovaleryl-CoA dehydrogenase, which is involved in valine, leucine, and isoleucine degradation (Aftring et al., 1986), had generally lower abundance in subtidally-acclimated mussels (Fig. 10; cluster IV). Subtidally-acclimated mussels may have greater abundances of glutamate dehydrogenase and lower abundances of isovaleryl-CoA dehydrogenase because they have a constant supply of food and have no need to increase the catabolism or anabolism of proteins. We also identified $\mathrm{cMDH}$, which is involved in the malate-aspartate shuttle (Muller et al., 2012). It showed an interaction effect and decreased in abundance at 0NS and $72 \mathrm{~h}$ (72NT and 72AT) 
suggesting a shift in the transfer of reducing equivalents from the cytosol to mitochondria.

In sum, M. californianus experienced a general decline in the abundance of TCA and ETS proteins (except SDH) in subtidally-acclimated mussels, which suggests that the overall metabolic rate of these mussels is lower than in tidallyacclimated mussels (Hochachka and Somero, 2002). However, although subtidally-acclimated Mytilus (M. edulis) have almost no measurable oxygen consumption when acutely subjected to aerial exposure (de Zwaan and Eertman, 1996), we do not know how the different abundances of key metabolic proteins affect the metabolic rate of mussels from the two acclimation groups. Insight for the response of differently acclimated mussels to emersion may come from changes in the abundance of aconitase, which changed in a more sensitive fashion with emersion-induced anoxia in tidally- than in subtidally-acclimated mussels, possibly controlling the activity of the TCA cycle and the ETS. We hypothesize that the variable abundance of aconitase isoforms, possibly due to glutathionylation, is regulated by the occurrence of oxidative stress in tidallyacclimated mussels due to anoxic conditions resembling ischemia during low tide and reperfusion during the re-occurring high tide. Tidally-acclimated mussels also show decreased levels of SDH, which could also be due to preventing ROS formation in the ETS. Overall, tidally-acclimated mussels seem to alter their metabolic flux, at least in part by sensing ROS formation during anoxia through aconitase and in part to prevent ROS formation through the reaction of SDH. 


\section{Oxidative stress}

Oxidative stress is caused through the imbalance of ROS (e.g. superoxide anions, hydroxyl radicals, hydrogen peroxide) formation and ROS scavenging with antioxidants (e.g. superoxide dismutase (SOD), thioredoxin peroxidase (TPx)) (Finkel and Holbrook, 2000; Donaghy et al., 2015). Antioxidant proteins may either function to reduce ROS, protein thiol groups, or lipid aldehydes that form during oxidative stress, or produce NADPH to supply reducing equivalents needed for several ROS scavenging systems (Tomanek, 2015). When the balance shifts towards the antioxidant state, macromolecules remain undamaged and the production of ROS is limited. Conversely, when the balance shifts towards greater net production of ROS, macromolecular damage may occur in the form of lipid peroxidation, protein carbonylation, and oxidative DNA damage (Zhang et al., 2015). Lipid peroxidation of cellular phospholipids induces the formation of more than 200 highly-reactive aldehyde species, including 4hydroxynonenal (4-HNE) and malondialdehyde (MDA), among others (Singh et al., 2013). Overall, our data suggest that mussels cope with ROS production and lipid peroxidation during emersion by increasing the abundances of several aldehyde dehydrogenases and other antioxidant enzymes.

Cluster I (Fig. 10) contained proteins with possible antioxidant functions, including NADP-dependent isocitrate dehydrogenase (NADP-ICDH) and methylmalonate semialdehyde dehydrogenase (MMSA DH). NADP-ICDH had a significantly lower abundance in tidally-acclimated mussels. Given the hypothesized greater rates of ROS production in tidally-acclimated mussels, the 
finding is opposite of our expectations. NADP-ICDH plays a role in maintaining intracellular redox balance by facilitating the production of NADPH for either the thioredoxin-peroxiredoxin or glutathione ROS scavenging systems (Murphy, 2012). NADP-ICDH also plays a role in shifting metabolism from ROS-generating $\mathrm{NADH}$-producing to ROS-scavenging NADPH-producing pathways during heat stress in Mytilus (Tomanek, 2014). If the lower abundances of NADP-ICDH are reflecting in vivo activities, it is possible that the decrease in NADP-ICDH is the reason for the elevated levels of ROS in mussels experiencing emersion-induced anoxia (Jo et al., 2001; Lee et al., 2002).

Two isoforms of MMSA DH (Fig. 10; clusters I and IV) were significant for a tidal regime main effect $(\# 122,29)$ and one for an interaction effect $(\# 119)$. The abundances of the three isoforms were complementary, i.e. some increased and others decreased, indicating one or two PTMs in shifting the abundance of different isoforms (Fig. 10). MMSA DH is involved in the catabolism of the branched-chain amino acid valine (Singh et al., 2013; Fields et al., 2014) and helps form a precursor for the synthesis of odd-chain fatty acids by catalyzing the irreversible $\mathrm{NAD}^{+}$- and $\mathrm{CoA}$-dependent oxidative decarboxylation of methylmalonate semialdehyde to propionyl-CoA (Kedishvili et al., 2000). However, MMSA DH also functions as a scavenger of aldehydes (i.e. methylmalonate semialdehyde), which are cytotoxic products of lipid peroxidation (Singh et al., 2013). Lipid peroxidation was shown to occur during aerial exposure in mussel (Perna perna) gill tissue (Almeida et al., 2005). In addition, cluster II (Fig. 10) represents a group of proteins with a dominant main effect of 
tidal regime. We identified Cu/Zn-SOD (Fig 10; clusters II and IV), which is localized to the mitochondria, cytosol, and peroxisomes, scavenges superoxide anions produced by the ETS, and reduces them to the more stable hydrogen peroxide (Tomanek, 2015). Both isoforms of Cu/Zn-SOD (\#350, 334) did not significantly change in abundance (two-way permutation ANOVA; $P<0.02$ ). This pattern is consistent with a study by Letendre and colleagues (2009) in which SOD activity did not change in the gills of air-exposed $M$. edulis during shell closure.

Cluster III (Fig. 10) contains two aldehyde dehydrogenases (ALDHs) and one $\alpha$-aminoadipic semialdehyde dehydrogenase ( $\alpha$-AASA DH). ALDH is involved in the detoxification of aldehydes generated through the reaction of ROS with polyunsaturated fatty acids in membranes (i.e. lipid peroxidation) (Tomanek, 2014). a-AASA DH also reduces oxidative stress by metabolizing a number of lipid peroxidation-derived aldehydes (Brocker et al., 2009). Additionally, $\alpha$-AASA $\mathrm{DH}$ is primarily involved in lysine catabolism and also metabolizes betaine aldehyde to betaine during hyperosmotic stress (Brocker et al., 2009). Mitochondrial ALDH increased in tidally-acclimated mussels, especially after $72 \mathrm{~h}$ of anoxia (\#132; Fig. 11). Tidally-entrained mussels showed a general increase in the abundance of $\alpha$-AASA DH $(\# 139,43)$, especially at 72AT, which may help mussels deal with reperfusion stress during immersion. This suggests that tidallyacclimated mussels are capable of responding to lipid peroxidation-induced oxidative stress during acute anoxia. In addition, thioredoxin peroxidase (TPx) was also significant for a tidal regime main effect and also increased abundance 
in tidally-acclimated mussels (especially 72NT; Fig. 10). TPx is involved in repairing oxidative cysteine damage and the scavenging of hydrogen peroxide (Tomanek, 2015). Overall, these changes indicate that tidally-acclimated mussels are primed to deal with oxidative stress during acute anoxia.

Cluster IV, in contrast to the other clusters (Fig. 10), includes proteins with lower abundances in subtidally- than in tidally-acclimated mussels. $N(G), N(G)$ dimethylarginine dimethylamino hydrolase (DDAH) showed a significantly lower abundance in subtidally-acclimated mussels based on a tidal regime main effect (Fig. 10). $N(G), N(G)$-DDAH normally activates the production of nitric oxide (NO), a regulator of vascular homeostasis, and is impaired by oxidative stressinduced lipid peroxidation (i.e. 4-HNE) (Forbes et al., 2008). In a study on $M$. edulis, Rivera-Ingraham and colleagues (2016) hypothesize that the presence of NO in muscle cells is involved in muscle contraction/relaxation to alter blood sinus diameter and regulate hemolymph flow in response to variable oxygen availability (e.g. dilate blood vessels under hypoxic conditions). The NO signaling changes in response to oxygen availability as they found gill exposed to hypoxic conditions had 3.8-fold lower ROS formation than gills experiencing normoxia (Rivera-Ingraham et al., 2016). Their results corroborate our findings, providing rationale for our observed lower $\mathrm{N}(\mathrm{G}), \mathrm{N}(\mathrm{G})$-DDAH abundance in subtidallyacclimated mussels that had not been primed with periodic emersion during the acclimation. In addition, dihydrolipolyl dehydrogenase (DLDH), which is the E3 component of pyruvate dehydrogenase (PDH) and $\alpha$-ketoglutarate dehydrogenase ( $\alpha-K G D H)$ (Martin et al., 2005), increased in tidally-acclimated 
mussels and showed a significant acclimation effect (Fig. 10). DLDH is a potential source of ROS and may contribute to greater levels of oxidative stress in tidally-acclimated mussels (Tretter and Adam Vizi, 2000; Tahara et al., 2007). The SH3 domain-binding glutamic acid-rich (SH3BGRL) protein (nonsignificant), predicted to belong to thioredoxin-like protein family, increased in abundance at 6NT, 6NS, and 72AT, in a pattern similar to TPx. Fatty acid-binding protein (FABP) acts as an antioxidant and scavenger of 4-HNE to reduce the damaging effects of lipid peroxidation due to oxygen radicals interacting with membranes (Bennaars-Eiden et al., 2002). Changes in FABP, which increased at 6NT and 72AT, also support our hypothesis that tidally-acclimated mussels show a greater responsiveness to lipid peroxidation during emersion-induced anoxia.

To summarize, we identified several oxidative stress proteins, the majority of which were ALDHs known for their important role in metabolizing reactive aldehyde species, many of them products of lipid peroxidation (Singh et al., 2013). We observed greater abundances of ALDH and FABP as well as TPx in tidally-acclimated mussels, all indicating that frequent exposure to ischemicreperfusion cycles primed these mussels to cope with oxidative stress more effectively during post-hypoxic reoxygenation.

\section{Cytoskeleton}

The cytoskeletal network is a dynamic system that requires continual regulation and reorganization to coordinate several functions including cell structure, motility, cell division, endo- and exocytosis, and signal transduction 
(Hall, 1998; Valderrama et al., 2001). We identified cytoskeletal proteins that play a role in actin-treadmilling (F-actin capping protein), actin filament de/stabilization (gelsolin, fascin), gill cilliary structure (dynein light chain roadblock, radial spoke head protein, tektin), and the extracellular matrix (ECM) (collagen, fibulin, apextrin). Additionally, a number of actin and tubulin isoforms changed in response to tidal regime, oxygen, or their interaction (Fig. 12). In general, subtidally- and tidally-acclimated (at $6 \mathrm{~h}$ anoxia) mussels showed elevated levels of several cytoskeletal proteins involved in the formation of microtubules, ECM and actin-binding proteins (clusters I and II). In contrast, tidally-acclimated mussels, especially at 72NT and 72AT, increased the abundance of proteins involved in the formation of microfilaments and proteins signaling cytoskeletal modifications (clusters III and IV). Cluster I showed increased abundances of several tubulin ( $\beta$ ) isoforms and gelsolin, which showed a significant acclimation regime and oxygen main effect, respectively (Fig. 12), with the most distinguishable changes being an increase at 6AT and a decrease at ONS relative to all other treatments and time points. Cluster II includes proteins that increased in subtidally-acclimated mussels, i.e. isoforms of tubulin ( $\alpha$ ) and tektin4, which showed a tidal regime main and interaction effect, respectively. Cluster III showed the highest protein abundances at $72 \mathrm{~h}$ in tidally-acclimated mussels, although most changes in protein abundance were non-significant. Cluster III also contained six isoforms of actin, two isoforms of tubulin, one of ERK2, a MAP kinase, and two isoforms of apextrin, a protein most likely involved in an immune response (Dheilly et al., 2011). Finally, cluster IV includes proteins with a 
significant tidal regime main effect and generally higher protein abundances in tidally-acclimated mussels. The proteins of this cluster are involved in the signaling of cellular adhesion (progesterone receptor), cytoskeletal dynamics (CDC42), and vesicular transport (Rab-2 and ADP ribosylation factor). In addition to actin and actin-binding proteins (F-actin capping protein, gelsolin, tropomyosin), the cluster also included cilia proteins essential for gill function (radial spoke head protein). Generally, the majority of significantly changing cytoskeletal proteins showed a tidal regime main effect. In the following section we will analyze cytoskeletal proteins by function (i.e. microtubules, microfilaments, and extracellular matrix).

\section{Microtubules}

Microtubules are essential for cilia and flagella motility, intracellular transport, cell division, and differentiation (Gardner et al., 2011; Yang et al., 2006). They are comprised of tubulin dimers, $\alpha$ and $\beta$ subunits, which are constantly turned over by the dynamics of microtubular polymerization and depolymerization (Gardner et al., 2011). Tubulin heterodimers can carry multiple

PTMs (Garnham and Roll-Mecak, 2012; Janke and Bulinski, 2011). As part of the cilia in mussel gill tissue, cytoskeletal elements like tubulin may be modified as direct targets of ROS (Tomanek, 2012). For instance, periods of anoxia, we observed the strongest increase in tubulin ( $\alpha$ ) after $72 \mathrm{~h}$ of anoxia in tidallyacclimated mussels, while other isoforms generally increased, to a lesser degree, in subtidally-acclimated mussels. Additionally, one isoform of tubulin ( $\beta$ ) (\#127) 
increased in group 6AT (cluster I; Fig. 12). We hypothesize that acclimation to frequent aerial exposure influences the polymerization of microtubules.

Gill tissue is particularly dependent on ciliary movement to transport food particles across the gill epithelium (Moore, 1971). Cilia are composed of two central microtubules surrounded by nine microtubule doublets interconnected by nexin links, radial spokes, and dynein arms (Yang et al., 2006). These components provide both structural support and flexibility (Yang et al., 2006). Moreover, tektins are highly specialized microtubule-stabilizing proteins that aid in the assembly of cilia and flagella (Amos, 2008). A decrease in tektin-4 in subtidally-acclimated mussels in response to acute anoxia (\#142; Fig. 12; cluster II) may indicate that mussels inhibit the assembly of new ciliary elements following acclimation to constant immersion.

Axonemal and cytoplasmic dyneins are motor proteins made of heavy and light chains (Asai and Koonce, 2001). The heavy chain contains an ATPase and microtubule motor domain, making the cilia movement ATP-dependent. Axonemal dynein governs the beating of cilia and flagella, while cytoplasmic dynein aids in ATP-dependent retrograde transport of intracellular cargo (e.g. vesicles made by the endoplasmic reticulum, endosomes, and lysosomes) (Asai and Koonce, 2001). Dynein is necessary for cilia and flagella movement and coordination, which determines effective nutrient acquisition by gill tissue filterfeeding (Moore, 1971). Specifically, dynein light chain (roadblock) (\#360; Fig. 12; cluster IV), which increased significantly for 72AT based on an interaction effect (Fig. 13), may regulate ciliary movement in response to $72 \mathrm{~h}$ of anoxia. This 
suggests gill ciliary movement decreases in response to longer-term anoxia because dynein light chain roadblock inhibits microtubule movement, possibly to redirect cellular energy towards other functions.

Dyneins are also regulated using radial spoke head proteins (RSPs), which transmit signals to the dynein arms due to the positioning of a bulbous head that interacts with the projections of the central pair of microtubules (Yang et al., 2006). Cilia or flagella lacking RSPs may exhibit abnormal motility or may not function at all (Yang et al., 2006). RSPs may also regulate cilia orientation (i.e. beating direction) relative to tissue axes (Marshall and Kintner, 2008). We found greater abundances of RSPs in tidally-acclimated mussels, possibly improving cilia coordination and increasing the efficiency of filter feeding with acclimation to a tidal regime.

\section{Microfilaments}

We identified 11 actin isoforms, of which one was significant for each effect (acclimation regime, oxygen availability, or interaction) while the rest did not change significantly in abundance (two-way permutation ANOVA; $P<0.02$; Fig. 12). The network of actin filaments is dynamic due to "treadmilling," which is the balance between actin polymerization and depolymerization. Treadmilling serves to drive the formation of cellular protrusions, expands the cell membrane, and facilitates intracellular movement (Le Clainche and Carlier, 2008; Adams, 2004). Moreover, we identified three actin-binding proteins, tropomyosin, F-actin capping protein, and gelsolin, which function in the stabilization, growth, and 
severing of actin filaments, respectively. Tropomyosin, which stabilizes F-actin filaments, increased especially at 6NT possibly indicating greater actin stability in response to a normoxic low tide in tidally-acclimated mussels. Gelsolin is a $\mathrm{Ca}^{2+}$ dependent severing protein that disassembles the actin network and prevents future growth of those actin filaments by capping them (Sun et al., 1999). In cluster I, gelsolin (\#158), which was significant for a tidal regime main effect, increased in subtidally-acclimated mussels (Fig. 12). This suggests more cytoskeletal disassembly during acclimation to constant immersion. F-actin capping proteins bind to the barbed end of actin filaments to cap the filament from either growing or shrinking and to increase the availability of monomeric Gactin (Le Clainche and Carlier, 2008). However, F-actin capping protein differs from gelsolin in that it does not sever actin filaments. In contrast to gelsolin, Factin capping protein increased in abundance in tidally-acclimated mussels and was significant for both tidal regime and oxygen main effects (Fig. 12). Thus, acclimation to subtidal and tidal conditions affects the microfilament network differently, possibly through changes in the abundance of several actin binding proteins.

In addition to treadmilling as a part of microfilament regulation, proteins such as fascin help modulate cytoskeletal dynamics. Actin nucleation and filament reorganization are controlled spatially and temporally by extracellular cues and the activities of cell-signaling pathways (Adams, 2004). Fascin, which is strongly regulated by the ECM environment, is an actin-bundling protein that modulates cytoplasmic actin bundles, maintains cell adhesion, helps form cell 
protrusions, and coordinates motility (Adams, 2004). Fascin (\#117, 118; Fig. 12;

cluster I) increased in subtidally-acclimated and 6AT mussels. Fascin contributes to the organization of two major forms of actin-based structures: (1) cortical cell protrusions that mediate cell interactions and migration and (2) cytoplasmic microfilament bundles contributing to intracellular movements and cell architecture (Adams, 2004). Thus we hypothesize that fascin is involved in increasing the connectivity of actin filaments to aid in strengthening the gill tissue during acute $(6 \mathrm{~h})$ anoxia in tidally-acclimated mussels.

\section{Extracellular matrix}

We also identified several extracellular matrix (ECM) proteins including collagen, apextrin, and fibulin in the gill tissue. Collagen proteins not only help form the ECM, but also aid in the formation of byssal threads in foot tissue, which is vital for adhesion to the rocky substrate (Harrington and Waite, 2007). Apextrin has been shown to be involved in the immune response following bacterial infection (Dheilly et al., 2011), but its exact function remains unknown. Collagen and two isoforms of apextrin clustered together in cluster III and showed an increase in tidally-acclimated mussels. Thus it is possible that they function together, possibly to maintain the structure of the ECM. Additionally, fibulin-2 is an ECM protein important during tissue repair in smooth muscle (e.g. gill tissue) (Ström et al., 2006). Fibulin-2 (\#21, 22; Fig. 12; cluster I) showed lower abundance at ONS in comparison to ONT, indicating that acclimation to a tidal regime may affect the structure of the ECM. 
Overall, gill cytoskeletal proteins such as fascin, gelsolin, and radial spoke head proteins responded primarily to tidal regime, most likely to cope with desiccation stress due to aerial exposure. Signaling pathways that are changing in response to tidal regime in part control these changes.

\section{Intracellular signaling and vesicular transport}

In order to regulate cell structure, motility, adhesion, and vesicle transport, the cell has established control mechanisms using signaling cascades that include small G-proteins (Sasaki and Takai, 1998; Burridge and Wennerberg, 2004; Marks et al., 2009). More specifically, members of the Rho family facilitate signaling between the actin cytoskeleton and membrane receptors (Hall, 1998). We also identified signal transduction proteins that function in vesicular transport, including Rab GDP-dissociation inhibitor $\beta$ (Rab-GDI2), Ras-like Rab-2, and ADP-ribosylation factor (ARF) as well as cell division control protein 42 (CDC42) and the mitogen-activated protein kinase ERK 2 (MAPK ERK2), both of which are involved in modifying the cytoskeleton. Overall, intracellular signaling to the cytoskeleton and vesicular transport proteins primarily changed in response to tidal regime rather than in response to oxygen availability or their interaction.

We identified one isoform of MAPK ERK2 (cluster III), which is a signaltransducing protein that takes information from a number of signaling pathways into account before regulating a number of cellular processes, including cell proliferation and survival (Chang and Karin, 2001). The ERK2 MAPK pathway also receives signals from additional MAPK modules, such as p38, which is 
induced by different types of stress signals (cytokines, heat and osmotic shock) (Cheng and Feldman, 1998). ERK2 increased in abundance at 72AT and may indicate a signal cascade that initiates changes in cell growth due to longer exposure to emersion-induced anoxia. MacDonald and Storey (2006) reported a similar activation of the MAPK pathway by environmental stress in the periwinkle Littorina littorea following anoxia exposure. The MAPKs regulate nuclear transcription activity via protein phosphorylation (MacDonald and Storey, 2006). MAPKs and other signaling proteins that regulate cell proliferation, growth, and apoptosis during environmental stress vary in Mytilus congeners that differ in thermal and osmotic tolerances (Evans and Somero, 2010).

Cluster IV (Fig. 12) contains several signaling proteins including membrane-associated progesterone receptors, CDC42, Rab-2, and ARF. Membrane-associated progesterone receptors (\#322, 324), responsible for initiating cellular signaling and scaffolding interactions with cytoplasmic protein kinases (Hagan et al., 2009), showed an acclimation regime main effect and generally increased in tidally-acclimated mussels, similar to CDC42, which clustered together. CDC42 is a member of the Rho family of small G-proteins that affect cell shape and motility by controlling the dynamics of the actin cytoskeleteon (Burridge and Wennerberg, 2004; Marks et al., 2009). In addition, CDC42 allows for nucleation of F-actin filaments by preventing capping proteins from binding (Huang et al., 1999; Marks et al., 2009). As F-actin capping protein clustered with and thus had similar changes in abundance to CDC42 (Fig. 12; cluster IV), we predict CDC42 and F-actin capping protein work in concert to 
maintain filament growth in tidally-acclimated mussels. Furthermore, CDC42 coordinates cell cycle progression and is involved in stress fiber formation, membrane protrusion formation, motility, intracellular vesicle trafficking, and cell survival through the activation of stress signaling pathways (e.g. C-Jun $\mathrm{NH}_{2}$ terminal kinase (JNK) and p38 MAPK pathways) (Hall, 1998; Cowan and Storey, 2003; Marks et al., 2009). The increase in CDC42 in tidally-acclimated mussels could function to coordinate cell division and growth and regulate the cellular response to tidal conditions.

Ras-related proteins (e.g. Rab-2, ARF; cluster IV; Fig. 12) are molecular switches that regulate several components of intracellular actin dynamics and are involved in vesicle transport (Sasaki and Takai, 1998). These small G-proteins are active when bound to GTP (Sasaki and Takai, 1998). Rab-GDI2 (\#161) and Rab-2 (\#335) both play a role in the vesicular transport between the ER and Golgi (Marks et al., 2009). Rab-2 is a Rab GTPase involved in retrograde traffic or recycling of molecules from the Golgi back to the ER (Hutagalung and Novick, 2011). Specifically, Rab-2 is involved in recruiting tethering proteins for contact between the vesicle and target membrane. Rab-GDI2 regulates the intracellular location of Rab, thereby controlling its activity (Marks et al., 2009). While Rab-2 showed lower abundances in subtidally- in comparison to tidally-acclimated mussels (Fig. 12; cluster IV), Rab-GDI2 showed higher levels for subtidal groups (except 0NS) (cluster I). However, tidal regime only significantly influenced Rab-2 abundance, while Rab-GDI2 did not change significantly. 
In addition to Rho-mediated vesicular transport, we also identified ADPribosylation factor (ARF), which increased in tidally-acclimated mussels at $72 \mathrm{~h}$ of acute anoxia (72AT; Fig. 12; cluster IV). ARF is another GTP-binding protein involved in vesicular transport of secretory proteins from the ER to Golgi (Alberts et al., 1994). Specifically, ARF functions in the binding of the coat protein of nonclathrin-coated (COP-coated) vesicles and adaptor proteins to clathrin-coated vesicles to Golgi membranes (Stamnes and Rothman, 1993). It is possible that this increase in response to acute anoxia affects the export of vesicles of glycosylated proteins for mucus secretion in mussel gill cells ( $\mathrm{Ng}$ et al., 2015). Additionally, ARF has cilium-associated functions, such as trafficking to the cilliary base, establishing links to the intraflagellar transport system, localizing cilia, and regulating ciliary length (Keeling et al., 2016). After longer exposure to anoxia (i.e. 72AT), ARF could act as an important effector protein of ciliary structure and function in gill tissue in order to maintain gas exchange and filter feeding despite the regular occurrence of low tides and the collapse of gill structure within the shell cavity during low tide.

In general, the abundance of cell signaling and vesicular transport proteins increased in tidally- and decreased in subtidally-acclimated mussels (Fig. 12) and were primarily significant for a tidal regime main effect (two-way permutation ANOVA; $P<0.02)$. Thus, microfilament structure and signaling (CDC42 and MAPK ERK) and vesicular transport (Rab-2, Rab-GDI, ARF) changed more in response to acute anoxia in gill tissue in tidally- than in subtidally-acclimated mussels. 
Ion regulation

We identified several proteins that are putatively involved in ion homeostasis, including heavy metal-binding protein (HMBP), EF-hand domaincontaining protein $\left(\mathrm{Ca}^{2+}\right.$-regulation), and $\mathrm{Na}^{+} / \mathrm{H}^{+}$exchange regulatory cofactor (osmoregulation). In cluster I (Fig. 10), we identified three isoforms of HMBP, which were significant for either an acclimation regime $(\# 190,194)$ or oxygen (\#199) main effect. HMBP showed increased abundance in subtidally- in comparison to tidally-acclimated mussels at $72 \mathrm{~h}$ of anoxia (72AT) (Fig. 10). HMBP, similar in homology to both extrapallial (EP) protein and histidine-rich glycoprotein (Yin et al., 2005), is known to carry and chelate divalent metal cations $\left(\mathrm{Ca}^{2+}, \mathrm{Mg}^{2+}, \mathrm{Cd}^{2+}, \mathrm{Ni}^{+}, \mathrm{Zn}^{2+}, \mathrm{Hg}^{2+}\right.$, and $\left.\mathrm{Pd}^{2+}\right)$ in the plasma, possibly for transport to the kidney for excretion (Schneeweiss et al., 2002; Abebe et al., 2007; Devoid et al., 2007). Moreover, EP protein has been hypothesized to play a role in shell matrix formation, heavy metal detoxification, and $\mathrm{Ca}^{2+}$ transport (Yin et al., 2005). Temporary increases in $\mathrm{Ca}^{2+}$ in the cell may be caused by external signals, e.g. light, stress, pathogens, hormones (Nikapitiya et al., 2010). Given that several isoforms of the $\mathrm{Ca}^{2+}$-binding EF-hand domain-containing protein clustered with HMBP (clusters I and II), we think it is likely that the role of HMBP in the gill of Mytilus may also involve $\mathrm{Ca}^{2+}$ transport.

We found three isoforms of EF-hand domain-containing protein that were significant for a tidal regime (\#69), an interaction (\#64) effect, or did not change significantly (Fig. 10; two-way permutation ANOVA; $P<0.02$ ). The EF-hand motif is the most common $\mathrm{Ca}^{2+}$-binding motif; proteins containing this domain are 
hypothesized to function in cytosolic $\mathrm{Ca}^{2+}$ buffering and signal transduction between cellular compartments (Lewit-Bentley and Réty, 2000). Furthermore, in bivalves, the gill is the major organ that takes up $\mathrm{Ca}^{2+}$ from the external environment. Calcium is then transported to the mantle epithelium, and ultimately to the extrapallial space for shell formation (Nikapitiya et al., 2010). EF-hand domain-containing proteins increased at $0 \mathrm{NT}$ and $6 \mathrm{NT}$, and were higher in subtidally-acclimated mussels. As $\mathrm{Ca}^{2+}$ ions are important second messengers that change in response to cellular stress (Nikapitiya et al., 2010), we hypothesize that EF-hand domain-containing proteins increased as part of regulating the CSR to acute anoxia.

In addition, intracellular $\mathrm{pH}$ influences the energy status of the organism (Hochachka and Somero, 2002), with many potential downstream effects on the proteome. We identified the $\mathrm{pH}$ homeostasis protein $\mathrm{Na}^{+} / \mathrm{H}^{+}$exchange regulatory cofactor (NHE-RF3) (Fig. 10; clusters II and III). Na ${ }^{+} / \mathrm{H}^{+}$exchanger isoform 3 (NHE3) mediates the reabsorption of $\mathrm{NaCl}$ and $\mathrm{NaHCO}_{3}$ in the renal proximal tubules of the kidney (Shenolikar and Weinman, 2001) and may play a role in apical $\mathrm{H}^{+}$export in the osmoregulation of marine organisms (Grosell et al., 2009). NHE3 activity is modulated by NHE-RF3, which links NHE3 to the actin cytoskeleton, helps target transport proteins to the apical membrane, and is an essential cofactor for CAMP-mediated inhibition of NHE3 activity (Shenolikar and Weinman, 2001). NHE-RF3 helps to maintain the balance of $\mathrm{Na}^{+}$and $\mathrm{H}^{+}$ions to regulate electrolyte and fluid transport (Seidler et al., 2009). Both NHE-RF3 isoforms $(\# 96,92)$ significantly changed between the different acclimation 
regimes (two-way permutation ANOVA; $P<0.02 ;$ Fig. 10). However, the two isoforms show opposite abundance patterns, likely due to a PTM. To our knowledge, NHE-RF3 has not been previously found in mussel gill tissue. Its specific role in mussel gill is not known, but given its role in several osmoregulatory organs, it is likely involved in ion homeostasis, $\mathrm{pH}$ balance, and cell volume regulation.

In summary, all three of these proteins indicate that mussel gill tissue is mainly responding to the acclimation to different tidal regimes with changes in calcium and ion homeostasis, possibly involving the cytoskeleton and cell volume regulation.

\section{Conclusions}

PCAs based on significantly changing proteins indicated a greater response to either the acclimation to different tidal regimes, acute anoxia, or their interaction (Fig. 7). Several proteins showing an interaction effect indicate that tidally-acclimated mussels are primed to respond to acute anoxia. For example, ER chaperones, specifically CRT and PDI, as well the actin and tubulin chaperone TCP-1 and several SHSPs responded to acute anoxia with a decrease in abundance in tidally- but an increase in subtidally-acclimated mussels. In addition, a number of sHSPs showed greater levels at $6 \mathrm{~h}$ of normoxic conditions in tidally- in comparison to subtidally-acclimated mussels, suggesting that aerial exposure requires stabilization of denaturing proteins and coordination of protein aggregation (Kim et al., 2013). In addition, it is possible 
that tidally-, in contrast to subtidally-acclimated mussels are primed to inhibit protein folding and maturation in the ER during emersion-induced anoxia. This may be due to an increased capacity to reduce metabolism during emersion and the redox-sensitivity of the protein maturation process.

The majority of metabolic proteins, including almost all TCA and ETS proteins, with SDH being the exception, showed higher abundance in tidally- than in subtidally-acclimated mussels. Furthermore, changes in several isoforms of aconitase in response to acute anoxia in tidally-acclimated mussels might indicate a greater sensitivity to detect ROS produced by repeated ischemicreperfusion (tidal) cycles. The lower abundance of SDH, in light of overall higher levels of almost all other metabolic enzymes, may further indicate that tidallyacclimated mussels are primed with potentially higher rates of ROS production. This inference is further supported by the elevated levels of several ALDHs, which function as scavengers of dozens of aldehyde species that are produced as a result of increased lipid peroxidation. We also detected changes in proteins involved in ion regulation, cytoskeletal and ECM structure and function, and vesicular transport and the signaling pathways associated with these processes, which indicate that tidally- more so than subtidally-acclimated mussels are primed to deal with emersion-induced anoxia.

Our results therefore implicate several major cellular processes, ranging from proteostasis, energy metabolism, and oxidative stress to cytoskeletal and vesicle trafficking, of being modified more so in tidally- than in subtidallyacclimated mussels to prime the organism to respond to acute emersion-induced 
anoxia. While we detected modifications in some signaling pathways, associated mainly with changes in MAPKs and small G-proteins, we propose that other signaling proteins, (e.g. hypoxia inducible factor 1 ) and several known to affect the response to oxidative stress (e.g. p53 and NRF2), may be candidates for being key regulators of the greater sensitivity due to ROS sensing, and the capability of tidally-acclimated mussels to response to acute anoxia.

\section{Materials and Methods}

Animal collection and acclimation

Adult Mytilus californianus (Conrad, 1837) were collected during low tide at Hazards Reef in Montaña de Oro State Park, Los Osos, CA, USA (35'17'23"N, $120^{\circ} 53^{\prime} 1$ 'W) in May 2011. Mussels were promptly transported to the California Polytechnic State University (Cal Poly) pier facility in Avila Beach, CA for acclimation. Animals were kept at the CCMS facility for seven weeks in tidal simulator tanks equipped with flow-through raw seawater $\left(13^{\circ} \mathrm{C}\right)$, aquarium reef LED lights (Ecoxotic, Vista, CA, USA) to simulate circadian rhythms (12 h day:12 h night), and stop valves to control seawater level and thus tidal height. Mussels were acclimated to one of two acclimation regimes: 1) constant immersion in seawater to mimic subtidal conditions (subtidal), or 2 ) a semidiurnal tide (6 h emersion:6 $\mathrm{h}$ immersion, twice daily) to simulate intertidal conditions (tidal). 


\section{Experimental design}

Following acclimation, mussels were separated into two experimental groups consisting of normoxia and anoxia treated animals. The normoxia treated mussels ( $n=6$ per acclimation regime) remained under conditions of their respective acclimation regime, subtidal and tidal, with flow through raw seawater allowing for continuous oxygenation. For the anoxia treated mussels ( $n=6$ per acclimation regime), the subtidal or tidal acclimation regime ceased and mussels were placed into sealed acrylic fish tanks within each tidal simulator tank where the anoxia exposure was administered. To create the anoxic conditions, nitrogen gas was pumped into the sealed fish tanks through a one-way valve at 5 PSI with a flow rate of $10 \mathrm{~mL} / \mathrm{min}$ for 10 minutes every two hours (Table 3 ). Each sealed tank was surrounded with sufficient seawater to maintain a constant seawater temperature $\left(13^{\circ} \mathrm{C}\right)$ and air moisture during the anoxia exposure. Following treatment exposure, gill tissue was extracted at 0 (normoxia only), 6 , and $72 \mathrm{~h}$ and immediately frozen on dry ice. Tissues were subsequently maintained at $80^{\circ} \mathrm{C}$ until homogenization for proteomic analysis.

\section{Homogenization}

Frozen gill tissue was thawed, weighed, and lysed in a 1:4 ratio of tissue to homogenization buffer (7M urea, $2 \mathrm{M}$ thiourea, $40 \mathrm{mM}$ Tris- $\mathrm{HCl}, 1 \%$, amidosulfobetaine-14, 0.5\% pH 4-7 IPG buffer (GE Healthcare, Piscataway, NJ, USA), 40mM dithiothreitol) with an ice-cold ground-glass homogenizer. The homogenate was centrifuged at $13.2 \mathrm{~g}$ for 30 minutes at $20^{\circ} \mathrm{C}$ (room 
temperature) to obtain a supernatant. Each aliquot was washed in 4 volumes icecold $10 \%$ trichloroacetic acid (TCA) in acetone to precipitate the proteins overnight at $-20^{\circ} \mathrm{C}$.

Samples were subsequently centrifuged at $4^{\circ} \mathrm{C}$ for 15 minutes at $13.2 \mathrm{~g}$. The supernatant was decanted and each pellet was subsequently washed with ice-cold $100 \%$ acetone to remove any remaining TCA. After centrifugation, the acetone was immediately decanted and the pellet was resuspended in rehydration buffer (7M urea, $2 \mathrm{M}$ thiourea, $2 \%$ cholamidopropyldimethylammonio-propanesulfonic acid (CHAPS), $2 \%$ nonyl phenoxylpolyethoxylethanol-40, 0.002\% Bromophenol Blue, 0.5\% pH 4-7 IPG buffer, $100 \mathrm{mM}$ dithioerythritol) through vortexing. The resulting rehydrated protein concentration was determined using a 2D Quant kit (GE HealthCare) according to the manufacturer's instructions.

Two-dimensional gel electrophoresis

Proteins $(400 \mu \mathrm{g})$ were separated based on their isoelectric point $(\mathrm{pl})$ along $11 \mathrm{~cm} \mathrm{pH} \mathrm{4-7} \mathrm{ReadyStrips} \mathrm{IPG} \mathrm{strips} \mathrm{(BioRad,} \mathrm{Hercules,} \mathrm{CA,} \mathrm{USA).} \mathrm{IPG}$ strips were passively rehydrated for $5 \mathrm{~h}$, followed by $12 \mathrm{~h}$ of active rehydration (50 V), using an isoelectric focusing cell (BioRad). The following protocol was used for the remainder of the run (with voltage changes in rapid mode): $500 \mathrm{~V}$ for $1 \mathrm{~h}, 1000 \mathrm{~V}$ for $1 \mathrm{~h}$, and $8000 \mathrm{~V}$ for $2.5 \mathrm{~h}$. The strips were frozen and stored at $80^{\circ} \mathrm{C}$. 
IPG strips were thawed and incubated for two 15 minute intervals in denaturing equilibration buffer ( $6 \mathrm{M}$ urea, $50 \mathrm{mM}$ Tris- $\mathrm{HCl}$, pH 8.8, 30\% glycerol, $2 \%$ sodium dodecyl sulfate (SDS), $0.002 \%$ Bromophenol Blue)—first with $65 \mathrm{mM}$ dithiothreitol to reduce all disulfide bonds and second with $135 \mathrm{mM}$ iodoacetamide to cap resulting cysteine residues and prevent protein reaggregation. IPG strips were placed on top of $11.8 \%$ SDS-acrylamide gels with a $0.8 \%$ agarose solution containing Laemmli SDS electrophoresis running buffer (25 mM Tris base, $192 \mathrm{mM}$ glycine, and 0.1\% SDS). Gels were run (Criterion Dodeca; BioRad) at $200 \mathrm{~V}$ for 55 minutes with a recirculating water bath at $10^{\circ} \mathrm{C}$. Gels were stained with colloidal Coomassie Blue (G-250) overnight and destained by rinsing repeatedly with Milli-Q water (Millipore, Billerica, MA, USA) for $48 \mathrm{~h}$. Destained gels were scanned on an Epson 1680 transparency scanner (Epson, Long Beach, CA, USA).

\section{Gel image analysis}

Digitized two-dimensional gel images were quantitatively analyzed with 2D gel image analysis software, Delta2D (version 3.6, Decodon, Greifswald, Germany) (Berth et al., 2007). The group warping strategy was used to connect gel images through match vectors. All gel images were fused to generate a composite image (proteome map), which represents mean volumes for each spot (Figure 6). The proteome map was used to generate spot boundaries, which were subsequently transferred to all gel images using the match vectors from the 
wrapping process. After background subtraction, protein spot volumes were normalized against total spot volume of all proteins in a gel image.

\section{Trypsin digestion}

All protein spots (significant and non-significant) were excised from gels using a spot cutter, specifically a Manual Tissue Array Punch MP15 $-1.5 \mathrm{~mm}$ diameter (Beecher Instruments, Inc., Prairie, WI, USA). Each spot was placed in a destaining buffer (25 mM ammonium bicarbonate $\left(\mathrm{NH}_{4} \mathrm{HCO}_{3}\right)$ in $50 \%$ acetonitrile) for 45 min to remove a residual colloidal Coomassie Blue stain, dehydrated with $100 \%$ acetonitrile for 10 min and digested with trypsin (Promega, Madison, WI, USA) solution ( $40 \mathrm{mM} \mathrm{NH}_{4} \mathrm{CO}_{3}, 10 \%$ acetonitrile, $4.3 \mu \mathrm{g} / \mu \mathrm{L}$ trypsin) overnight at $37^{\circ} \mathrm{C}$. Spots were then washed with analyte solution $(0.1 \%$ TFA in acetonitrile, 2:1 ratio) for $1 \mathrm{~h}$ to elute any remaining peptides from the gel matrix. Gel plugs were discarded and the analyte solution was pooled with the trypsin solution and concentrated in the SpeedVac (Thermo Fisher Scientific, Waltham, MA, USA) at $45^{\circ} \mathrm{C}$ for $50 \mathrm{~min}$. Matrix solution $(0.2 \mathrm{mg} / \mathrm{mL}$ a-hydroxycyano cinnamic acid in acetonitrile, $0.1 \%$ trifluoroacetic acid (TFA) in acetonitrile) was added directly to the samples prior to plating on a $600 \mu \mathrm{m}$ Anchorchip target plate (Bruker Daltonics Inc., Billerica, MA, USA). Each spot was washed two times with wash buffer ( $0.1 \%$ TFA, $10 \mathrm{mM}$ ammonium phosphate) and recrystallized with a buffer containing ethanol, acetone, 0.1\% TFA, 6:3:1 dilution). 


\section{Mass spectrometry}

A matrix-assisted laser desorption ionization time of flight (MALDIToF/ToF) mass spectrometer (Ultraflex II; Bruker Daltonics Inc.) was used to generate peptide mass fingerprints (PMFs) of each protein. FlexAnalysis (version 3.0; Bruker Daltonics Inc.) was used to detect peptide peaks (SNAP algorithm with a signal-to-noise-ratio of 6 for MS and 1.5 for MS/MS). Monoisotropic masses of significant peptides were determined using PMF peak intensities.

Proteins were identified using the Mascot (version 2.2; Matrix Science Inc., Boston, MA, USA) Expressed Sequence Tab (EST) library for Mytilus in combination with PMFs and tandem mass spectra. A significant score obtained from the EST library is representative of the correlation between the experimental data and to the database entry of the corresponding peptide match. NCBI Blast search engine was compared the sequence homology of identified proteins to sequence data entries. Our search allowed one missed cleavage during trypsin digestion. For tandem MS we set the precursor ion mass tolerance to 0.6 Da. The molecular weight search (MOWSE) score that indicated a significant hit was dependent on the database: scores higher than 43 were significant $(P<0.05)$ in a search in the Mytilus EST database. However, we only accepted positive identifications that included two matched peptides regardless of the MOWSE score. Analysis of peptide spectra followed procedures from previous studies (Tomanek and Zuzow, 2010). 


\section{Statistical analysis}

Normalized spot volumes (a metric of protein abundance) were analyzed within Delta2D (version 3.6; Decodon, Greifswald, Germany) using a two-way ANOVA (1000 permutations, $\alpha=0.02$ ). This statistical method accounts for unequal variance and non-normal distributions of the response variables (protein abundance). The unbalanced design and missing group (normoxia $72 \mathrm{~h}$ ) led us to conduct a two-way ANOVA analyses (tidal regime acclimation x oxygen availability). We did not analyze the effect of time on protein spot changes. Additionally, Tukey's post hoc pairwise comparison tests were conducted $(P<0.05)$, using Minitab (version 16; Minitab Inc., State College, PA, USA) following an F-distribution ANOVA for individual proteins to determine which groups had significant differences in average protein abundance. Because the permutation ANOVA (nonparametric) results are based on an F-statistic of the entire set of proteins, but the pairwise comparisons are based on using an (parametric) ANOVA of the abundance changes of a single protein, not all proteins showing significance for a main or interaction effect also showed a significant difference in pairwise comparisons.

For the hierarchical clustering within heat maps of protein abundance, we used average linking in the statistical tool suite within Delta2D based on Pearson's correlation. We also used a principle component analysis (PCA) within Delta2D to assess the contribution of acclimation, anoxia, and time to the variation in protein abundance patterns. The results of the PCA comparing treatments within each acclimation were interpreted with the help of loading 
values known as Eigenvalues, which assess which proteins contributed the most to the component of interest. 


\section{REFERENCES}

Abbott, A. (1999). A post-genomic challenge: learning to read patterns of protein synthesis. Nature. 402, 715-720.

Abebe, A. T., Devoid, S. J., Sugumaran, M., Etter, R. and Robinson, W.E. (2007). Identification and quantification of histidine-rich glycoprotein $(\mathrm{HRG})$ in the blood plasma of six marine bivalves. Comp. Biochem. Physiol. Part B, Biochem. Molec. Biol. 147, 74-81.

Abele, D., Brey, T. and Philipp, E. (2009). Bivalve models of aging and the determination of molluscan lifespans. Exp. Gerontol. 44, 307-315. Adams, J. C. (2004). Roles of fascin in cell adhesion and motility. Curr. Opin. Cell Biol. 16, 590-596.

Aebersold, R. and Goodlett, D. R. (2001). Mass spectrometry in proteomics. Chem. Rev. 101, 269-95.

Aebersold, R. and Mann, M. (2003). Mass spectrometry-based proteomics. Nature 422, 198-207.

Aftring, R. P., Block, K. P., Buse, M. G., Aftring, R., Paul, K. P. and Block, M. G. B. (1986). Leucine and isoleucine activate skeletal muscle branched-chain a-keto acid dehydrogenase in vivo. Am. J. Physiol. 250, E599-604.

Ahn, S. M. and Simpson, R. J. (2007). Body fluid proteomics: Prospects for biomarker discovery. Proteomics - Clinical Appl. 1, 1004-1015. 
Almeida, E. A., Dias Bainy, A. C., Dafre, A. L., Gomes, O. F., Medeiros, M. H. G. and Di Mascio, P. (2005). Oxidative stress in digestive gland and gill of the brown mussel (Perna perna) exposed to air and re-submersed. J. of Exp. Mar. Biol. Ecol. 318, 21-30.

Altieri, A. H. (2006). Inducible variation in hypoxia tolerance across the intertidal - subtidal distribution of the blue mussel Mytilus edulis. Mar. Ecol. Progr. Ser. 325, 295-300.

Amos, L. A. (2008). The tektin family of micotubule-stabilizing proteins. Genome Biol. 9, 229.

Anderson, M. J. and Braak, C. J. F. T. E. R. (2006). Permutation tests for multifactorial analysis of variance. J. Stat. Comput. Simul. 73, 85-113.

Andreyev, A. Y., Kushnareva, Y. E. and Starkov, A. A. (2005). Mitochondrial metabolism of reactive oxygen species. Biochem. 70, 200-14.

Anestis, A., Pörtner, H. O. and Michaelidis, B. (2010). Anaerobic metabolic patterns related to stress responses in hypoxia exposed mussels Mytilus galloprovincialis. J. Exp. Mar. Biol. Ecol. 394, 123-133.

Araki, K. and Nagata, K. (2012). Protein folding and quality control in the ER. Cold Spring Harbor Perspectives in Biol. 4, a015438.

Asai, D. J. and Koonce, M. P. (2001). The dynein heavy chain: structure, mechanics and evolution. Cell Biol. 11, 196-202.

Ball, M. S. and Karuso, P. (2007). Mass spectral compatibility of four proteomics stains. J. Proteome Res. 6, 4313-4320. 
Barsotti, G. and Meluzzi, C. (1968). Osservazioni su Mytilus edulis L. e Mytilus galloprovincialis Lam. Conchiglie. 4, 50-58.

Bayne, B. L., Bayne, C. J., Carefoot, T. C. and Thompson, R. J. (1976a). Physiological ecology of Mytilus californianus Conrad. 1. Metabolism and energy balance. Oecologia. 22, 211-228.

Bayne, B. L., Bayne, C. J., Carefoot, T. C. and Thompson, R. J. (1976b). The physiological ecology of Mytilus californianus Conrad. 2. Adaptations to low oxygen tension and air exposure. Oecologia. 22, 229-250.

Bennaars-Eiden, A., Higgins, L., Hertzel, A. V., Kapphahn, R. J., Ferrington, D. A. and Bernlohr, D. A. (2002). Covalent modification of epithelial fatty acidbinding protein by 4-hydroxynonenal in vitro and in vivo. Evidence for a role in antioxidant biology. J. Biol. Chem. 277, 50693-702.

Ben-Yoseph, O., Boxer, P. A and Ross, B. D. (1996). Assessment of the role of the glutathione and pentose phosphate pathways in the protection of primary cerebrocortical cultures from oxidative stress. J. Neurochem. 66, 2329-2337.

Berger, W., Steiner, E., Grusch, M., Elbling, L. and Micksche, M. (2009). Vaults and the major vault protein: novel roles in signal pathway regulation and immunity. Cell. Molec. Life Sci. 66, 43-61.

Berth, M., Moser, F. M., Kolbe, M. and Bernhardt, J. (2007). The state of the art in the analysis of two-dimensional gel electrophoresis images. Appl. Microbiol. Biotechnol. 76, 1223-1243. 
Blackstock, W. P. and Weir, M. P. (1999). Proteomics: quantitative and physical mapping of cellular proteins. Trends Biotechnol. 17, 121-127.

Boudreau, A. C., Ferrario, C. R., Glucksman, M. J. and Wolf, M. E. (2009).

Signaling pathway adaptations and novel protein kinase A substrates related to behavioral sensitization to cocaine. J. Neurochem. 110, 363377.

Braby, C. E. and Somero, G. N. (2006). Following the heart: temperature and salinity effects on heart rate in native and invasive species of blue mussels (genus Mytilus). J. Exp. Biol. 209, 2554-2566.

Brackley, K. I. and Grantham, J. (2009). Activities of the chaperonin containing TCP-1 (CCT): implications for cell cycle progression and cytoskeletal organisation. Cell Stress Chaperones. 14, 23-31.

Brocker, C., Lassen, N., Estey, T., Pappa, A., Cantore, M., Orlova, V. V., Chavakis, T., Kavanagh, K. L., Oppermann, U. and Vasiliou, V. (2010). Aldehyde dehydrogenase 7A1 (ALDH7A1) is a novel enzyme involved in cellular defense against hyperosmotic stress. J. of Biol. Chem., 285, $18452-18463$.

Brooks, S. P. J. and Storey, K. B. (1997). Glycolytic controls in estivation and anoxia: a comparison of metabolic arrest in land and marine molluscs. Comp. Biochem. Physiol. A. 118, 1103-1114.

Buchberger, A., Bukau, B. and Sommer, T. (2010). Protein quality control in the cytosol and the endoplasmic reticulum: brothers in arms. Molec. Cell. 40, 238-252. 
Buckley, B.A., Owen, M.E. and Hofmann, G.E. (2001). Adjusting the thermostat: the threshold induction temperature for the heat-shock response in intertidal mussels (genus Mytilus) changes as a function of thermal history. J. Exp. Biol. 204, 2816-2829.

Bulleid, N. J. and Ellgaard, L. (2011). Multiple ways to make disulfides. Trends Biochem. Sci. 36, 485-492.

Campos, A., Tedesco, S., Vasconcelos, V. and Cristobal, S. (2012). Proteomic research in bivalves: towards the identification of molecular markers of aquatic pollution. J. Proteomics. 75, 4346-4359.

Carrington, E., Moeser, G. M., Thompson, S. B., Coutts, L. C. and Craig, C. A. (2008). Mussel attachment on rocky shores: the effect of flow on byssus production. Integr. Comp. Biol. 48, 801-807.

Chang, L. and Karin, M. (2001). Mammalian MAP kinase signalling cascades. Nature. 410, 37-40.

Cheng, H. L. and Feldman, E. L. (1998). Bidirectional regulation of p38 kinase and c-Jun $\mathrm{N}$-terminal protein kinase by insulin-like growth factor-I. J. of Biol. Chem. 273, 14560-14565.

Choudhary, J. S., Blackstock, W. P., Creasy, D. M. and Cottrell, J. S. (2001). Matching peptide mass spectra to EST and genomic DNA databases. Trends in Biotech. 19, S17-22.

Coleman, N. (1973). Water loss from aerially exposed mussels. J. Exp. Mar. Biol. Ecol. 12, 145-155. 
Connor, K. M. and Gracey, A. Y. (2012). High-resolution analysis of metabolic cycles in the intertidal mussel Mytilus californianus. AJP: Regul., Integr. Comp. Physiol. 302, R103-R111.

Cowan, K. J. and Storey, K. B. (2003). Mitogen-activated protein kinases: new signaling pathways functioning in cellular responses to environmental stress. J. Exp. Biol. 206, 1107-1115.

de Zwaan, A. and Eertman, R. H. M. (1996). Anoxic or aerial survival of bivalves and other euryoxic invertebrates as a useful response to environmental stress - a comprehensive review. Comp. Biochem. Physiol. - C Pharmacol. Toxicol. Endocrinol. 113, 299-312.

de Zwaan, A. and Mathiew, M. (1992). The mussel Mytilus: ecology, physiology, genetics and culture. In Cellular biochemistry and endocrinology (ed. E. Gosling), pp. 223-307. Amsterdam, London, New York, Tokyo: Elsevier. de Zwaan, A., van den Thillart, G., Weber, R. E and P. Cortesi. (1991). Responses to oxygen depletion: energy metabolism. Delta Institute for Hydrobiological Research Progress Report. 1990, 38-40.

de Zwaan, A. and Wijsman, T. C. M. (1976). Anaerobic metabolism in bivalvia (Mollusca): characteristics of anaerobic metabolism. Comp. Biochem. Physiol. B. Comp. Biochem., 313-323.

Denny, M. W. and Gaines, S.D. (2007). Encyclopedia of tidepools and rocky shores. University of California Press. 735 pp. 
Devoid, S. J., Etter, R., Sugumaran, M., Wallace, G. T. and Robinson, W. E. (2007). Histidine-rich glycoprotein from the hemolymph of the marine mussel Mytilus edulis L. binds Class A, Class B, and borderline metals. Environ. Toxicol. Chem. 26, 872-7.

Dheilly, N. M., Haynes, P. A., Bove, U., Nair, S. V. and Raftos, D. A. (2011). Comparative proteomic analysis of a sea urchin (Heliocidaris erythrogramma) antibacterial response revealed the involvement of apextrin and calreticulin. J. Invertebr. Pathol. 106, 223-229.

Diaz, R. J. and Rosenberg, R. (1995). Marine benthic hypoxia: a review of its ecological effects and the behavioural responses of benthic macrofauna. Oceanography Mar. Biol.: an Annual Rev. 33, 245-303.

Donaghy, L., Hong, H.-K., Jauzein, C. and Choi, K.-S. (2014). The known and unknown sources of reactive oxygen and nitrogen species in haemocytes of marine bivalve molluscs. Fish Shellfish Immunol. 42, 91-97.

Dowd, W. W. and Somero, G. N. (2013). Behavior and survival of Mytilus congeners following episodes of elevated body temperature in air and seawater. J. Exp. Biol. 216, 502-514.

Edmunds, P. J. (2014). Is acclimation beneficial to scleractinian corals, Porites spp.? Mar. Biol. 161, 1531-1542.

Ellington, W. R. (1989). Phosphocreatine represents a thermodynamic and functional improvement over other muscle phosphagens. J. Exp. Biol. 143, 177-194. 
Ellington, W. R. (2001). Evolution and physiological roles of phosphagen systems. Annu. Rev. Physiol. 63, 289-325.

Erlandson, J. M., Rick, T. C., Braje, T. J., Steinberg, A. and Vellanoweth, R. L. (2008). Human impacts on ancient shellfish: a 10,000 year record from San Miguel Island, California. J. Archaeol. Sci. 35, 2144-2152.

Fan, C. Y., Lee, S., and Cyr, D. M. (2003). Mechanisms for regulation of Hsp70 function by Hsp40. Cell Stress Chaperones. 8, 309-316.

Feder, M. E. and Hofmann, G. E. (1999). Heat-shock proteins, molecular chaperones, and the stress response: evolutionary and ecological physiology. Annu. Rev. Physiol. 61, 243-282.

Fields, P. A., Cox, K. M. and Karch, K. R. (2012a). Latitudinal variation in protein expression after heat stress in the salt marsh mussel Geukensia demissa. Integr. Comp. Biol. 52, 636-647.

Fields, P. A., Eurich, C., Gao, W. L. and Cela, B. (2014). Changes in protein expression in the salt marsh mussel Geukensia demissa: evidence for a shift from anaerobic to aerobic metabolism during prolonged aerial exposure. J. Exp. Biol. 217, 1601-1612.

Fields, P. A., Zuzow, M. J. and Tomanek, L. (2012b). Comparative proteomics of blue mussel (Mytilus) congeners to temperature acclimation. J. Exp. Biol. $215,1106-1116$.

Finkel, T., and Holbrook, N. J. (2000). Oxidants, oxidative stress and the biology of ageing. Nature. 408, 239-247. 
Forbes, S. P., Druhan, L. J., Guzman, J. E., Parinandi, N., Zhang, L., GreenChurch, K. B., and Cardounel, A. J. (2008). Mechanism of 4-HNE mediated inhibition of hDDAH-1: implications in no regulation. Biochem. 47, 1819-1826.

Gakh, O., Cavadini, P. and Isaya, G. (2002). Mitochondrial processing peptidases. Biochimica et Biophysica Acta - Molec. Cell Res. 1592, 6377.

Gardner M. K., Charlebois, B. D., Janosi, I. M., Howard, J., Hunt, A. J., and D. J. Odde. (2011). Rapid microtubule self-assembly kinetics. Cell. 146, 582592.

Garland, M. A., Stillman, J. H. and Tomanek, L. (2015). The proteomic response of cheliped myofibril tissue in the eurythermal porcelain crab, Petrolisthes cinctipes, to heat shock following acclimation to daily temperature fluctuations. J. Exp. Biol. 218, 388-403.

Garnham, C. P., and Roll-Mecak, A. (2012). The chemical complexity of cellular microtubules: tubulin post-translational modification enzymes and their roles in tuning microtubule functions. Cytoskeleton. 69, 442-463.

Görg, A. (2004). 2-D Electrophoresis: principles and methods. Little Chalfont, UK: GE Healthcare.

Gracey, A. Y., Chaney, M. L., Boomhower, J. P., Tyburczy, W. R., Connor, K. and Somero, G. N. (2008). Rhythms of gene expression in a fluctuating intertidal environment. Curr. Biol. 18, 1501-1507. 
Grieshaber, M. K., Hardewig, I., Kreutzer, U. and Pörtner, H.-O. (1994).

Physiological and metabolic responses to hypoxia in invertebrates. Rev. Physiol. Biochem. Pharmacol. 125, 43-147.

Grosell, M., Genz, J., Taylor, J. R., Perry, S. F. and Gilmour, K. M. (2009). The involvement of $\mathrm{H}^{+}$-ATPase and carbonic anhydrase in intestinal $\mathrm{HCO}^{-}$ secretion in seawater-acclimated rainbow trout. J. Exp. Biol. 212, 19401948.

Guderley, H., Demers, A. and Couture, P. (1994). Acclimatization of blue mussel (Mytilus edulis Linnaeus, 1758) to intertidal conditions: effects on mortality and gaping during air exposure. J. Shellfish Res. 13, 379-385.

Hagan, C. R., Faivre, E. J., and Lange, C. A. (2009). Scaffolding actions of membrane-associated progesterone receptors. Steroids. 74, 568-572.

Hall, A. (1998). Rho GTPases and the actin cytoskeleton. Science. 279, 509-514.

Halliwell, B. and J. M. C. Gutteridge. (1999). Free radicals in biology and medicine. Oxford, UK: Oxford University Press.

Halpin, P. M., Menge, B. A. and G. E. Hofmann. (2004). Experimental demonstration of plasticity in the heat shock response of the intertidal mussel Mytilus californianus. Mar. Ecol. Prog. Ser. 276, 137-145.

Halpin, P. M., Sorte, C. J., Hofmann, G. E. and Menge, B. A. (2002). Patterns of variation in levels of hsp70 in natural rocky shore populations from microscales to mesoscales. Integr. Comp. Biol. 42, 815-824. 
Han, D., Canali, R., Garcia, J., Aguilera, R., Gallaher, T. K. and Cadenas, E. (2005). Sites and mechanisms of aconitase inactivation by peroxynitrite: modulation by citrate and glutathione. Biochem. 44, 11986-11996.

Harrington, M. J. and Waite, J. H. (2007). Holdfast heroics: comparing the molecular and mechanical properties of Mytilus californianus byssal threads. J. Exp. Biol. 210, 4307-4318.

Haslbeck, M., Franzmann, T., Weinfurtner, D. and Buchner, J. (2005). Some like it hot: the structure and function of small heat-shock proteins. Nat. Struct. Molec. Biol. 12, 842-846.

Heath, D. D., Rawson, P.D. and Hilbish, T. J. (1995) PCR-based nuclear markers identify alien blue mussel (Mytilus spp.) genotypes on the west coast of Canada. Can. J. Fish. Aquat. Sci. 52, 2621-2627.

Helmuth, B. (2002). How do we measure the environment? Linking intertidal thermal physiology and ecology through biophysics. Integr. Comp. Biol. 42, 837-845.

Hermes-Lima, M. and Zenteno-Savín, T. (2002). Animal response to drastic changes in oxygen availability and physiological oxidative stress. Comp. Biochem. Physiol. 133C, 537-556.

Hochachka, P. W. and Somero, G. N. (2002). Biochemical adaptation: mechanism and process in physiological evolution. Oxford, UK: Oxford University Press. 
Hofmann, G. E. and Somero, G. N. (1996). Interspecific variation in thermal denaturation of proteins in the congeneric mussels Mytilus trossulus and M. galloprovincialis: evidence from the heat-shock response and protein ubiquitination. Mar. Biol. 126, 65-75.

Huang, M., Yang, C., Schafer, D. A., Cooper, J. A., Higgs, H. N. and Zigmond, S. H. (1999). Cdc42-induced actin filaments are protected from capping protein. Curr. Biol. 9, 979-982.

Hutagalung, A. H. and Novick, P. J. (2011). Role of Rab GTPases in membrane traffic and cell physiology. Physiol Rev. 91, 119-149.

Ivanina, A. V., Kurochkin, I. O., Leamy, L. and Sokolova, I. M. (2012). Effects of temperature and cadmium exposure on the mitochondria of oysters (Crassostrea virginica) exposed to hypoxia and subsequent reoxygenation. J. Exp. Biol. 215, 3142-3154.

Janke, C. and Bulinski, J. C. (2011). Post-translational regulation of the microtubule cytoskeleton: mechanisms and functions. Nat. Rev. 12, 773786.

Jo, S.- H., Son, M.-K., Koh, H.- J., Lee, S.- M., Song, I.- H., Kim, Y.- O., Lee, Y.S., Jeong, K.- S., Kim, W. B., Park, et al. (2001). Control of mitochondrial redox balance and cellular defense against oxidative damage by mitochondrial $\mathrm{NADP}^{+}$-dependent isocitrate dehydrogenase. J. Biol. Chem. 276, 16168-16176. 
Joo, N. S., Evans, I. A. T., Cho, H. J., Park, I. H., Engelhardt, J. F. and Wine, J. J. (2015). Proteomic analysis of pure human airway gland mucus reveals a large component of protective proteins. PLOS ONE. 10, 1-16.

Kedishvili, N. Y., Popov, K. M., Rougraff, P. M., Zhao, Y., Crabb, D. W. and Harris, R. A. (1992). CoA-dependent methylmalonate-semialdehyde dehydrogenase, a unique member of the aldehyde dehydrogenase superfamily: cDNA cloning, evolutionary relationships, and tissue distribution. J. Biol. Chem. 267, 19724-19729.

Keeling, J., Tsiokas, L. and Maskey, D. (2016). Cellular mechanisms of ciliary length control. Cells. 5, 6.

Kim, Y. E., Hipp, M. S., Bracher, A., Hayer-Hartl, M. and Hartl, F. U. (2013). Molecular chaperone functions in protein folding and proteostasis. Annu. Rev. Biochem. 82, 323-355.

Kourtidis, A., Drosopoulou, E., Nikolaidis, N., Hatzi, V. I., Chintiroglou, C. C. and Scouras, Z. G. (2006). Identification of several cytoplasmic HSP70 genes from the Mediterranean mussel (Mytilus galloprovincialis) and their longterm evolution in Mollusca and Metazoa. J. Molec. Evol. 62, 446-459.

Kruger, N. J. and Von Schaewen, A. (2003). The oxidative pentose phosphate pathway: structure and organisation. Curr. Opin. Plant Biol. 6, 236-246.

Kültz, D. (2005). Molecular and evolutionary basis of the cellular stress response. Annu. Rev. Physiol. 67, 225-257.

Kwast K. E. and Hand S. C. (1996). Acute depression of mitochondrial protein synthesis during anoxia. J. Biol. Chem. 271, 7313-7319. 
Le Clainche, C. and Carlier, M. F. (2008). Regulation of actin assembly associated with protrusion and adhesion in cell migration. Physiol. Rev. 88, 489-513.

Lee, A. S. (2001). The glucose-regulated proteins: stress induction and clinical applications. Trends in Biochem. Sci. 26, 504-510.

Lee, S. M., Koh, H. J., Park, D. C., Song, B. J., Huh, T. L. and Park, J. W. (2002). Cytosolic NADP ${ }^{+}$-dependent isocitrate dehydrogenase status modulates oxidative damage to cells. Free Radical Biol. Med. 32, 1185-1196.

Letendre, J., Chouquet, B., Manduzio, H., Marin, M., Bultelle, F., Leboulenger, F. and Durand, F. (2009). Tidal height influences the levels of enzymatic antioxidant defenses in Mytilus edulis. Mar. Environ. Res. 67, 69-74.

Lewit-Bentley, A. and Réty, S. (2000). EF-hand calcium-binding proteins. Curr. Opin. Struct. Biol. 10, 637-643.

Lockwood, B. L., Connor, K. M. and Gracey, A. Y. (2015). The environmentally tuned transcriptomes of Mytilus mussels. J. Exp. Biol. 218, 1822-1833.

Lodish, H., Berk, A., Kaiser, C. A., Krieger, M., Scott, M. P., Bretscher, A., Ploegh, H. and Ludbrook, J. and Dudley, H. (1998). Why permutation tests are superior to $\mathrm{t}$ and $\mathrm{F}$ tests in biomedical research. Am. Statistician. 52, 127.

Logan, C. A. and Buckley, B. A. (2015). Transcriptomic responses to environmental temperature in eurythermal and stenothermal fishes. $\mathrm{J}$. Exp. Biol. 218, 1915-1924. 
Lortz, S., Lenzen, S. and Mehmeti, I. (2015). Impact of scavenging hydrogen peroxide in the endoplasmic reticulum for $\beta$ cell function. J. Mol. Endocrinol. 55, 21-29.

Lovrić, J. (2011). Introducing proteomics: from concepts to sample separation, mass spectrometry and data analysis. Singapore: John Wiley \& Sons, Ltd.

MacDonald, J. A. and Storey, K. B. (2006). Identification of a 115 kDa MAPkinase activated by freezing and anoxic stresses in the marine periwinkle, Littorina littorea. Archives of Biochem. Biophys. 450, 208-214.

Mackintosh, J. A., Veal, D. A. and Karuso, P. (2005). Fluoroprofile, a fluorescence-based assay for rapid and sensitive quantitation of proteins in solution. Proteomics. 5, 4673-4677.

Mailloux, R. J., McBride, S. L. and Harper. M. E. (2013). Unearthing the secrets of mitochondrial ROS and glutathione in bioenergetics. Trends in Biochem. Sci. 38, 592-602.

Marden, J. H. (2013). Nature's inordinate fondness for metabolic enzymes: why metabolic enzyme loci are so frequently targets of selection. Molec. Ecol. $23,5743-5764$.

Marks, F., Klingmuller, U. and Muller-Decker, K. (2009). Cellular signal processing: an introduction to the molecular mechanisms and signal transduction, New York: Garland Science, Taylor and Francis Group. Marshall, W. F. and Kintner, C. (2008). Cilia orientation and the fluid mechanics of development. Curr. Opinion in Cell Biol. 20, 48-52. 
Martin, E., Rosenthal, R. E. and Fiskum, G. (2005). Pyruvate dehydrogenase complex: metabolic link to ischemic brain injury and target of oxidative stress. J. Neurosci. Res. 79, 240-247.

Matsudaira, P. (2007). Molecular cell biology. New York, NY: W. H. Freeman. Mazzocco, M., Maffei, M., Egeo, A., Vergano, A., Arrigo, P., Di Lisi, R., Ghiotto, F. and Scartezzini, P. (2002). The identification of a novel human homologue of the SH3 binding glutamic acid-rich (SH3BGR) gene establishes a new family of highly conserved small proteins related to thioredoxin superfamily. Gene. 291, 233-239.

McCall, M. R. and Frei, B. (1999). Can antioxidant vitamins materially reduce oxidative damage in humans? Free Radical Biol. Med. 26, 1034-1053.

McDonagh, B. and Sheehan, D. (2007). Effect of oxidative stress on protein thiols in the blue mussel Mytilus edulis: proteomic identification of target proteins. Proteomics. 18, 3395-3403.

Mei, Y., Thompson, M. D., Shiraishi, Y., Cohen, R. A. and Tong, X. (2014). Sarcoplasmic/endoplasmic reticulum $\mathrm{Ca}^{2+}$ ATPase $\mathrm{C} 674$ promotes ischemia- and hypoxia-induced angiogenesis via coordinated endothelial cell and macrophage function. J. Molec. Cell. Cardiol. 76, 275-282.

Menge, B. A, Berlow, E. L., Blanchette, C. A, Navarrete, S. A, Yamada, B., Monographs, S. E. and Aug, N. (1994). The keystone species concept: variation in interaction strength in a rocky intertidal habitat. Ecol. Soc. Amer. 64, 249-286. 
Menge, B. A., Chan, F. and Lubchenco, J. (2008). Response of a rocky intertidal ecosystem engineer and community dominant to climate change. Ecol. Letters. 11, 151-162.

Michel, P. E., Reymond, F., Arnaud, I. L., Josserand, J., Girault, H. H. and Rossier, J. S. (2003). Protein fractionation in a multicompartment device using Off-GelTM isoelectric focusing. Electrophoresis. 24, 3-11.

Moon, T. W. and Pritchard, A. W. (1970). Metabolic adaptations in verticallyseparated populations of Mytilus californianus Conrad. J. Exp. Mar. Biol. Ecol. 5, 35-46.

Moore, H. J. (1971). The structure of the latero-frontal cirri on the gills of certain lamellibranch molluscs. Mar. Biol. 11, 23-27.

Morris, R. H., D. P. Abbott and E. C. Haderlie. (1980). Intertidal invertebrates of California. Stanford, CA: Stanford University Press.

Müller, M., Mentel, M., van Hellemond, J. J., Henze, K., Woehle, C., Gould, S. B., Yu, R.-Y., van der Giezen, M., Tielens, A. G. M. and Martin, W. F. (2012). Biochemistry and evolution of anaerobic energy metabolism in eukaryotes. Microbiol. Molec. Biol. Rev. 76, 444-495.

Murphy, M. P. (2012). Mitochondrial thiols in antioxidant protection and redox signaling: distinct roles for glutathionylation and other thiol modifications. Antioxid. Redox Signal. 16, 476-95.

Newell, R. C. (1979). Biology of intertidal animals. Kent, UK: Marine Ecological Surveys Ltd. 
Ng, T. B., Fai Cheung, R. C., Wing Ng, C. C., Fang, E. F. and Wong, J. H. (2015). A review of fish lectins. Curr. Prot. Peptide Sci. 16, 337-351.

Nikapitiya, C., De Zoysa, M., Whang, I., Kim, S. J., Choi, C. Y., Lee, J. S. and Lee, J. (2010). Characterization and expression analysis of EF hand domain-containing calcium-regulatory gene from disk abalone: calcium homeostasis and its role in immunity. Fish Shellfish Immunol. 29, 334342.

Ort, B. S. and Pogson, G. H. (2007). Molecular population genetics of the male and female mitochondrial DNA molecules of the California sea mussel, Mytilus californianus. Genetics. 177, 1087-1099.

Paine, R. T. (1966). Food web complexity and species diversity. Am. Nat. 118, $65-75$.

Paine, R. T. (1974). Intertidal community structure: experimental studies on the relationship between a dominant competitor and its principal predator. Oecologia. 5, 93-120.

Palmer, J. D. (1973). Tidal rhythms: the clock control of the rhythmic physiology of marine organisms. Biol. Rev. 48, 377-418.

Palmer, J. D. (1975). Biological clocks of the tidal zone. Sci. Am. 232, 70-79.

Perkins, D. N., Pappin, D. J. C., Creasy, D. M. and Cottrell, J. S. (1999). Probability-based protein identification by searching sequence databases using mass spectrometry data. Electrophoresis. 20, 3551-3567. 
Petes, L. E., Menge, B. A. and Harris, A. L. (2008). Intertidal mussels exhibit energetic trade-offs between reproduction and stress resistance. Ecol. Monogr. 78, 387-402.

Pluquet, O., Pourtier, A. and Abbadie, C. (2015). The unfolded protein response and cellular senescence. A review in the theme: cellular mechanisms of endoplasmic reticulum stress signaling in health and disease. Am. J. Physiol. - Cell Physiol. 308, C415-C425.

Prosser, C. L. (1991). Comparative animal physiology. Environmental and Metabolic Physiology. New York, NY: Wiley.

Rabilloud, T. (2002). Two-dimensional gel electrophoresis in proteomics: old, old fashioned, but still climbs up the mountains. Proteomics. 2, 3-10.

Rencher, A. C. and Christensen, W. F. (2012). Introduction in methods of multivariate analysis. Hoboken, NJ: John Wiley \& Sons, Inc.

Righetti, P. G., Gianazza, E. and Bjellqvist, B. (1983). Modern aspects of isoelectric focusing: two-dimensional maps and immobilized pH gradients. J. Biochem. Biophys. Methods. 8, 89-108.

Riisgård, H. U., Jørgensen, B. H., Lundgreen, K., Storti, F., Walter, J. H., Meyer, K. E. and Larsen, P. S. (2011). The exhalant jet of mussels Mytilus edulis. Mar. Ecol. Prog. Ser. 437, 147-164.

Rivera-Ingraham, G. A., Rocchetta, I., Bickmeyer, U., Meyer, S. and Abele, D. (2016). Spatial compartmentalization of free radical formation and mitochondrial heterogeneity in bivalve gills revealed by live-imaging techniques. Front. in Zool. 13, 4. 
Rivera-Ingraham, G. A., Rocchetta, I., Meyer, S. and Abele, D. (2013). Oxygen radical formation in anoxic transgression and anoxia-reoxygenation: foe or phantom? Experiments with a hypoxia tolerant bivalve. Mar. Environ. Res. 92, 110-119.

Roberts, D. A., Hofmann, G. E. and Somero, G. N. (1997). Heat-shock protein expression in Mytilus californianus: Acclimatization (seasonal and tidalheight comparisons) and acclimation effects. Biol. Bull. 192, 309-320.

Sasaki, T. and Takai, Y. (1998). The rho small g protein family-rho GDI system as a temporal and spatial determinant for cytoskeletal control. Biochem. Biophys. Res. Commun. 245, 641-645.

Schick, J. M., Gnaiger, E., Widdows, J., Bayne, B. L. and de Zwaan, A. (1986), Activity and metabolism in the mussel Mytilus edulis L. during intertidal hypoxia and aerobic recovery. Physiol. Zool. 59, 627-642.

Seed, R. (1992). Population and community ecology of Mytilus. The mussel Mytilus. 87-169.

Seidler, U., Singh, A. K., Cinar, A., Chen, M., Hillesheim, J., Hogema, B. and Riederer, B. (2009). The role of the NHERF family of PDZ scaffolding proteins in the regulation of salt and water transport: lessons learned from knockout mice. Annals New York Acad. Sci. 1165, 249-260. 
Seo, J., Jeong, J., Kim, Y. M., Hwang, N., Paek, E. and Lee, K.-J. (2008).

Strategy for comprehensive identification of post-translational modifications in cellular proteins, including low abundant modifications: application to glyceraldehyde-3-phosphate dehydrogenase. J. Proteome Res. 7, 587-602.

Shaw, M. M. and Riederer, B. M. (2003). Sample preparation for two-dimensional gel electrophoresis. Proteomics. 3, 1408-1417.

Shenolikar, S. and Weinman, E.J. (2001). NHERF: targeting and trafficking membrane proteins. Am. J. Physiol. Renal Physiol. 280, F389-95.

Shick, J. M., Gnaiger, E., Widdows, J., Bayne, B. L. and de Zwaan, A. (1986). Activity and metabolism in the mussel Mytilus edulis L. during intertidal hypoxia and aerobic recovery. Physiol. Zool. 59, 627-642.

Shick, J. M., Widdows, J. and Gnaiger, E. (1988). Calorimetric studies of behavior, metabolism and energectics of sessile intertidal animals. Am. Zool. 28, 161-181.

Singh, R., Lemire, J., Mailloux, R. J. and Appanna, V.D. (2008). A novel strategy involved anti-oxidative defense: the conversion of NADH into NADPH by a metabolic network. PLOS ONE. 3, e2682.

Sokolova, I. M. (2013). Energy-limited tolerance to stress as a conceptual framework to integrate the effects of multiple stressors. Integr. Comp. Biol. $53,597-608$. 
Sokolova, I. M., Frederich, M., Bagwe, R., Lannig, G. and Sukhotin, A. A. (2012). Energy homeostasis as an integrative tool for assessing limits of environmental stress tolerance in aquatic invertebrates. Mar. Environ. Res. 79, 1-15.

Somero, G. N. (2002). Thermal physiology and vertical zonation of intertidal animals: optima, limits, and costs of living. Integr. Comp. Biol. 42, 780796.

Somero, G. N., Beers, J. M., Chan, F., Hill, T. M., Klinger, T. and Litvin, S. Y. (2016). What changes in the carbonate system, oxygen, and temperature portend for the northeastern Pacific Ocean: a physiological perspective. BioSci. 66, 14-26.

Song, M., Shao, H., Mujeeb, A., James, T. L. and Miller, W. L. (2001). Gelsolin, a multifunctional actin regulatory protein. J. Biol. Chem. 158, 151-158.

Stamnes, M. A. and Rothman, J. E. (1993). The binding of AP-1 clathrin adaptor particles to Golgi membranes requires ADP-ribosylation factor, a small GTP-binding protein. Cell. 73, 999-1005.

Sternlicht, H., Farr, G. W., Sternlicht, M. L., Driscoll, J. K., Willison, K. and Yaffe, M. B. (1993). The t-complex polypeptide 1 complex is a chaperonin for tubulin and actin in vivo. PNAS USA. 90, 9422-9426.

Stillman, J. H. and Barnwell, F. H. (2004). Relationship of daily and circatidal activity rhythms of the fiddler crab, Uca princeps, to the harmonic structure of semidiurnal and mixed tides. Mar. Biol. 144, 473-482. 
Ström, Å., Olin, A. I., Aspberg, A. and Hultgårdh-Nilsson, A. (2006). Fibulin-2 is present in murine vascular lesions and is important for smooth muscle cell migration. Cardiovasc. Res. 69, 755-763.

Suckau, D., Resemann, A., Schuerenberg, M., Hufnagel, P., Franzen, J. and Holle, A. (2003). A novel MALDI LIFT-TOF/TOF mass spectrometer for proteomics. Analytical Bioanalytical Chem. 376, 952-965.

Suprenant, K. A., Bloom, N., Fang, J. and Lushington, G. (2007). The major vault protein is related to the toxic anion resistance protein (TelA) family. J. Exp. Biol. 210, 946-955.

Tahara, E. B., Barros, M. H., Oliveira, G. A., Netto, L. E. S. and Kowaltowski, A. J. (2007). Dilipoyl dehydrogenase as a source of reactive oxygen species inhibited by caloric restriction and involved in Saccharomyces cerevisiae aging. FASEB J. 21, 274-283.

Thannical, V. J. (2000). Reactive oxygen species in cell signaling. Am. J. Physiol. Lung Cell. Molec. Physiol. 279, 1005-1028.

Tomanek, L. (2008). The importance of physiological limits in determining biogeographical range shifts due to global climate change: the heat-shock response. Physiol. Biochem. Zool. 81, 709-717.

Tomanek, L. (2010). The role of oxidative stress in setting thermal tolerance limits in Mytilus. Comp. Biochem. Physiol. Part A: Molec. Integr. Physiol. 157, S43. 
Tomanek, L. (2012). Environmental proteomics of the mussel Mytilus: implications for tolerance to stress and change in limits of biogeographic ranges in response to climate change. Integr. Comp. Biol. 52, 648-664.

Tomanek, L. (2014). Proteomics to study adaptations in marine organisms to environmental stress. J. Proteomics. 105, 92-106.

Tomanek, L. (2015). Proteomic responses to environmentally induced oxidative stress. J. Exp. Biol. 218, 1867-1879.

Tomanek, L. and Zuzow, M. J. (2010). The proteomic response of the mussel congeners Mytilus galloprovincialis and M. trossulus to acute heat stress: Implications for thermal tolerance and metabolic costs of thermal stress. J. Exp. Biol. 213, 3559-3574.

Tomanek, L., Zuzow, M. J., Ivanina, A. V, Beniash, E. and Sokolova, I. M. (2011). Proteomic response to elevated $\mathrm{PCO}_{2}$ level in eastern oysters, Crassostrea virginica: evidence for oxidative stress. J. Exp. Biol. 214, $1836-1844$.

Tretter, L. and Adam-Vizi, V. (2000). Inhibition of Krebs cycle enzymes by hydrogen peroxide: a key role of $\alpha$-ketoglutarate dehydrogenase in limiting NADH production under oxidative stress. J. Neurosci.: Official J. Society Neurosci. 20, 8972-8979.

Tu, B. P. and Weissman, J. S. (2004). Oxidative protein folding in eukaryotes: mechanisms and consequences. J. Cell Biol. 164, 341-346. 
Ubuka, T., Masuoka, N., Yoshida, S. and Ishino, K. (1987). Determination of isoelectric point value of 3-mercaptopyruvate sulfurtransferase by isoelectric focusing using ribonuclease A-glutathione mixed disulfides as standards. Anal. Biochem. 167, 284-289.

Valderrama, F., Durán, J. M., Babià, T., Barth, H., Renau-Piqueras, J. and Egea, G. (2001). Actin microfilaments facilitate the retrograde transport from the Golgi complex to the endoplasmic reticulum in mammalian cells. Traffic. 2, 717-726.

Veldhoen, N., Ikonomou, M. G. and Helbing, C. C. (2012). Molecular profiling of marine fauna: integration of omics with environmental assessment of the world's oceans. Ecotoxicol. Environ. Safety. 76, 23-38.

Vermeij, G. J. (1991). Anatomy of an invasion: the trans-Arctic interchange.

Paleobiol. 17, 281-307.

Walden, W. E. (2002). From bacteria to mitochondria: aconitase yields surprises. PNAS USA. 99, 4138-4140.

Walsh, C. T., Garneau-Tsodikova, S. and Gatto, G. J. Jr. (2005). Protein posttranslational modifications: the chemistry of proteome diversifications. Angew. Chem. Int. Ed. Engl. 44, 7342-7372.

Wang, W. and Widdows, J. (1993). Metabolic responses of the common mussel Mytilus edulis to hypoxia and anoxia. Mar. Ecol. Prog. Ser. 95, 205-214. 
Welker, A. F., Moreira, D. C., Campos, Élida G. and Hermes-Lima, M. (2013). Role of redox metabolism for adaptation of aquatic animals to drastic changes in oxygen availability. Comp. Biochem. Physiol. - A Molec. Integr. Physiol. 165, 384-404.

Widdows, J. (1976). Physiological adaptation of Mytilus edulis to cyclic temperatures. J. Comp. Physiol. 105, 115-128.

Widdows, J., Bayne, B. L., Livingstone, D. R., Newell, R. I. E. and Donkin, P. (1979). Physiological and biochemical responses of bivalve molluscs to exposure to air. Comp. Biochem. Physiol., Part A. 62, 301- 308.

Widdows, J. and Shick, J. M. (1985). Physiological responses of Mytilus edulis and Cardium edule to aerial exposure. Mar. Biol. 85, 217-232.

Wootton, J. T. (2002). Indirect effects in complex ecosystems: recent progress and future challenges. J. Sea Res. 48, 157-172.

Yang, P., Diener, D. R., Yang, C., Kohno, T., Pazour, G. J., Dienes, J. M., Agrin, N. S., King, S. M., Sale, W. S., Kamiya, R. et al. (2006). Radial spoke proteins of Chlamydomonas flagella. J. of Cell Sci. 119, 1165-1174.

Yin, Y. Huang, J., Paine, M. L., Reinhold, V. N. and Chasteen, N. D. (2005). Structural characterization of the major extrapallial fluid protein of the mollusc Mytilus edulis: implications for function. Biochem. 44, 1072010731.

Zaldibar, B., Cancio, I. and Marigomez, I. (2004). Circatidal variation in epithelial cell proliferation in the mussel digestive gland and stomach. Cell Tissue Res. 318, 395-402. 
Zhang, Y., Liang, S., He, J., Bai, Y., Niu, Y., Tang, X., Li, D. and Chen, Q. (2015). Oxidative stress and antioxidant status in a lizard Phrynocephalus vlangalii at different altitudes or acclimated to hypoxia. Comp. Biochem. Physiol. Part A: Molec. Integrative Physiol. 190, 9-14.

Zhang, W., Wang, Y., Lee, O., Tian, R., Cao, H., Gao, Z., Li, Y., Yu, L., Xu, Y. and Qian, P-Y. (2013). Adaptation of intertidal biofilm communities is driven by metal ion and oxidative stresses. Sci. Reports. 3, 3180.

Zhao, H. T., Endo, S., Ishikura, S., Chung, R., Hogg, P. J., Hara, A. and ElKabbani, O. (2009). Structure/function analysis of a critical disulfide bond in the active site of I-xylulose reductase. Cell. Molec. Life Sci. 66, 15701579. 


\section{APPENDIX}

Table 1A. PCA: Acclimation. Positive and negative loadings for principal components 1 and 2 of identified proteins significant for an acclimation effect.

\begin{tabular}{|c|c|c|c|c|}
\hline \multirow{2}{*}{$\begin{array}{l}\text { Component } \\
\text { loading rank }\end{array}$} & \multicolumn{2}{|l|}{ Principal component 1} & \multicolumn{2}{|l|}{ Principal component 2} \\
\hline & Protein (spot ID) & Loading value & Protein (spot ID) & Loading value \\
\hline \multicolumn{5}{|c|}{ Positive loadings for acclimation effect } \\
\hline 1 & Major vault protein (5) & 1.70427 & Tropomyosin (248) & 2.28951 \\
\hline 2 & Tubulin $(\alpha)(110)$ & 1.3931 & sHsp 24.1 (266) & 2.26206 \\
\hline 3 & Heavy metal-binding protein (190) & 1.36306 & sHsp 24.1 (268) & 2.22055 \\
\hline 4 & Calreticulin (133) & 1.34022 & sHsp 24.1 (271) & 2.17625 \\
\hline 5 & sHsp 24.1 (109) & 1.27086 & sHsp 24.1 (264) & 2.12666 \\
\hline 6 & GRP78 (73) & 1.26272 & sHsp 24.1 (278) & 1.6187 \\
\hline 7 & NADP-dependent isocitrate dehydrogenase (176) & 1.246 & sHsp 24.1 (258) & 1.61438 \\
\hline 8 & sHsp $24.1(106)$ & 1.23245 & L-xylulose reductase (293) & 1.60822 \\
\hline 9 & Tubulin $(\alpha)(11)$ & 1.21314 & sHsp 24.1 (259) & 1.60737 \\
\hline 10 & T-complex protein $(\alpha)(107)$ & 1.15945 & GRP78 (73) & 1.3233 \\
\hline \multicolumn{5}{|c|}{ Negative loadings for acclimation effect } \\
\hline 1 & sHsp 24.1 (254) & -1.5105 & ATP synthase $(\alpha)(143)$ & -1.87406 \\
\hline 2 & F-actin capping protein $(\alpha)(229)$ & -1.40844 & Tubulin $(\beta)(124)$ & -1.36259 \\
\hline 3 & Peptidyl-prolyl cis-trans isomerase $(\beta)(285)$ & -1.38515 & Tubulin $(\alpha)(110)$ & -1.33399 \\
\hline 4 & Progesterone receptor (324) & -1.33724 & Heavy metal-binding protein $(190)$ & -1.22795 \\
\hline 5 & Cdc42 (333) & -1.29696 & Apextrin (319) & -1.12808 \\
\hline 6 & Actin (198) & -1.22307 & Heavy metal-binding protein (194) & -1.11635 \\
\hline 7 & Pyruvate dehydrogenase $(\alpha)(160)$ & -1.21597 & NHE-RF3 (92) & -1.10275 \\
\hline 8 & Eukaryotic translation initiation factor $3(233)$ & -1.17491 & Methylmalonate-semialdehyde dehydrogenase (29) & -1.08494 \\
\hline 9 & Mitochondrial-processing peptidase ( $\beta$ ) (151) & -1.14017 & NADP-dependent isocitrate dehydrogenase (176) & -1.07373 \\
\hline 10 & Proteasome $(\alpha)(272)$ & -1.13123 & Eukaryotic translation initiation factor $3(233)$ & -1.0299 \\
\hline
\end{tabular}

Table 1B. PCA: Oxygen. Positive and negative loadings for principal components 1 and 2 of identified proteins significant for an oxygen effect.

\begin{tabular}{|c|c|c|c|c|}
\hline \multirow{2}{*}{$\begin{array}{l}\text { Component } \\
\text { loading rank }\end{array}$} & \multicolumn{2}{|l|}{ Principal component 1} & \multicolumn{2}{|l|}{ Principal component 2} \\
\hline & Protein (spot ID) & Loading value & Protein (spot ID) & Loading value \\
\hline \multicolumn{5}{|c|}{ Positive loadings for oxygen effect } \\
\hline 1 & Heavy metal-binding protein (199) & 1.35059 & F-actin capping protein $(\alpha)(229)$ & 2.05356 \\
\hline 2 & ATP synthase $(\beta)(152)$ & 1.3294 & Tubulin $(\beta)(125)$ & 1.6847 \\
\hline 3 & Hsp70 (66) & 1.26172 & Tubulin ( $\beta)(127)$ & 1.08296 \\
\hline 4 & Tubulin $(\beta)(125)$ & 0.89143 & Aconitase (61) & 0.99337 \\
\hline 5 & Tubulin ( $\beta)(127)$ & 0.57712 & L-xylulose reductase $(302)$ & 0.98331 \\
\hline 6 & Dynein light chain (roadblock) (360) & 0.46017 & Dynein light chain (roadblock) (360) & 0.64381 \\
\hline 7 & sHsp $24.1(106)$ & 0.08869 & Heterogenous nuclear ribonucleoprotein A/B (369) & 0.45629 \\
\hline \multicolumn{5}{|c|}{ Negative loadings for oxygen effect } \\
\hline 1 & sHsp 24.1 (207) & -1.51993 & sHsp 24.1 (106) & -1.91126 \\
\hline 2 & Heterogenous nuclear ribonucleoprotein A/B (369) & -1.28774 & ATP synthase $(\alpha)(136)$ & -1.16566 \\
\hline 3 & Arginine kinase (193) & -1.24189 & ATP synthase $(\beta)(152)$ & -0.75526 \\
\hline 4 & L-xylulose reductase (293) & -1.23404 & Hsp70 (66) & -0.64454 \\
\hline 5 & sHsp 24.1 (255) & -1.18434 & Actin (145) & -0.52315 \\
\hline 6 & Aconitase (61) & -1.11862 & sHsp 24.1 (207) & -0.41943 \\
\hline 7 & L-xylulose reductase (302) & -0.81212 & Peptidyl-prolyl cis-trans isomerase ( $\beta$ ) (301) & -0.23802 \\
\hline
\end{tabular}


Table 1C. PCA: Interaction. Positive and negative loadings for principal components 1 and 2 of identified proteins significant for an interaction (acclimation by oxygen) effect.

\begin{tabular}{|c|c|c|c|c|}
\hline \multirow{2}{*}{$\begin{array}{l}\text { Component } \\
\text { loading rank }\end{array}$} & \multicolumn{2}{|l|}{ Principal component 1} & \multicolumn{2}{|l|}{ Principal component 2} \\
\hline & Protein (spot ID) & Loading value & Protein (spot ID) & Loading value \\
\hline \multicolumn{5}{|c|}{ Positive loadings for interaction effect } \\
\hline 1 & Cytochrome b-C1 (156) & 1.46805 & sHsp $24.1(254)$ & 2.08402 \\
\hline 2 & Aldehyde dehydrogenase $(\mathrm{m})(132)$ & 1.30819 & Aconitase (57) & 1.41665 \\
\hline 3 & Tubulin ( $\alpha)(343)$ & 1.15168 & sHsp 24.1 (225) & 1.13919 \\
\hline 4 & Triosephosphate isomerase (292) & 0.95097 & Hsp70 (27) & 1.08299 \\
\hline 5 & Actin (173) & 0.85254 & sHsp 24.1 (252) & 1.06492 \\
\hline 6 & ATP synthase $(\alpha)(143)$ & 0.84661 & sHsp 24.1 (207) & 0.95803 \\
\hline 7 & Dynein light chain (roadblock) $(360)$ & 0.69711 & Aconitase (61) & 0.86134 \\
\hline 8 & a-aminoadipic semialdehyde dehydrogenase (139) & 0.68325 & Tubulin ( $\alpha)(343)$ & 0.59203 \\
\hline 9 & Malate dehydrogenase $(\mathrm{m})(232)$ & 0.58861 & Dynein light chain (roadblock) (360) & 0.41476 \\
\hline 10 & sHsp $24.1(254)$ & 0.14413 & Triosephosphate isomerase (292) & 0.30101 \\
\hline \multicolumn{5}{|c|}{ Negative loadings for interaction effect } \\
\hline 1 & T-complex protein $(\alpha)(107)$ & -1.61157 & ATP synthase $(\alpha)(143)$ & -1.78594 \\
\hline 2 & Protein disulfide isomerase (105) & -1.44839 & Calreticulin (133) & -1.59835 \\
\hline 3 & EF-hand domain-containing protein (64) & -1.38004 & Methylmalonate-semialdehyde dehydrogenase (119) & -1.16532 \\
\hline 4 & Malate dehydrogenase (c) (219) & -1.32986 & Protein disulfide isomerase (105) & -0.96142 \\
\hline 5 & Tektin-4 (142) & -1.26193 & a-aminoadipic semialdehyde dehydrogenase (139) & -0.91061 \\
\hline 6 & Calreticulin (133) & -0.96047 & T-complex protein $(\alpha)(107)$ & -0.78742 \\
\hline 7 & sHsp 24.1 (252) & -0.87403 & Cytochrome b-C1 (156) & -0.73513 \\
\hline 8 & sHsp 24.1 (225) & -0.85964 & EF-hand domain-containing protein (64) & -0.7195 \\
\hline 9 & sHsp $24.1(207)$ & -0.85258 & Actin (173) & -0.47202 \\
\hline 10 & Methylmalonate-semialdehyde dehydrogenase (119) & -0.82609 & sHsp $24.1(277)$ & -0.13213 \\
\hline
\end{tabular}


Table 2. Protein identification. Protein identification with estimated and predicted molecular mass $(\mathrm{kD})$, isoelectric point $(\mathrm{pl})$, GenBank identifier, MASCOT score, matched peptides, sequence coverage, and putative functional category.

\begin{tabular}{|c|c|c|c|c|c|c|c|c|c|c|}
\hline $\begin{array}{c}\text { Spot } \\
\text { ID }\end{array}$ & Protein ID & $\begin{array}{c}\text { Estimated } \\
\mathrm{MW}\end{array}$ & $\begin{array}{c}\text { Estimated } \\
\mathrm{pl}\end{array}$ & $\begin{array}{c}\text { Predicted } \\
\mathrm{MW}\end{array}$ & $\begin{array}{c}\text { Predicted } \\
\mathrm{pl}\end{array}$ & GenBank ID & $\begin{array}{l}\text { MASCOT } \\
\text { Score }\end{array}$ & $\begin{array}{r}\text { Peptide } \\
\text { Matches }\end{array}$ & $\begin{array}{l}\text { Identity } \\
(\%)\end{array}$ & Functional Category \\
\hline 4 & Major vault protein & 95 & 6.11 & 96 & 5.58 & gi|405974681|EKC39307.1 & 120 & 4 & 86 & Nuclear Transport \\
\hline 5 & Major vault protein & 94 & 5.98 & 96 & 5.58 & gi|405974681|ЕKC39307.1 & 116 & 4 & 86 & Nuclear Transport \\
\hline 6 & Major vault protein & 95 & 6.04 & 96 & 5.58 & gi|405974681|ЕКС39307.1 & 98 & 4 & 86 & Nuclear Transport \\
\hline 7 & Succinate dehydrogenase & 83 & 6.00 & 73 & 6.04 & gi|524896638|XP_005104791.1 & 61 & 4 & 86 & Energy Metabolism \\
\hline 9 & HSP70 & 84 & 6.12 & 69 & 5.35 & gi|76780606|САH04106.1 & 111 & 3 & 98 & Molecular Chaperone \\
\hline 10 & Tubulin (a) & 77 & 6.06 & 40 & 6.20 & gi|568249318|ETN59126.1 & 87 & 4 & 99 & Cytoskeletal \\
\hline 11 & $\begin{array}{l}\text { Tubulin }(\alpha) \\
\text { Aldehyde dehydrogenase, }\end{array}$ & 78 & 5.92 & 40 & 6.20 & gi|568249318|ETN59126.1 & 84 & 2 & 99 & Cytoskeletal \\
\hline 14 & $\begin{array}{l}\text { mitochondrial } \\
\text { mase }\end{array}$ & 70 & 5.93 & 57 & 6.18 & gi|405965075|ЕKC30500.1 & 153 & 4 & 72 & Oxidative Stress \\
\hline 15 & Gelsolin & 64 & 5.92 & 42 & 5.22 & gi|41349563|CAF2186 & 188 & 4 & 58 & Cytoskeletal \\
\hline 17 & Gelsolin & 64 & 5.87 & 42 & 5.22 & gi|41349563|CAF21863.1 & 161 & 2 & 58 & Cytoskeletal \\
\hline 21 & Fibulin-2 & 100 & 5.61 & 13 & 5.94 & gi|405966512|ЕKC31789.1 & 66 & 2 & 50 & Extracellular Matrix \\
\hline 22 & Fibulin-2 & 99 & 5.66 & 125 & 5.94 & gi|405966512|ЕКС31789.1 & 84 & 2 & 50 & Extracellular Matrix \\
\hline 24 & Actin & 60 & 5.76 & 42 & 5.30 & gi|47116423|Q964E3.1 & 275 & 6 & 97 & Cytoskeletal \\
\hline 27 & HSP70 & 83 & 6.22 & 69 & 5.35 & gi|766780606|CAH04106.1 & 72 & 3 & 90 & Molecular Chaperone \\
\hline 29 & $\begin{array}{l}\text { Methyiralanate-semaladenyde } \\
\text { dehydrogenase }\end{array}$ & 71 & 6.25 & 57 & 6.48 & gi|405970294|ЕКС35210.1 & 255 & 5 & 83 & Energy Metabolism \\
\hline 43 & a-Aminoadipic semialdehyde synthase & 99 & 6.83 & 106 & 6.44 & gil156548972|XP_001607166.1 & 85 & 2 & 74 & Protein Degradation \\
\hline 45 & Major vault protein & 95 & 6.22 & 96 & 5.58 & gi|405974681|EKC39307.1 & 68 & 6 & 86 & Nuclear Transport \\
\hline 50 & GRP78 & 93 & 5.14 & 73 & 5.02 & gi|405968607|ЕКС33663.1 & 147 & 5 & 87 & Molecular Chaperone \\
\hline 53 & Aconitase & 94 & 6.37 & 85 & 6.84 & gil405964761|EKC30210.1 & 130 & 6 & 81 & Energy Metabolism \\
\hline 55 & Aconitase & 92 & 6.90 & 85 & 6.84 & gi|405964761|EKC30210.1 & 176 & 5 & 81 & Energy Metabolism \\
\hline 57 & Aconitase & 93 & 5.40 & 85 & 6.84 & gi|405964761|ЕKC30210.1 & 222 & 5 & 81 & Energy Metabolism \\
\hline 60 & Aconitase & 91 & 6.80 & 85 & 6.84 & gi|405964761|EKC30210.1 & 95 & 3 & 81 & Energy Metabolism \\
\hline 61 & Aconitase & 91 & 6.86 & 85 & 6.84 & gi|405964761|ЕKC30210.1 & 118 & 5 & 81 & Energy Metabolism \\
\hline 64 & EF-hand domain-containing protein & 85 & 6.68 & 74 & 6.23 & gi|405964721|EKC30173.1 & 118 & 2 & 83 & Homeostasis \\
\hline 65 & EF-hand domain-containing protein & 91 & 6.44 & 74 & 6.23 & gi|405964721|EKC30173.1 & 138 & 3 & 83 & Homeostasis \\
\hline 66 & HSP70 & 82 & 5.57 & 71 & 5.29 & gi|553303828|AGY56119.1 & 216 & 5 & 99 & Molecular Chaperone \\
\hline 69 & EF-hand domain-containing protein & 86 & 6.61 & 74 & 6.23 & gi|405964721|EKC30173.1 & 79 & 2 & 83 & Homeostasis \\
\hline 72 & GRP78 & 85 & 4.96 & 73 & 5.02 & gil405968607|EKC33663.1 & 64 & 3 & 87 & Molecular Chaperone \\
\hline 73 & GRP78 & 84 & 5.16 & 73 & 5.02 & gi|405968607|ЕКС3з663.1 & 124 & 4 & 87 & Molecular Chaperone \\
\hline 74 & HSP70 & 82 & 5.50 & 71 & 5.29 & gi|553303828|AGY56119.1 & 192 & 5 & 99 & Molecular Chaperone \\
\hline 76 & GRP78 & 86 & 5.00 & 73 & 5.02 & gi|405968607|EKC33663.1 & 64 & 3 & 87 & Molecular Chaperone \\
\hline 82 & HSP70 & 81 & 5.42 & 71 & 5.29 & gi|553303828|AGY56119.1 & 78 & 2 & 99 & Molecular Chaperone \\
\hline 92 & NHE-RF3 3 iry & 83 & 5.02 & 64 & 6.24 & gi|391336261|XP_003742500.1 & 89 & 4 & 34 & Ion Transport \\
\hline 93 & GRP78 & 83 & 5.06 & 73 & 5.02 & gi|405968607|EKC33663.1 & 197 & 5 & 80 & Molecular Chaperone \\
\hline 96 & 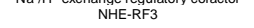 & 83 & 5.09 & 64 & 6.24 & gi|391336261|XP_003742500.1 & 89 & 4 & 34 & Ion Transport \\
\hline 98 & Intermediate filament protein & 80 & 5.70 & 69 & 5.38 & gi|405950795|EKC18758.1 & 61 & 2 & 60 & Cytoskeletal \\
\hline 101 & Glutamate dehydrogenase & 75 & 6.77 & 56 & 7.16 & gi|524893900|XP_005103458.1 & 104 & 5 & 81 & Urea Cycle \\
\hline 103 & PremRNA-processing factor 19 & 77 & 6.60 & 55 & 6.36 & gi|524891985|XP_005102524.1 & 90 & 5 & 79 & Molecular Chaperone \\
\hline 104 & Cytochrome oxidase & 78 & 5.00 & 23 & 4.94 & gi|328485137|AEB16862.1 & 62 & 3 & 100 & Energy Metabolism \\
\hline 105 & Protein disulfide isomerase $\mathrm{A} 3$ & 72 & 6.67 & 55 & 5.64 & gi|405967698|ЕКС32832.1 & 58 & 2 & 72 & Molecular Chaperone \\
\hline 106 & Small HSP 24.1 & 73 & 5.81 & 29 & 5.61 & gi|347545633|AEP02968.1 & 114 & 4 & 83 & Molecular Chaperone \\
\hline 107 & T-complex protein (a) & 76 & 6.64 & 60 & 5.96 & gil156550171|XP_001602512.1 & 68 & 4 & 78 & Molecular Chaperone \\
\hline 108 & Mitochondrial-processing peptidase & 70 & 5.34 & 53 & 5.60 & gi|332026485|EG|66611.1 & 106 & 4 & 54 & Protein Processing \\
\hline 109 & Small HSP 24.1 & 72 & 5.74 & 29 & 5.61 & gi|347545633|AEP02968.1 & 109 & 4 & 83 & Molecular Chaperone \\
\hline 110 & Tubulin (a) & 71 & 5.27 & 40 & 6.20 & gi|568249318|ETN59126.1 & 212 & 4 & 95 & Cytoskeletal \\
\hline 113 & HSP60 & 73 & 5.44 & 61 & 5.41 & gi|218683627|ACL00842.1 & 171 & 2 & 80 & Molecular Chaperone \\
\hline 117 & Fascin & 72 & 6.30 & 56 & 6.21 & gi|405961655|EKC27420.1 & 200 & 5 & 64 & Cytoskeletal \\
\hline 118 & $\begin{array}{l}\text { Small HSP } 24.1 \\
\text { Methylmalonate-semialdehyde }\end{array}$ & 72 & 6.55 & 29 & 5.61 & gi|347545633|AEP02968.1 & 114 & 4 & 83 & Molecular Chaperone \\
\hline 119 & $\begin{array}{l}\text { dehydrogenase } \\
\text { dent }\end{array}$ & 73 & 6.10 & 62 & 6.33 & gi $|363734519| X P_{2} 421260.2$ & 363 & 6 & 1 & Energy Metabolism \\
\hline 120 & T-complex protein ( $\eta$ ) & 72 & 6.52 & 25 & 5.59 & gi|405959601|EKC25616.1 & 57 & 3 & 84 & Molecular Chaperone \\
\hline
\end{tabular}




\begin{tabular}{|c|c|c|c|c|c|c|c|c|c|}
\hline 121 & Dihydrolipoyl dehydrogenase & 73 & 6.17 & 54 & 7.15 & gi|524878388|XP_005095881.1 & 213 & 4 & 78 \\
\hline 122 & Methylmalonate-semialdehyde dehydrogenase & 72 & 6.39 & 57 & 6.48 & gi|405970294|EKC35210.1 & 183 & 3 & 83 \\
\hline 123 & Aldehyde dehydrogenase, mitochondrial & 72 & 6.85 & 57 & 6.18 & gi|405965075|ЕКС30500.1 & 249 & 5 & 72 \\
\hline 124 & Tubulin ( $\beta$ ) & 69 & 4.91 & 50 & 4.76 & gi|194068375|BAG55008.1 & 87 & 3 & 99 \\
\hline 125 & Tubulin (B) & 71 & 6.41 & 50 & 4.76 & gi|410812227|AFV81455.1 & 155 & 7 & 99 \\
\hline 127 & Tubulin (B) & 72 & 6.34 & 41 & 5.51 & gi|390364950|XP_798772.3 & 147 & 2 & 99 \\
\hline 128 & Small HSP 24.1 & 74 & 6.62 & 28 & 5.61 & gi|347545633|AEP02968.1 & 130 & 5 & 83 \\
\hline 131 & Calreticulin & 69 & 5.38 & 70 & 5.38 & gil405950795|EKC18758.1 & 136 & 4 & 46 \\
\hline 132 & Aldehyde dehydrogenase, mitochondrial & 71 & 6.09 & 54 & 5.93 & gi|405965075|ЕKC30500.1 & 125 & 4 & 72 \\
\hline 133 & Calreticulin & 69 & 4.58 & 48 & 4.53 & gi|148717307|BAF63639.1 & 182 & 5 & 86 \\
\hline 135 & ATP synthase (a) & 69 & 6.90 & 60 & 8.92 & gi|116008297|ABJ51956.1 & 76 & 3 & 87 \\
\hline 136 & ATP synthase (a) & 69 & 6.76 & 60 & 8.92 & gi|157131648|XP_001655906.1 & 293 & 7 & 82 \\
\hline 137 & Protein disulfide isomerase $\mathrm{A} 6$ & 70 & 5.80 & 47 & 5.14 & gi|405951637|EKC19533.1 & 92 & 2 & 72 \\
\hline 139 & $\alpha$-Aminoadipic semialdehyde dehydrogenase & 69 & 6.49 & 55 & 5.85 & gi|405978696|EKC43065.1 & 175 & 3 & 81 \\
\hline 140 & Phosphoglycerate kinase 1 & 68 & 5.98 & 43 & 7.59 & gi|405963233|ЕKC28824.1 & 198 & 6 & 81 \\
\hline 142 & Tektin-4 & 68 & 5.78 & 52 & 5.53 & gi|405967050|ЕКС32264.1 & 137 & 5 & 86 \\
\hline 143 & ATP synthase (a) & 69 & 5.61 & 60 & 8.92 & gi|116008297|ABJ51956.1 & 125 & 3 & 87 \\
\hline 145 & Actin & 68 & 6.21 & 47 & 5.71 & gi|340369468|XP_003383270.1 & 249 & 5 & 84 \\
\hline 147 & Actin & 60 & 5.54 & 42 & 5.36 & gi|47116422|Q964E2.1 & 397 & 6 & 97 \\
\hline 148 & RuvB & 66 & 6.63 & 50 & 5.70 & gi|72014808|XP_782589.1 & 56 & 2 & 87 \\
\hline 151 & Mitochondrial-processing peptidase ( $\beta$ ) & 66 & 6.16 & 53 & 5.66 & gi|332026485|EG166611.1 & 106 & 4 & 54 \\
\hline 152 & ATP synthase ( $\beta$ ) & 65 & 5.08 & 55 & 5.33 & gi|307181472|EFN69064.1 & 792 & 11 & 82 \\
\hline 156 & Cytochrome b-C1 complex & 64 & 5.63 & 49 & 6.73 & gi|591371747|XP_007060684.1 & 333 & 7 & 42 \\
\hline 158 & Gelsolin & 64 & 6.28 & 17 & 4.93 & gi|390365961|XP_792301.2 & 366 & 7 & 73 \\
\hline 160 & Pyruvate dehydrogenase (a) & 61 & 6.78 & 49 & 6.83 & gi|405953655|ЕKC21276.1 & 79 & 3 & 70 \\
\hline 161 & Rab GDP dissociation inhibitor ( $\beta$ ) & 65 & 6.36 & 50 & 5.57 & gi|405976470|EKC40976.1 & 405 & 7 & 74 \\
\hline 162 & Citrate synthase & 63 & 6.89 & 49 & 6.47 & gi|405970598|ЕKC35491.1 & 120 & 4 & 80 \\
\hline 163 & Actin & 64 & 5.80 & 42 & 5.30 & gi|405973339|ЕКС38058.1 & 67 & 3 & 97 \\
\hline 167 & Actin & 63 & 6.23 & 42 & 5.29 & gi|385145402|CCG28026.1 & 98 & 2 & 87 \\
\hline 171 & Actin & 59 & 5.45 & 42 & 5.36 & gi|47116422|Q964E2.1 & 317 & 6 & 97 \\
\hline 172 & Actin & 60 & 5.64 & 42 & 5.29 & gi|385145402|CCG28026.1 & 92 & 2 & 87 \\
\hline 173 & Actin & 60 & 6.08 & 42 & 5.36 & gi|47116422|Q964E2.1 & 88 & 3 & 97 \\
\hline 174 & Actin & 61 & 6.13 & 42 & 5.36 & gi|47116422|Q964E2.1 & 129 & 4 & 97 \\
\hline 176 & NADP-dependent isocitrate dehydrogenase & 61 & 6.69 & 50 & 6.80 & gi|385268543|AFI56366.1 & 228 & 7 & 99 \\
\hline 177 & Astacin & 61 & 4.86 & 37 & 5.18 & gi|405978762|EKC43126.1 & 73 & 3 & 59 \\
\hline 179 & Actin & 61 & 6.32 & 42 & 5.36 & gi|47116422|Q964E2.1 & 101 & 3 & 97 \\
\hline 180 & ERK2 (MAP kinase) & 59 & 6.43 & 41 & 6.42 & gi|399932277|AFP57674.1 & 273 & 7 & 89 \\
\hline 181 & $\beta$-ureidopropionase & 60 & 6.55 & 42 & 6.34 & gi|405951534|EKC19438.1 & 134 & 3 & 82 \\
\hline 182 & Isovaleryl-CoA dehydrogenase & 59 & 6.57 & 47 & 8.35 & gi|524871584|XP_005092564.1 & 78 & 3 & 83 \\
\hline 185 & 40 S ribosomal protein $\mathrm{SA}$ & 58 & 4.73 & 33 & 5.24 & gi|229891605|A3RLT6.1 & 197 & 5 & 94 \\
\hline 190 & Heavy metal-binding protein & 53 & 5.21 & 28 & 5.33 & gil426207677|AFY13478.1 & 83 & 2 & 98 \\
\hline 193 & Arginine kinase & 56 & 6.80 & 39 & 8.84 & gi|347450694|AEO94538.1 & 78 & 3 & 78 \\
\hline 194 & Heavy metal-binding protein & 54 & 5.13 & 28 & 5.33 & gi|426207677|AFY13478.1 & 83 & 2 & 98 \\
\hline 195 & HSP40 & 57 & 5.93 & 40 & 5.79 & gi|524887319|XP_005100247.1 & 63 & 2 & 80 \\
\hline 198 & Actin & 56 & 6.10 & 42 & 5.36 & gi|47116422|Q964E2.1 & 110 & 3 & 97 \\
\hline 199 & Heavy metal-binding protein & 53 & 5.31 & 28 & 5.33 & gi|426207677|AFY13478.1 & 83 & 2 & 98 \\
\hline 207 & Small HSP 24.1 & 53 & 4.67 & 29 & 5.61 & gi|347545633|AEP02968.1 & 67 & 2 & 83 \\
\hline 213 & 40S Ribosomal protein SA & 52 & 4.80 & 33 & 5.24 & gi|229891605|A3RLT6.1 & 112 & 6 & 94 \\
\hline 218 & $N(G), N(G)$-dimethylarginine dimethylamino hydrolase 1 & 49 & 6.43 & 40 & 6.29 & gi|405975453|EKC40017.1 & 231 & 5 & 55 \\
\hline 219 & Malate dehydrogenase (cytosolic) & 50 & 6.55 & 36 & 6.15 & gi|73656362|AAZ79368.1 & 143 & 3 & 99 \\
\hline 222 & Radial spoke head protein 9 & 49 & 6.17 & 31 & 5.20 & gi|405959092|EKC25160.1 & 112 & 3 & 76 \\
\hline 225 & Small HSP 24.1 & 48 & 5.84 & 29 & 5.61 & gi|347545633|AEP02968.1 & 80 & 3 & 93 \\
\hline 229 & F-actin-capping protein (a) & 48 & 6.34 & 32 & 5.77 & gi|405951960|EKC19824.1 & 109 & 2 & 77 \\
\hline 231 & Proteasome (a) & 47 & 5.50 & 31 & 5.54 & gi|524885821|XP_005099514.1 & 112 & 3 & 76 \\
\hline 232 & Malate dehydrogenase (mitochondrial) & 49 & 6.77 & 36 & 8.44 & gil6746611|AAF27650.1 & 65 & 3 & 71 \\
\hline 233 & Eukaryotic translation initiation factor 3 & 46 & 6.39 & 36 & 5.16 & gi|597771365|XP_007249463.1 & 56 & 2 & 77 \\
\hline 234 & Malate dehydrogenase (mitochondrial) & 48 & 6.55 & 37 & 7.04 & gi|6746611|AAF27650.1 & 166 & 6 & 71 \\
\hline 241 & Collagen & 46 & 5.41 & 25 & 8.26 & gi|405960952|EKC26819.1 & 112 & 5 & 43 \\
\hline 245 & Small HSP 24.1 & 47 & 6.77 & 29 & 5.61 & gi|347545633|AEP02968.1 & 92 & 5 & 83 \\
\hline 248 & Tropomyosin & 46 & 4.88 & 33 & 4.61 & gi|317575584|NP_001187627.1 & 86 & 3 & 40 \\
\hline 249 & Pyruvate dehydrogenase $(\beta)$ & 46 & 5.62 & 39 & 6.02 & gi|405962672|ЕKC28328.1 & 123 & 4 & 78 \\
\hline 251 & Proteasome (a) & 45 & 5.44 & 31 & 5.54 & gi|524885821|XP_005099514.1 & 110 & 3 & 76 \\
\hline 252 & Small HSP 24.1 & 44 & 5.93 & 29 & 5.61 & gi|347545633|AEP02968.1 & 173 & 4 & 98 \\
\hline 254 & Small HSP 24.1 & 44 & 5.70 & 29 & 5.61 & gi|347545633|AEP02968.1 & 328 & 8 & 93 \\
\hline 255 & Small HSP 24.1 & 43 & 5.77 & 29 & 5.61 & gi|347545633|AEP02968.1 & 57 & 2 & 98 \\
\hline
\end{tabular}

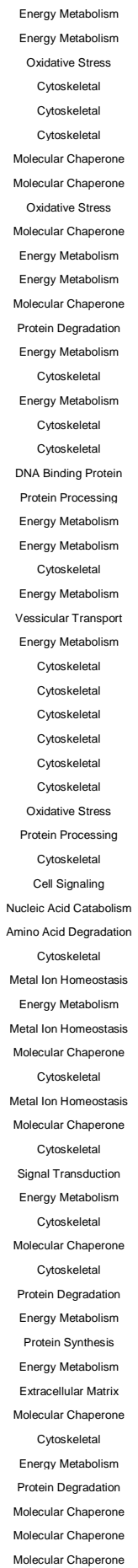




\begin{tabular}{|c|c|c|c|c|c|c|c|c|c|c|}
\hline 258 & Small HSP 24.1 & 43 & 6.07 & 29 & 5.61 & gi|347545633|AEP02968.1 & 212 & 4 & 83 & Molecular Chaperone \\
\hline 259 & Small HSP 24.1 & 42 & 6.00 & 29 & 5.61 & gi|347545633|AEP02968.1 & 215 & 6 & 78 & Molecular Chaperone \\
\hline 260 & Small HSP 24.1 & 43 & 5.29 & 29 & 5.61 & gi|347545633|AEP02968.1 & 71 & 3 & 78 & Molecular Chaperone \\
\hline 261 & Small HSP 24.1 & 42 & 6.25 & 29 & 5.61 & gi|347545633|AEP02968.1 & 145 & 4 & 83 & Molecular Chaperone \\
\hline 263 & Small HSP 24.1 & 42 & 5.34 & 29 & 5.61 & gi|347545633|AEP02968.1 & 110 & 3 & 83 & Molecular Chaperone \\
\hline 264 & Small HSP 24.1 & 41 & 5.48 & 29 & 5.61 & gi|347545633|AEP02968.1 & 201 & 4 & 83 & Molecular Chaperone \\
\hline 266 & Small HSP 24.1 & 42 & 5.60 & 29 & 5.61 & gi|347545633|AEP02968.1 & 181 & 4 & 83 & Molecular Chaperone \\
\hline 267 & Small HSP 24.1 & 41 & 5.83 & 29 & 5.61 & gi|347545633|AEP02968.1 & 330 & 6 & 83 & Molecular Chaperone \\
\hline 268 & Small HSP 24.1 & 42 & 5.54 & 29 & 5.61 & gi|347545633|AEP02968.1 & 273 & 5 & 83 & Molecular Chaperone \\
\hline 271 & Small HSP 24.1 & 41 & 5.41 & 29 & 5.61 & gi|347545633|AEP02968.1 & 125 & 2 & 76 & Molecular Chaperone \\
\hline 272 & Proteasome (a) & 42 & 6.36 & 29 & 6.91 & gi|56118656|NP_001007998.1 & 66 & 2 & 85 & Protein Degradation \\
\hline 274 & Cathepsin L & 41 & 4.50 & 40 & 5.23 & gi|229893789|ACQ90252.1 & 150 & 3 & 60 & Protein Degradation \\
\hline 276 & Small HSP 24.1 & 41 & 5.68 & 29 & 5.61 & gi|347545633|AEP02968.1 & 246 & 4 & 83 & Molecular Chaperone \\
\hline 277 & Small HSP 24.1 & 41 & 5.75 & 29 & 5.61 & gi|347545633|AEP02968.1 & 158 & 4 & 83 & Molecular Chaperone \\
\hline 278 & Small HSP 24.1 & 41 & 6.30 & 29 & 5.61 & gi|347545633|AEP02968.1 & 173 & 3 & 78 & Molecular Chaperone \\
\hline 280 & Apextrin & 38 & 6.76 & 24 & 8.42 & gi|339785142|AEK10750.1| & 121 & 4 & 67 & Cytoskeletal \\
\hline 281 & Sperm-associated antigen 8 & 39 & 5.16 & 24 & 6.01 & gi|405958072|ЕKC24235.1 & 76 & 2 & 71 & Unknown \\
\hline 284 & Proteasome (a) & 39 & 6.44 & 27 & 6.34 & gi|73962756|XP_537412.2 & 208 & 5 & 82 & Protein Degradation \\
\hline 285 & Peptidyl-prolyl cis-trans isomerase ( $\beta$ ) & 37 & 6.86 & 27 & 8.72 & gi|324526643|ADY48698.1 & 363 & 7 & 42 & Molecular Chaperone \\
\hline 286 & Proteasome (a) & 39 & 4.96 & 26 & 4.74 & gi|291243435|XP_002741602.1 & 66 & 3 & 85 & Protein Degradation \\
\hline 292 & Triosephosphate isomerase & 37 & 6.36 & 27 & 7.57 & gi|333449422|AEF33397.1 & 77 & 2 & 81 & Energy Metabolism \\
\hline 293 & L-xylulose reductase & 37 & 6.08 & 26 & 5.94 & gi|524874171|XP_005093825.1 & 402 & 7 & 56 & Energy Metabolism \\
\hline 301 & Peptidyl-prolyl cis-trans isomerase ( $\beta$ ) & 36 & 6.63 & 24 & 5.97 & gi|405963687|EKC29243.1 & 71 & 3 & 89 & Molecular Chaperone \\
\hline 302 & L-xylulose reductase & 36 & 5.87 & 28 & 5.94 & gi|524874171|XP_005093825.1 & 58 & 3 & 56 & Energy Metabolism \\
\hline 312 & NADH dehydrogenase & 35 & 6.58 & 27 & 5.71 & gi|524871774|XP_005092658.1 & 58 & 2 & 75 & Energy Metabolism \\
\hline 319 & Apextrin & 33 & 6.80 & 24 & 8.42 & gi|339785142|AEK10750.1 & 86 & 4 & 67 & Cytoskeletal \\
\hline 322 & Progesterone receptor & 32 & 4.90 & 21 & 4.65 & gi|524872801|XP_005093157.1 & 82 & 2 & 67 & Signal Transduction \\
\hline 324 & Progesterone receptor & 32 & 4.97 & 21 & 4.60 & gi|524872801|XP_005093157.1 & 63 & 2 & 67 & Signal Transduction \\
\hline 326 & Thioredoxin peroxidase & 32 & 6.80 & 22 & 5.95 & gi|306451460|ADM88874.1 & 187 & 5 & 83 & Oxidative Stress \\
\hline 330 & Proteasome (a) & 29 & 6.30 & 26 & 5.52 & gi|405964525|ЕКС30000.1 & 238 & 5 & 94 & Protein Degradation \\
\hline 333 & CDC42 & 28 & 6.25 & 21 & 6.16 & gi|333449473|AEF33422.1 & 115 & 4 & 98 & Molecular Chaperone \\
\hline 334 & Cu/Zn-superoxide dismutase & 28 & 6.17 & 16 & 5.84 & gi|332356353|AEE60900.1 & 182 & 3 & 100 & Oxidative Stress \\
\hline 335 & Rab-2 & 28 & 6.60 & 23 & 6.21 & gi|405950969|EKC 18921.1 & 105 & 3 & 100 & Vessicular Transport \\
\hline 340 & Signal sequence receptor $(\beta)$ & 24 & 5.73 & 21 & 6.96 & gi|40643038|CAD91446.1 & 71 & 2 & 75 & Cell Signaling \\
\hline 342 & Tubulin (a) & 23 & 5.73 & 31 & 5.23 & gi|85753308|AAG49533.3 & 30 & 2 & 94 & Cytoskeletal \\
\hline 343 & Tubulin (a) & 22 & 5.74 & 40 & 6.20 & gi|568249318|ETN59126.1 & 28 & 2 & 99 & Cytoskeletal \\
\hline 347 & $\mathrm{CDC} 42$ & 20 & 5.93 & 21 & 6.16 & gi|333449473|AEF33422.1 & 74 & 3 & 98 & Signal Transduction \\
\hline 348 & Eukaryotic translation initiation factor $5 \mathrm{~A}$ & 19 & 5.62 & 17 & 5.30 & gi|45594242/AAS68511.1 & 83 & 3 & 74 & Protein Synthesis \\
\hline 350 & Cu/Zn-superoxide dismutase & 18 & 6.33 & 16 & 5.84 & gi|332356353|AEE60900.1 & 209 & 4 & 96 & Oxidative Stress \\
\hline 352 & ADP-ribosylation factor & 19 & 6.57 & 21 & 5.78 & gi|355669060|AER94400.1 & 81 & 3 & 93 & Vessicular Transport \\
\hline 359 & ATP synthase $(\Delta)$ & 16 & 4.68 & 18 & 5.02 & gi|126697378|ABO26646.1 & 149 & 2 & 60 & Energy Metabolism \\
\hline 360 & Dynein light chain (roadblock) & 15 & 5.89 & 11 & 9.14 & gi|511863709|XP_004753999.1 & 89 & 3 & 90 & Cytoskeletal \\
\hline 361 & SH3 domain-binding glutamic acid-rich protein & 15 & 4.82 & 59 & 4.32 & gi|405973087|ЕКС37819.1 & 76 & 3 & 54 & Signal Transduction \\
\hline 364 & Heterogenous nuclear ribonucleoprotein $27 \mathrm{C}$ & 12 & 5.85 & 59 & 8.32 & gi|405977312|EKC41770.1 & 120 & 4 & 62 & RNA Binding \\
\hline 365 & Heterogenous nuclear ribonucleoprotein $27 \mathrm{C}$ & 10 & 6.57 & 59 & 8.32 & gi|405977312|EKC41770.1 & 85 & 4 & 61 & RNA Binding \\
\hline 368 & Fatty acid-binding protein & 9 & 4.90 & 15 & 4.98 & gi|405951541|EKC19445.1 & 115 & 3 & 56 & Lipid Transport \\
\hline 369 & Heterogenous nuclear ribonucleoprotein A/B & 8 & 5.80 & 32 & 8.62 & gi|432901707|XP_004076907.1 & 56 & 2 & 56 & RNA Binding \\
\hline 370 & Heterogeneous nuclear ribonucleoprotein A/B & 7 & 6.34 & 32 & 8.62 & gil45384514|NP_990659.1 & 219 & 4 & 43 & RNA Binding \\
\hline
\end{tabular}


Table 3. Oxygen measurements. Oxygen measurements $\left(\% \mathrm{O}_{2}\right)$ taken with an oxygen analyzer (Sable Systems, Intn'l, Las Vegas, NV, USA) at 6, 12, 24, 56, and $72 \mathrm{~h}$, which corresponded with timed flushing of nitrogen gas (at $10 \mathrm{~L} / \mathrm{min}$ for 5 min every 2 h).

\begin{tabular}{cccccc}
\hline \multicolumn{6}{c}{ Gas sampling time (h) } \\
\hline $\begin{array}{c}\text { Length of } \\
\text { anoxia (h) }\end{array}$ & 6 & 12 & 24 & 56 & 72 \\
\hline 6 & - & - & - & - & - \\
12 & 1.0175 & - & - & - & - \\
24 & 0.634 & 0.156 & - & - & - \\
72 & 0.525 & 0.041 & 0.178 & 0.148 & - \\
\hline
\end{tabular}




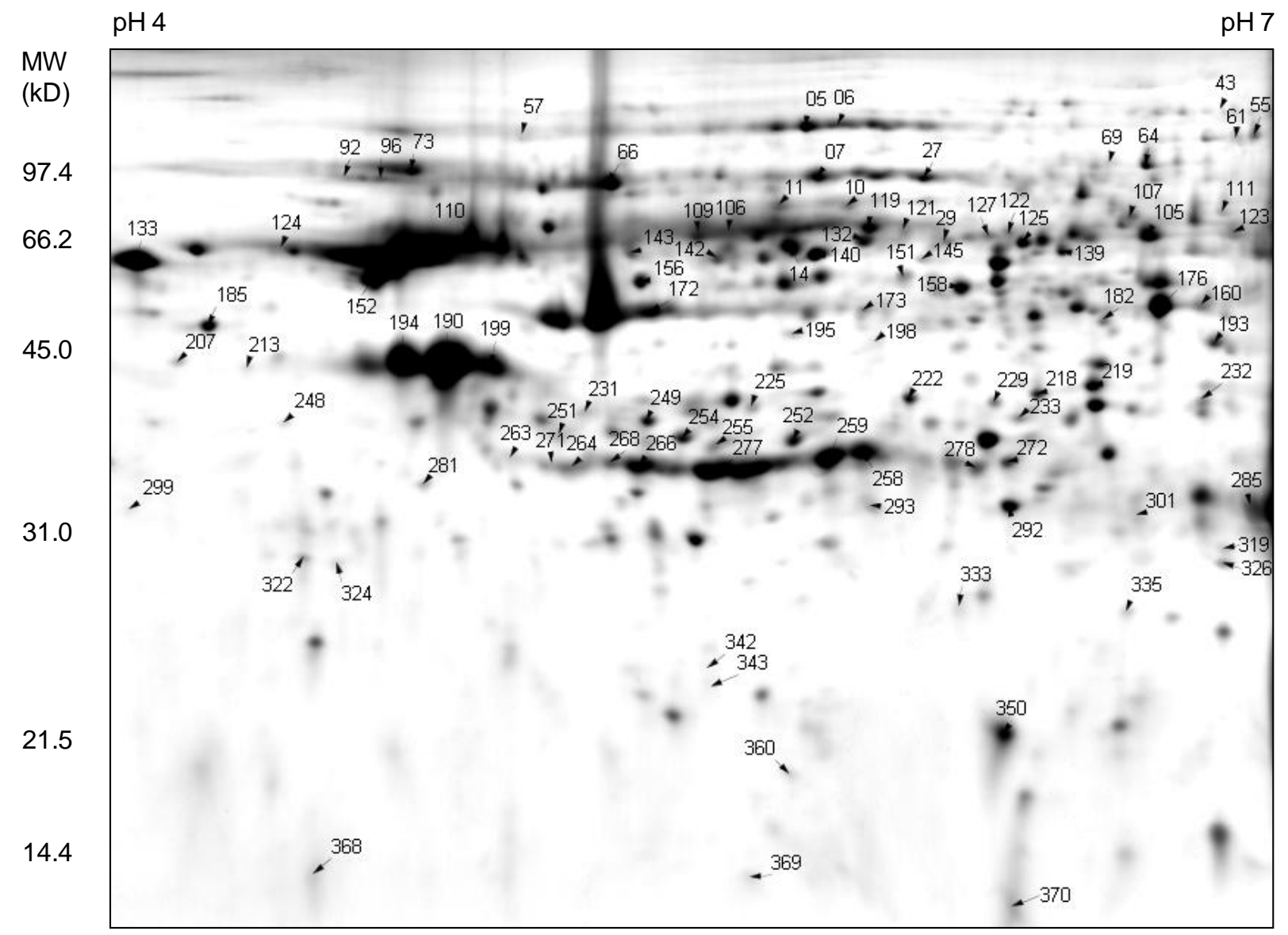

Figure 6. Fused gel image. Proteome map of gels from all treatments depicting 163 identified (of 370 detected) proteins from gill tissue of the California mussel, Mytilus californianus. The proteome map represents average pixel volumes for each protein detected. Numbered proteins are those that significantly changed abundance in response to either acclimation, oxygen, or the interaction (two-way permutation ANOVA, $P<0.02$ ) and were identified using mass spectrometry (for identification, see supplementary material Table 2). 

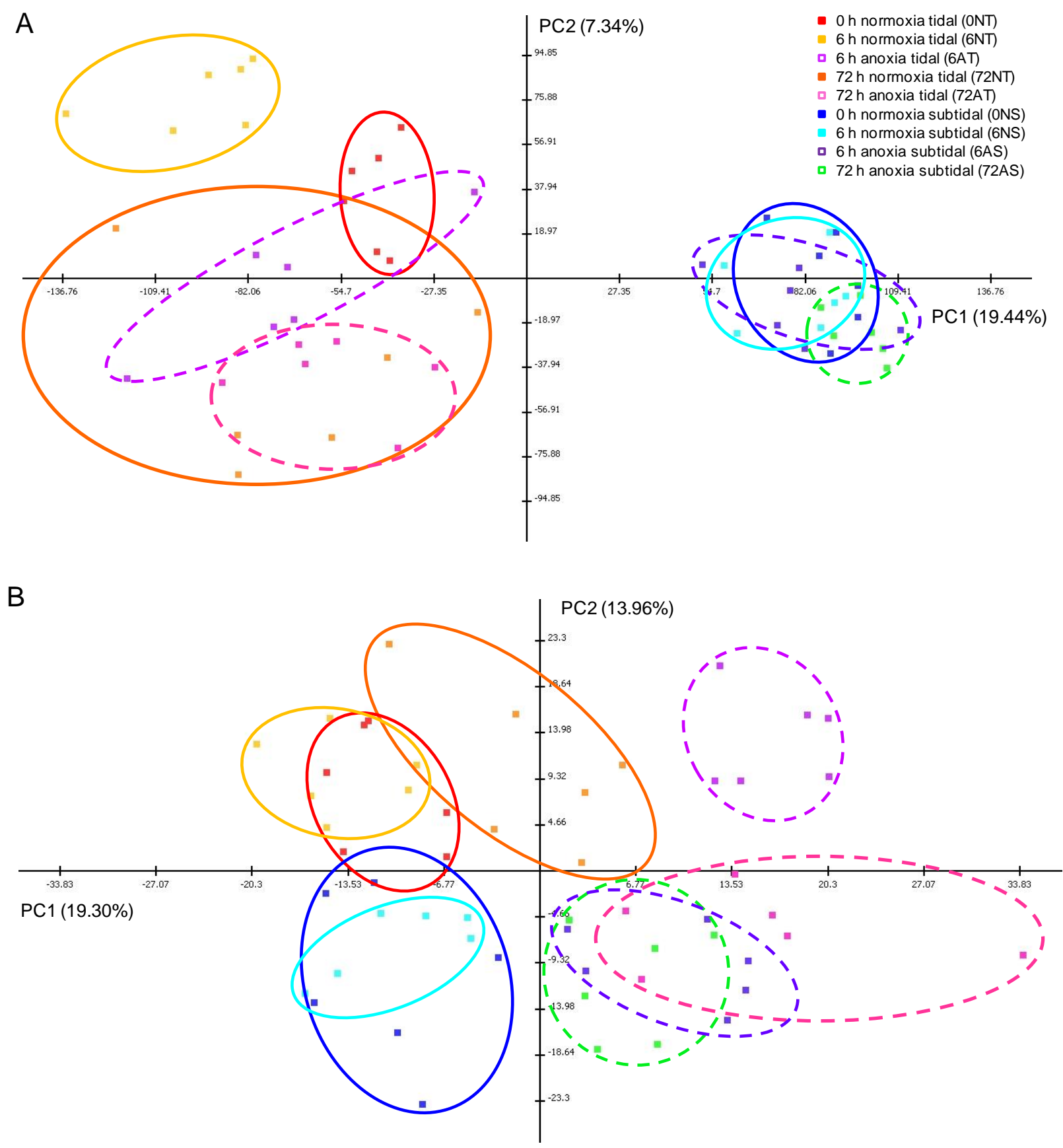


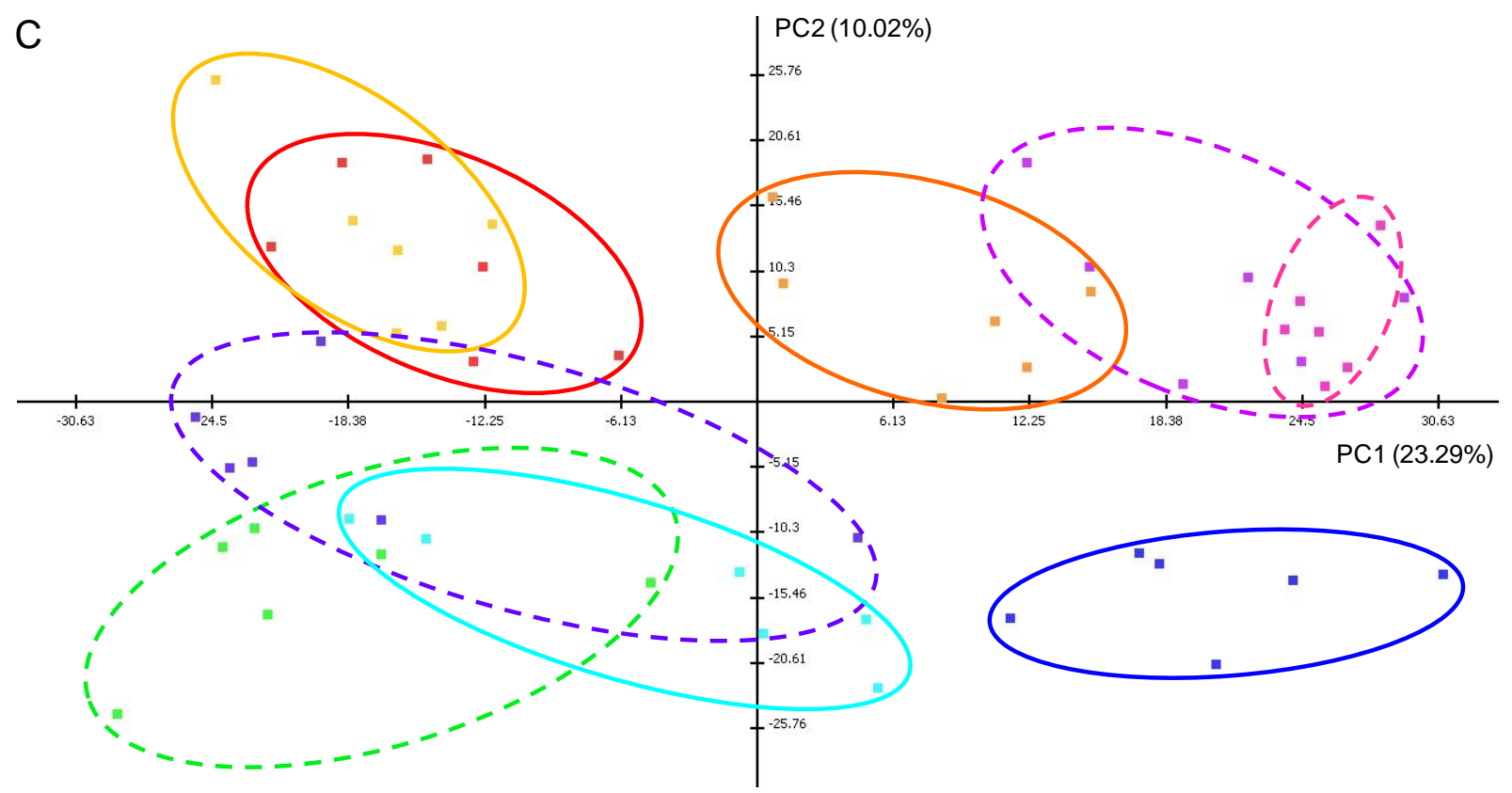

Figure 7. Principal component analysis. Principal component analysis (PCA) of treatments based on proteins that showed a significant acclimation, oxygen, or interaction effect. (A) Acclimation, (B) oxygen, and (C) interaction effect (based on a two-way permutation ANOVA, $P<0.02)$. Each symbol represents a mussel acclimated to intermittent immersion (tidal; warm colors) or constant immersion (subtidal; cool colors) and was either subsequently exposed to normoxia (solid) or anoxia (dashed). Principal components 1 and 2 (PC1 and PC2) and the percentage of the total variation of the selected (significant protein) data set they explain are shown. See text for explanation of PC1 and PC2 for each PCA. 


\section{ONT 6NT 6AT 72NT 72AT ONS 6NS 6AS 72AS}

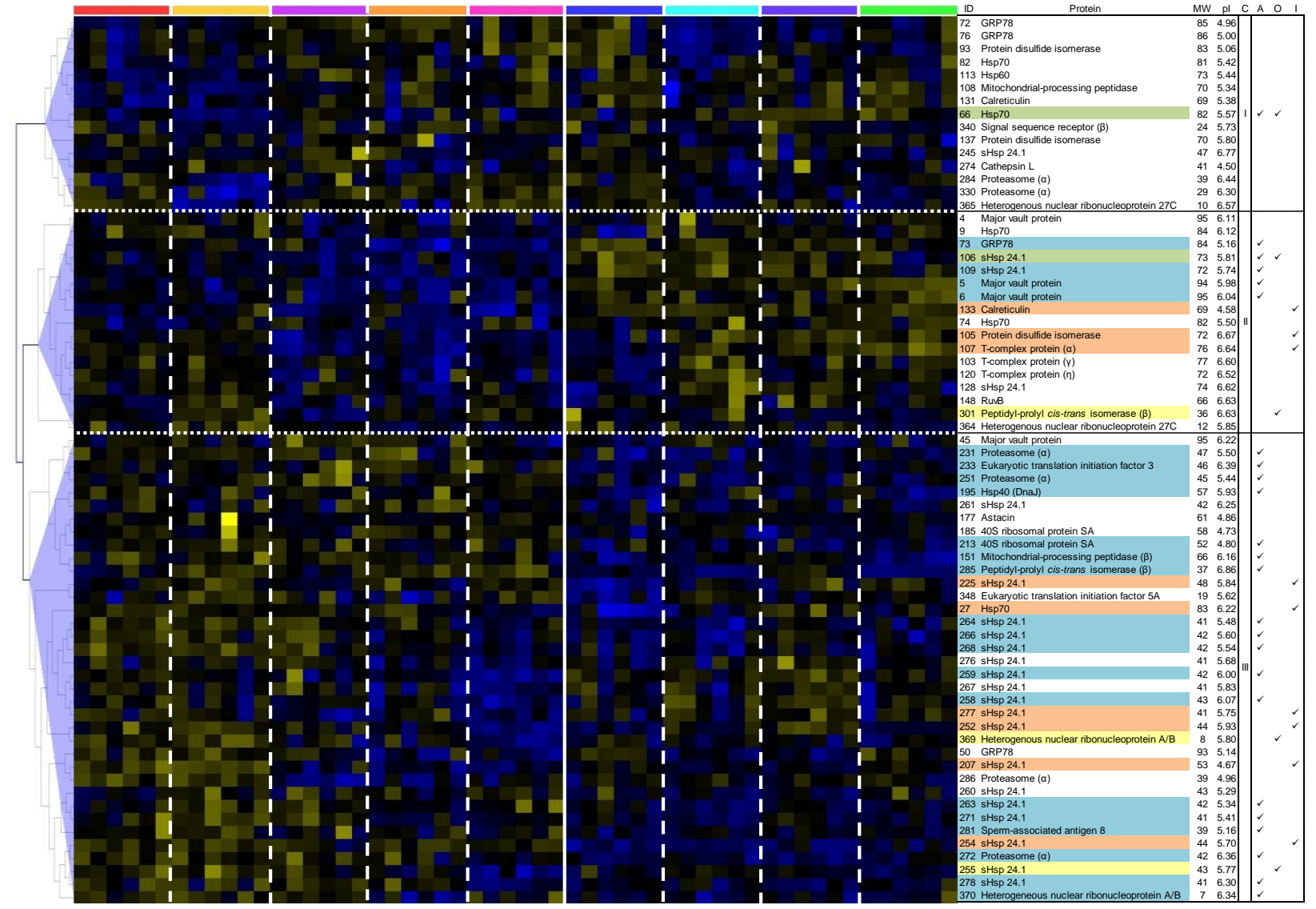

Protein abundance changes

Figure 8. Hierarchical clustering: Protein homeostasis. Hierarchical clustering of changes in abundance of proteins involved in protein homeostasis. Pearson's correlation of protein abundances in response to acclimation to subtidal or tidal fluctuations and subsequent normoxic or anoxic conditions during aerial exposure from gill tissue of the California mussel, Mytilus californianus. Blue coloring represents a lower than average protein abundance, whereas yellow represents a higher than average protein abundance. Each column represents an individual mussel's gill tissue sample, grouped by treatment ( $n=6$ for each treatment). Each row represents the standardized abundances of protein, organized by clusters of similar abundance changes, which are identified to the right and whose molecular weight (MW in $\mathrm{kD}$ ) and isoelectric point ( $\mathrm{pl}$ in $\mathrm{pH}$ ) is listed. Significance for acclimation regime (A; blue highlight), oxygen availability (O; yellow), acclimation and oxygen (green), or interaction (I; orange) effect are ticked based on a two-way permutation ANOVA $(P<0.02)$. 

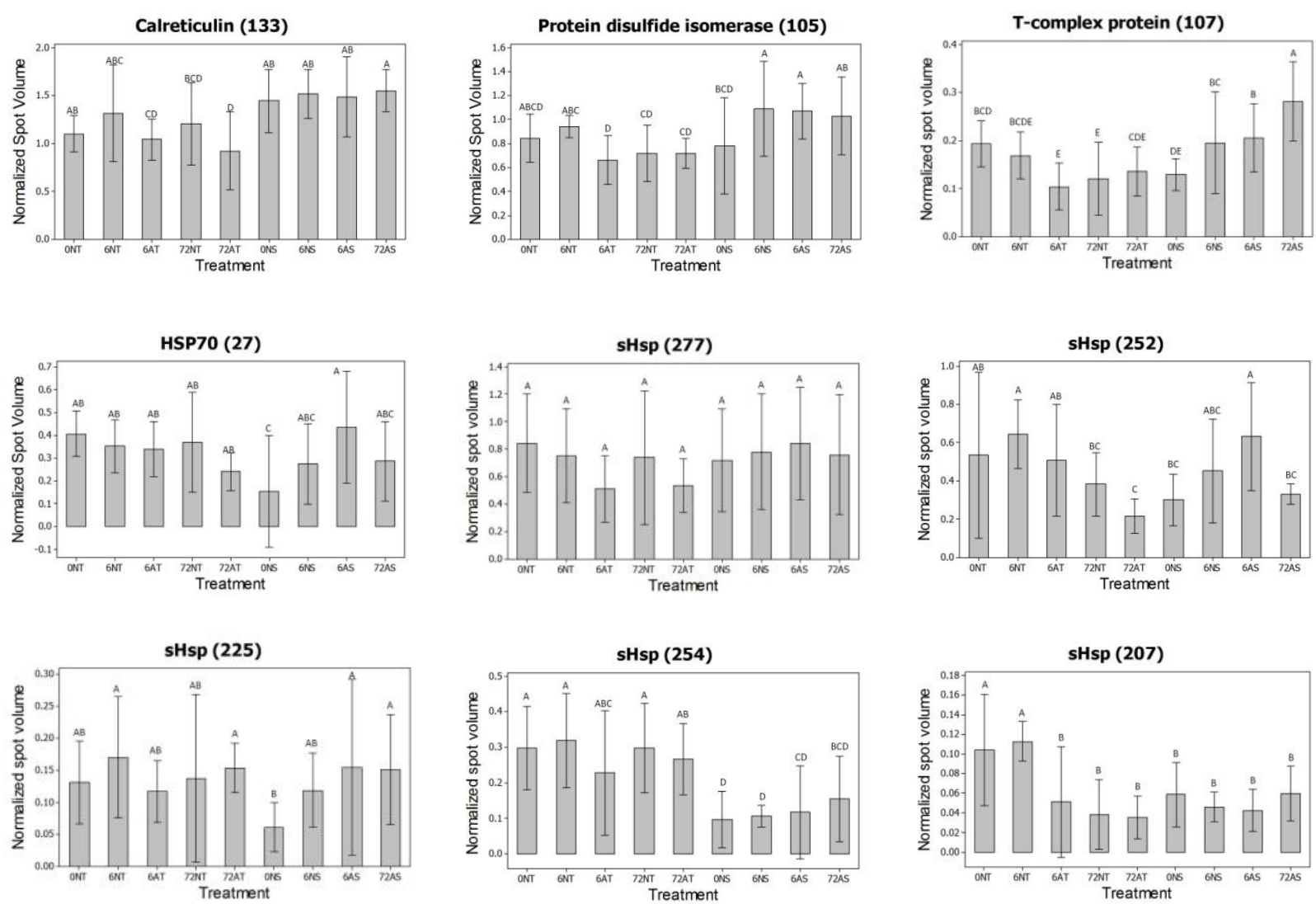

Figure 9. Expression profiles: Protein homeostasis. Protein homeostasis expression profiles for proteins significant for the interaction effect (two-way permutation ANOVA, $\mathrm{P}<0.02$ ). Proteins were subsequently analyzed using Tukey's post hoc pairwise comparison tests $(P<0.05)$. 


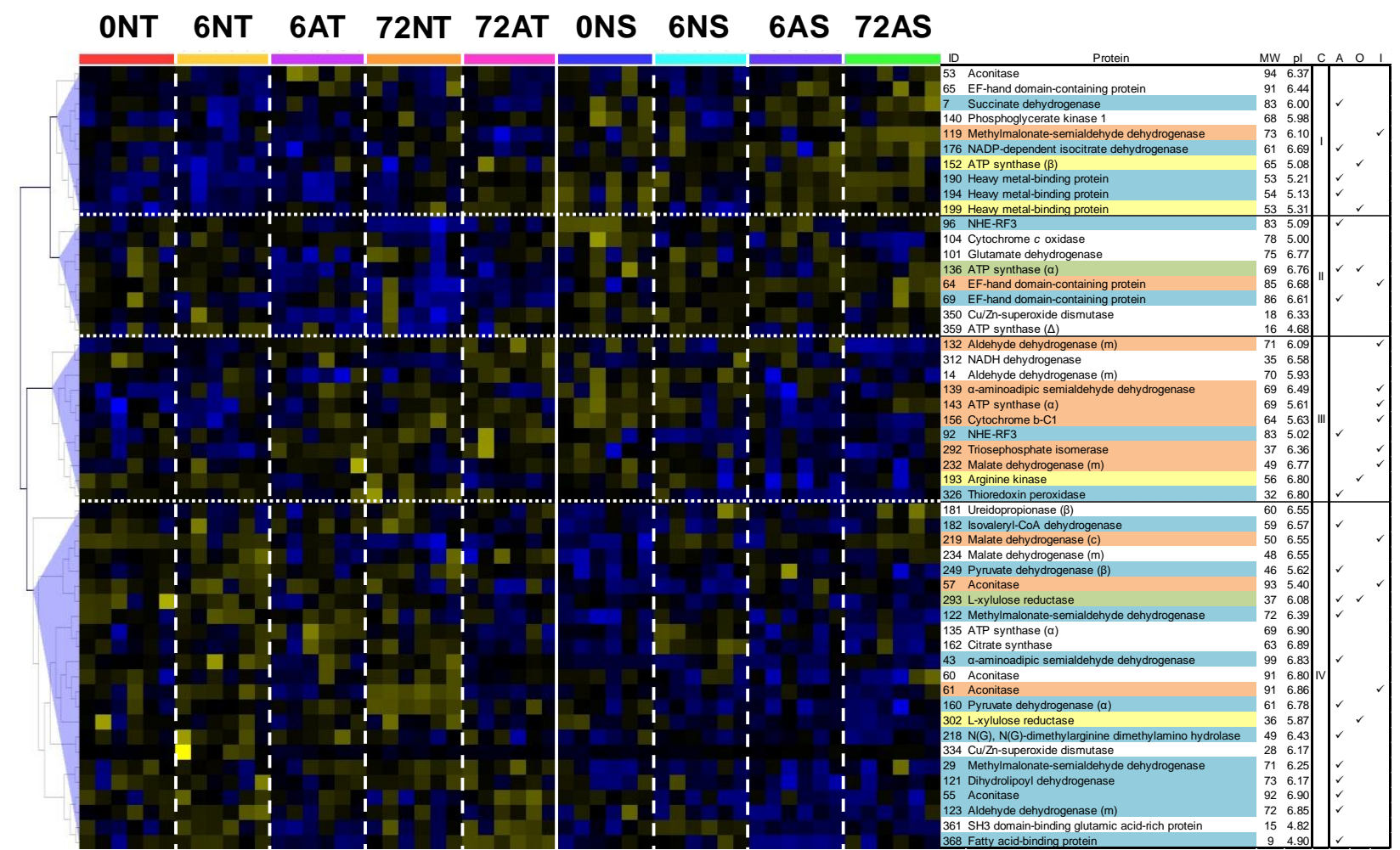

Figure 10. Hierarchical clustering: Energy metabolism. Hierarchical clustering of changes in abundance of proteins involved in energy metabolism, oxidative stress, and ion regulation. Pearson's correlation of protein abundances in response to treatment conditions from gill tissue of the California mussel, Mytilus californianus, showing clusters I-IV. For additional details, see Figure 8. 

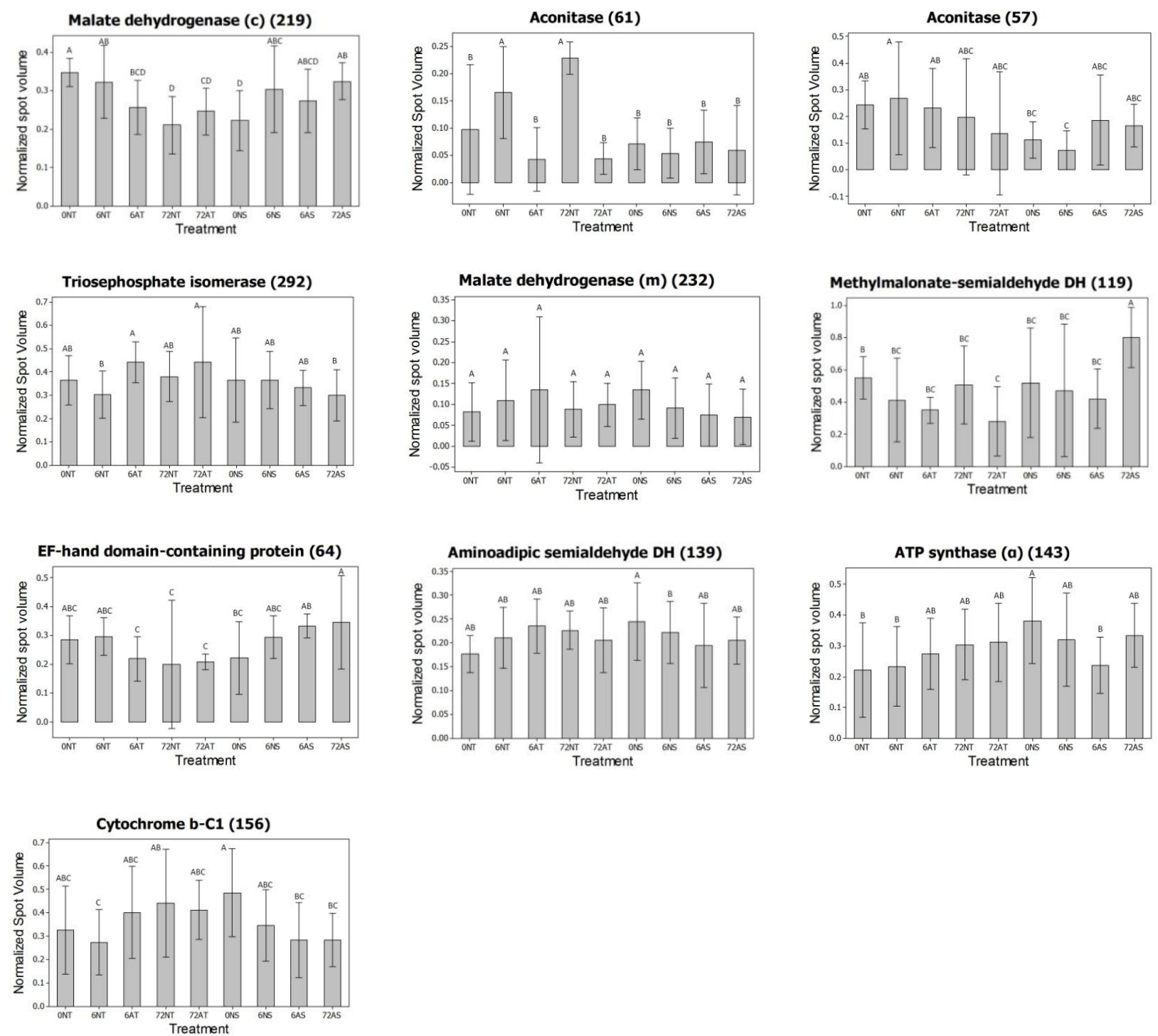

Figure 11. Expression profiles: Energy metabolism. Energy metabolism and ion transport expression profiles for proteins significant for the interaction effect (two-way permutation ANOVA, $P<0.02$ ). Proteins were subsequently analyzed using Tukey's post hoc pairwise comparison tests $(P<0.05)$. 


\section{ONT 6NT 6AT 72NT 72AT ONS 6NS 6AS 72AS}
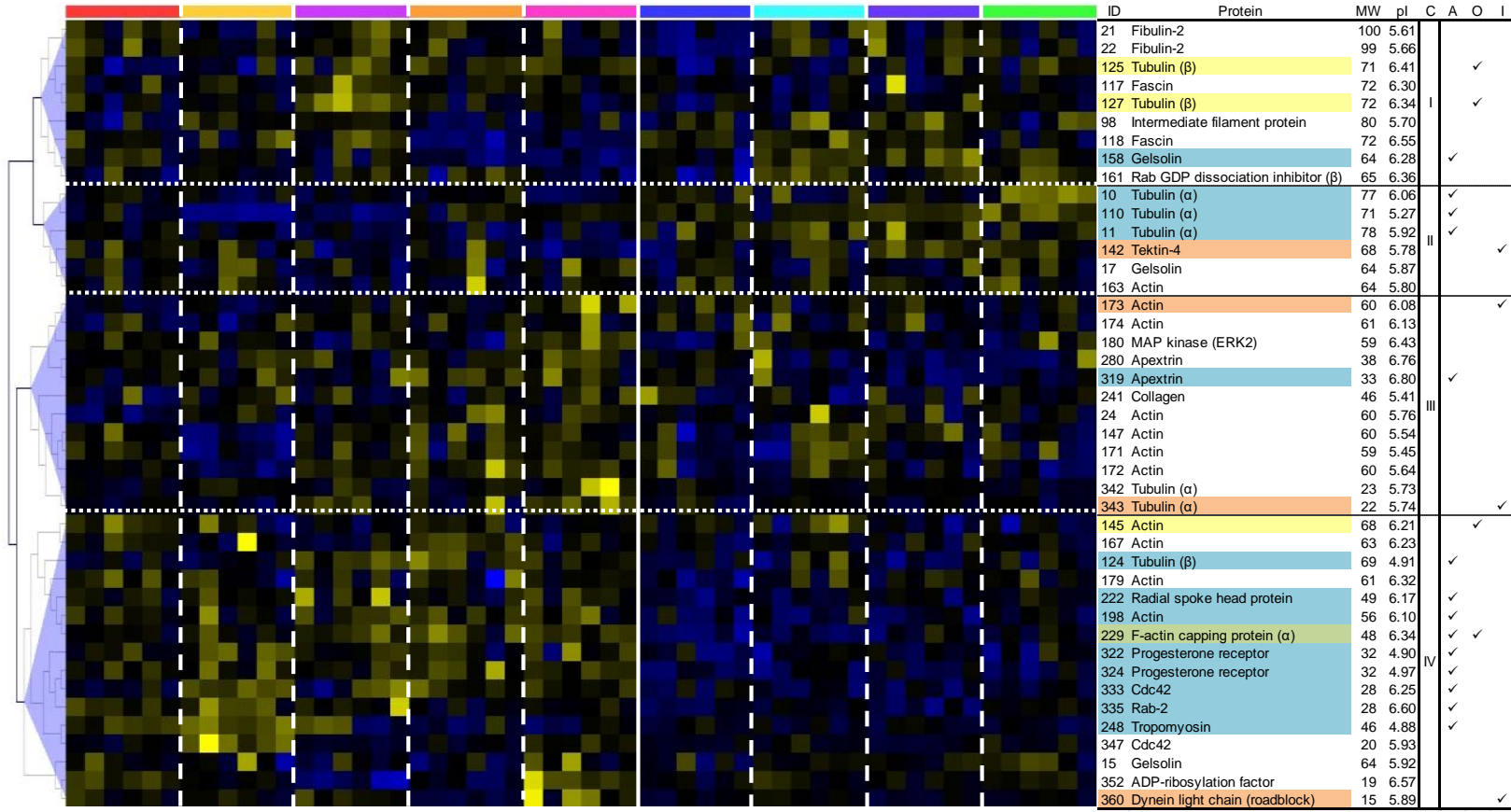

Figure 12. Hierarchical clustering: Cytoskeleton. Hierarchical clustering of changes in abundance of proteins involved in the cytoskeleton, extracellular matrix, vesicular transport, and signaling. Pearson's correlation of protein abundances in response to treatment conditions from gill tissue of the California mussel, Mytilus californianus, showing clusters I-IV. For details, see Figure 8. 

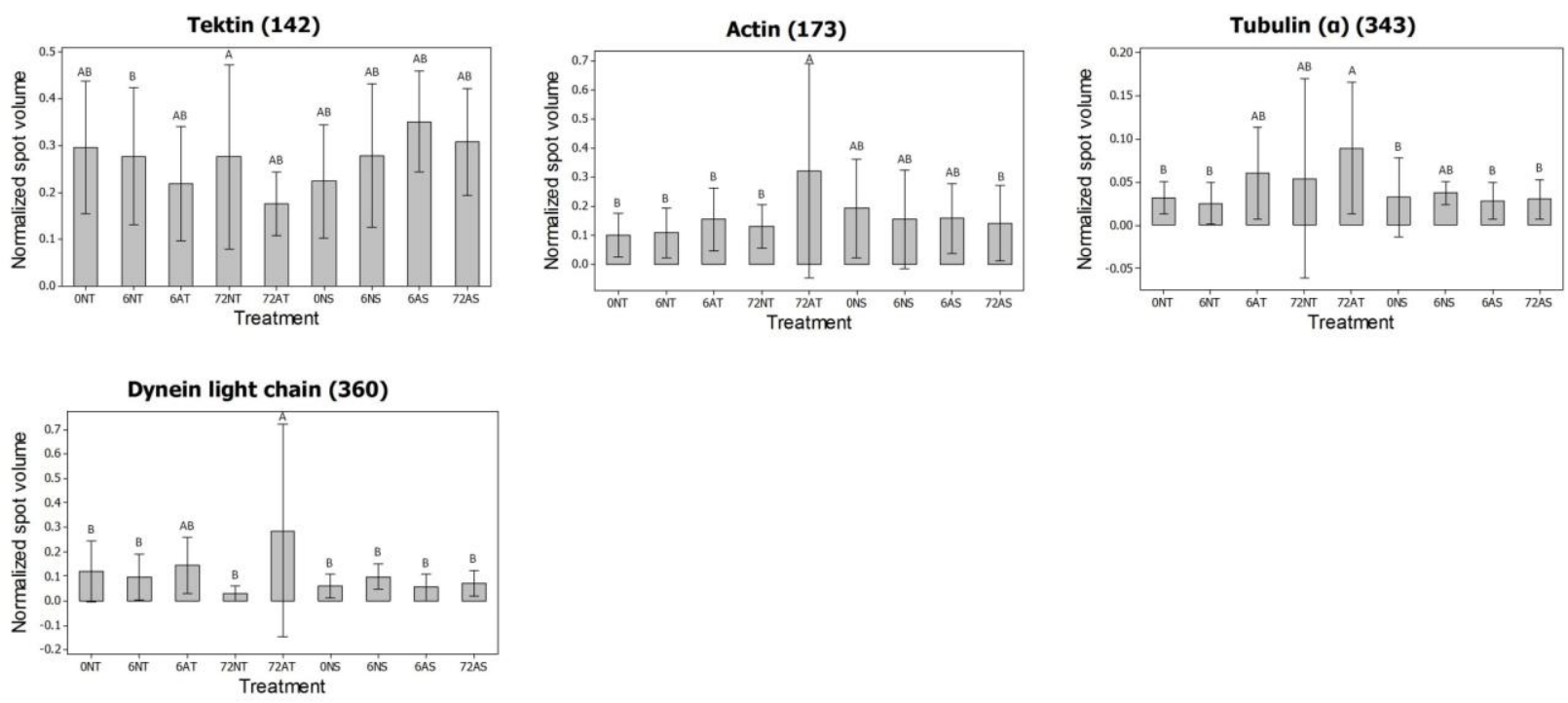

Figure 13. Expression profiles: Cytoskeleton. Cytoskeletal expression profiles for proteins significant for the interaction effect (two-way permutation ANOVA, $P<0.02)$. Proteins were subsequently analyzed using Tukey's post hoc pairwise comparison tests $(P<0.05)$. 